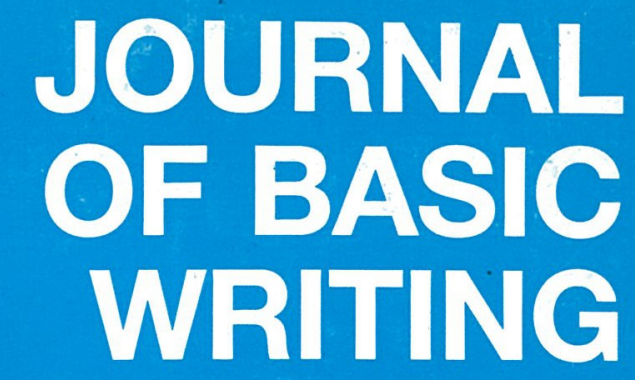

\title{
FALL 1993
}

VOLUME 12, NUMBER 2

What Works? How Do We Know?

Ann E. Berthoff

The Vanishing Site of Mina Shaughnessy's

Errors and Expectations

Patricia Laurence

Rereading Shaughnessy from

A Postcolonial Perspective

Pamela Gay

Computerized Scoring of Placement Exams: A Validation Emil L. Roy

Reinventing the University: Finding the Place for Basic Writers Jane E. Hindman

Encouraging Students to (Continue to)

Share Authority in the Classroom:

A Response to Patricia Bizzell Bill Bolin

Basic Writing Instruction

Lynée Lewis Gaillet 


\section{CHECKPOINTS}

\section{SECOND EDITION}

Jack Page, Merritt College

* Stressing the relationship between reading and writing, this best-selling worktext integrates both reading and writing, in addition to grammar coverage to build paragraph and essay writing skills. The eagerly anticipated second edition puts new emphasis on writing as a process and offers step-by-step preparation guides along with student writing samples to illustrate the various types of writing.

\section{PROCESS AND PRACTICE}

\section{THIRD EDITION}

\section{Phillip Eggers, Borough of Manhattan Community College}

This popular paragraph-to-essay text teaches the essentials of paragraph and short essay construction while providing systematic instruction and practice in basic grammar and usage.

\section{WRITING WITH CONFIDENCE: FORM B}

\section{FOURTH EDITION}

\section{Alan Meyers, Harry S Truman College}

This alternate version of the best-selling worktext provides the same essential grammar information and practice in basic writing skills as the original, but offers all new examples and exercise content on fascinating people and events in history.

Don't forget to apply for the fourth annual HarperCollins Fellowship. We'll be sending five non-tenured faculty to the March 1994 Conference on College Composition and Communication in Nashville. The deadline for proposals is December 31,1993. For an application form, write to

Ann Stypuloski, HarperCollins College Publishers 10 East 53rd Street, New York, NY 10022

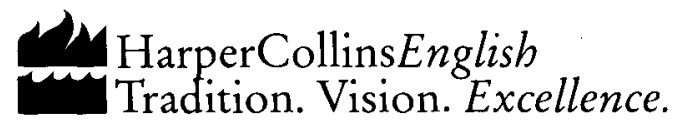




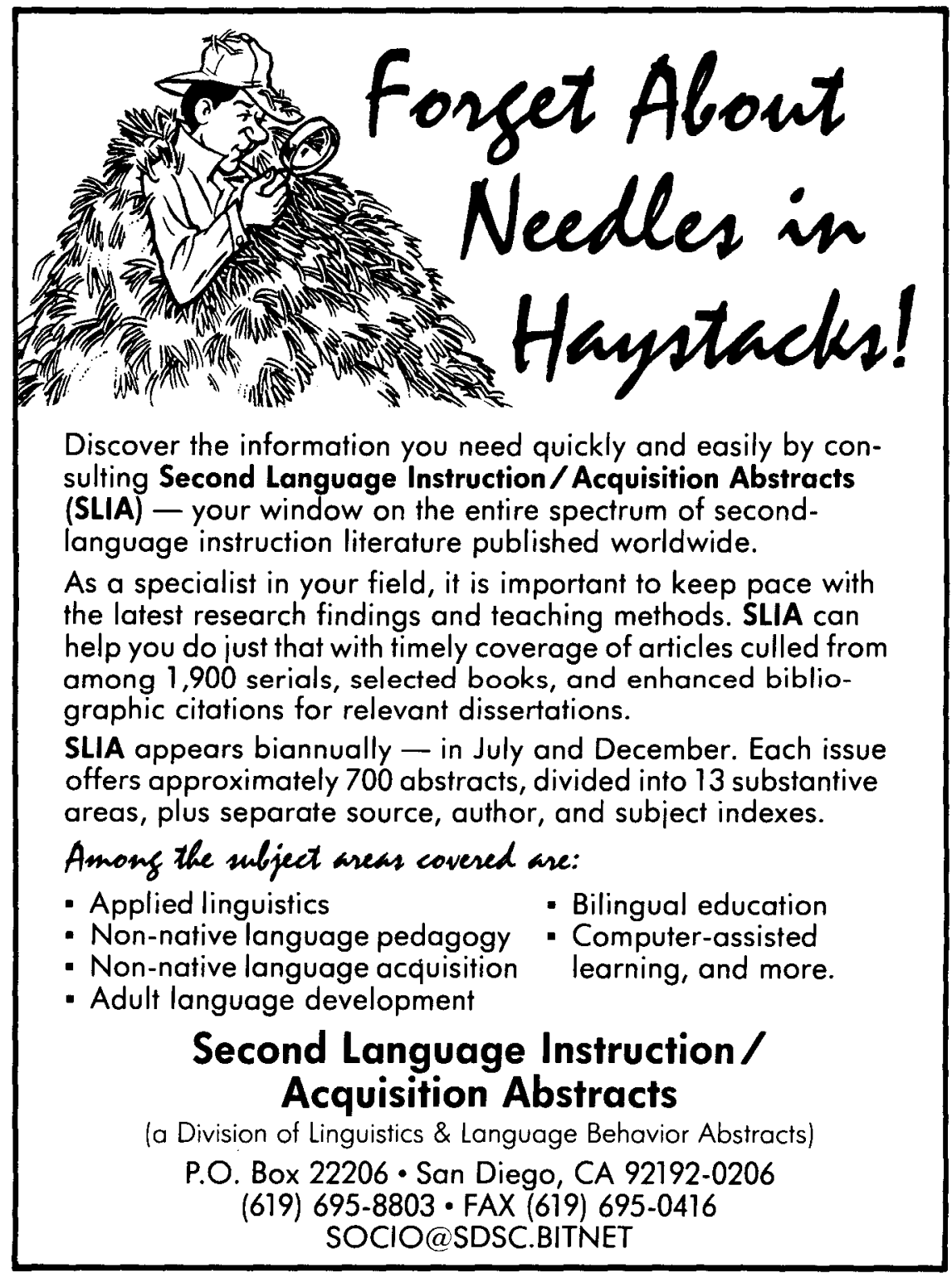




\section{Newsworlby from St. Martin's!}

\section{EXPLORATIONS IN BASIC WRITING}

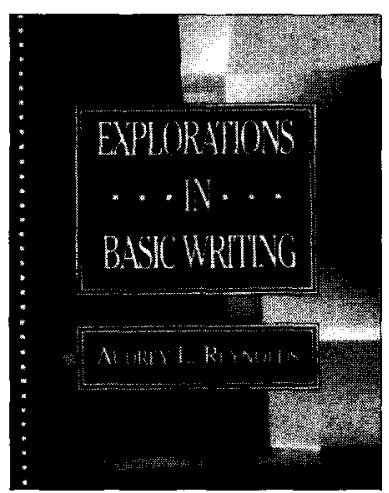

AUDREY L. REYNOLDS, Northeastern University, Illinois A developmental text that provides intensive work on sentence-level skills - Teaches basic rhetorical techniques for developing paragraphs and brief essays Includes an introduction to the grammar of written English, with numerous exercises

Paper / 261 perforated pp. / 1993 Instructor's Manual available

\section{Coming in January!}

\section{THEMES FOR WRITERS}

PAUL ESCHHOLZ and ALFRED ROSA

both of the University of Vermont

Paper / 450 pp. (approx.) / January 1994 Instruclor's Manual available

\section{SENTENCE BASICS}

Diction, Usage, and Mechanics

ELLIOTT L. SMITH and BLYTHE M. SMITH both of Ferris State University

Paper / 384 pp. (approx.) / January 1994 Instructor's Manual available 


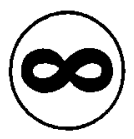

The paper used in this publication meets the minimum requirements of the American National Standard for Information Science-Permanence of Paper for Printed Library Materials, ANSI Z39.48-1984.

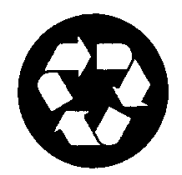

The text stock is also recycled

\section{This publication is available in microform from UMI.}

Please send me information about the titles I've listed below:

Name

Title

Company/Institution

Address

City/State/Zip

Phone ( )

U.M.I

A Bell \& Howell Company

300 North Zeeb Road, Ann Arbor, MI 48106 USA 800-521-0600 toll-free

$313-761-4700$ collect from Alaska and Michigan 800-343-5299 toll-free from Canada 


\section{JOURNAL OF BASIC WRITING}

VOLUME 12 NUMBER 2 FALL 1993

The Journal of Basic Writing publishes articles of theory, research, and teaching practices related to basic writing. Articles are refereed by members of the Editorial Board (see overleaf) and the Editors.

\section{BILL BERNHARDT and PETER MILLER Editors}

\section{RUTH DAVIS}

Associate \& Managing Editor

\section{RICHARD A. MANDELBAUM, Copyreader}

\section{MARY E. CARNEY, Subscriptions}

The Journal of Basic Writing is published twice a year, in the spring and fall. We welcome unsolicited manuscripts and ask authors to consult the detailed "Call for Articles" in this issue. Subscriptions for individuals are $\$ 10.00$ for one year and $\$ 19.00$ for two years; subscriptions for institutions are $\$ 15.00$ for one year and $\$ 29.00$ for two years. Foreign postage is $\$ 5.00$ extra per year. ADDRESS: Journal of Basic Writing, Instructional Resource Center, The City University of New York, 535 East 80th Street, Now York, NY 10021.

Cover design by E. H. Jaffe

Copyright 1993 by the Journal of Basic Writing 


\title{
JOURNAL OF BASIC WRITING
}

\author{
EDITORIAL BOARD
}

David Bartholomae

University of Pittsburgh

Milton Baxter

Borough of Manhattan

Community College, CUNY

Sarah Benesch

The College of Staten Island, CUNY

Hugh Burns

University of Texas at Austin

Nancy Carriuolo

New England Association of

Schools and Colleges

Robert Christopher

Ramapo College of New Jersey

Robert J. Connors

University of New Hampshire

Edward P. J. Corbett

Ohio State University

Lisa Ede

Oregon State University

Mary Epes

York College, CUNY, retired

Thomas J. Farrell

University of Minnesota at Duluth

Sara Garnes

Ohio State University

Emily R. Gordon

Hofstra University

Karen L. Greenberg

Hunter College, CUNY

Brenda M. Greene

Medgar Evers College, CUNY

Muriel Harris

Purdue University

Irvin Hashimoto

Whitman College

Warren Herendeen

Mercy College

George Hillocks, Jr.

University of Chicago

Carolyn Kirkpatrick

York College, CUNY
Myra Kogen

Brooklyn College, CUNY

Patricia Ondek Laurence

The City College, CUNY

Marie Jean Lederman

Baruch College, CUNY

Elaine O. Lees

Carlow Hill College

Andrea A. Lunsford

Ohio State University

Susan Miller

University of Utah

Charles Moran

University of Massachusetts

Jerrold Nudelman

Queensborough Community

College, CUNY

George Otte

Baruch College, CUNY

Jane Peterson

Richland College, Dallas County

Community College District

Peter Rondinone

LaGuardia Community College, CUNY

John Scarry

Hostos Community College, CUNY

Linda Shohet

Dawson College (Canada)

Marilyn S. Sternglass

The City College, CUNY

Steven Tribus

New York City Board of Education

Lynn Quitman Troyka

Instructional Resource Center,

Academic Affairs, CUNY

Evelyn Webb

Mississippi Gulf Coast

Community College

Irwin Weiser

Purdue University

Harvey S. Wiener

Vice Provost for Academic Affairs

Adelphi University 


\section{JOURNAL OF BASIC WRITING}

ANN E. BERTHOFF

PATRICIA LAURENCE

PAMELA GAY

EMIL L. ROY

JANE E. HINDMAN

BILL BOLIN

LYNÉE LEWIS GAILLET
CONTENTS

1 Editors' Column

3 What Works? How Do We Know?

18 The Vanishing Site of Mina Shaughnessy's Error and Expectations

29 Rereading Shaughnessy from a Postcolonial Perspective

41 Computerized Scoring of Placement Exams:

A Validation

55 Reinventing the University: Finding the Place for Basic Writers

77 Encouraging Students to (Continue to) Share Authority in the Classroom: A Response to Patricia Bizzell

86 A Legacy of Basic Writing Instruction

100 News and Announcements 


\section{CALL FOR ARTICLES}

We welcome manuscripts of $10-20$ pages on topics related to basic writing, broadly interpreted.

Manuscripts will be refereed anonymously. We require four copies of a manuscript and an abstract of about 100 words. To assure impartial review, give author information and a short biographical note for publication on the cover page only. Papers which are accepted will eventually have to supply camera-ready copy for all ancillary material (tables, charts, etc.). One copy of each manuscript not accepted for publication will be returned to the author, if we receive sufficient stamps (no meter strips) clipped to a self-addressed envelope. We require the MLA style (MLA Handbook for Writers of Research Papers, 3rd ed., 1988). For further guidance, send a stamped letter-size, self-addressed envelope for our style sheet and for camera-ready specifications.

All manuscripts must focus clearly on basic writing and must add substantively to the existing literature. We seek manuscripts that are original, stimulating, well-grounded in theory, and clearly related to practice. Work that reiterates what is known or work previously published will not be considered.

We invite authors to write about such matters as classroom practices in relation to basic writing theory; cognitive and rhetorical theories and their relation to basic writing; social, psychological, and cultural implications of literacy; discourse theory; grammar, spelling, and error analysis; linguistics; computers and new technologies in basic writing; English as a second language; assessment and evaluation; writing center practices; teaching logs and the development of new methodologies; and cross-disciplinary studies combining basic writing with psychology, anthropology, journalism, and art. We publish observational studies as well as theoretical discussions on relationships between basic writing and reading, or the study of literature, or speech, or listening. The term "basic writer" is used with wide diversity today, sometimes referring to a student from a highly oral tradition with little experience in writing academic discourse, and sometimes referring to a student whose academic writing is fluent but otherwise deficient. To help readers, therefore, authors should describe clearly the student population which they are discussing.

We particularly encourage a variety of manuscripts: speculative discussions which venture fresh interpretations; essays which draw heavily on student writing as supportive evidence for new observations; research reports, written in nontechnical language, which offer observations previously unknown or unsubstantiated; and collaborative writings which provocatively debate more than one side of a central controversy.

A "Mina P. Shaughnessy Writing Award" is given to the author of the best $J B W$ article every two years (four issues). The prize is $\$ 500$, now courtesy of Lynn Quitman Troyka. The winner, to be selected by a jury of three scholars/teachers not on our editorial board, is announced in our pages and elsewhere. 


\section{Editors' Column}

Although the phrase, "basic writing," is used primarily in the United States and Canada, the complex reality to which it refers is increasingly a worldwide concern, as we were reminded during a writing workshop in Besançon, France this past August. Colleagues informed us that there is now a numerous cohort of adolescents and older who speak fluent French, but "cannot write" well enough to meet the demands of secondary and higher education in a modern technological society. Furthermore, several of the participants in our workshop taught in programs for members of ethnic and racial minorities for whom the acquisition of "literacy" in French raised complex questions of personal and cultural identity. Sound familiar?

It seems unfortunate that the $J B W$ discourse community, which more or less overlaps with teachers of ESL, does not yet include teachers of "basic writing" who are working in French, German, Portuguese, and Spanish throughout Europe and South America. There are also colleagues engaged in similar enterprises in Israel, China, South Africa, and other countries in Africa and Asia.

Our visit to France reminds us that we should not only perceive basic writing as a layer of the "English" curriculum in North America, but also as a more universal enabling discipline which exists both within and across linguistic and cultural lines. We would welcome submissions which embody or extend this awareness.

We turn now to a brief summary of the articles in the present issue. If there is any motif or emergent theme, it could be the various resonances of Mina Shaughnessy's work.

In the first article, Ann Berthoff argues that teaching reading and writing is not, as the deans would have it, a matter of correcting errors or teaching the five-paragraph essay, but a philosophical enterprise founded on notions of the Ineinandersein (in-one- 
anotherness) of the personal and public, the now and then, the here and there, the particular and the universal, and the individual and the group, and where language is a process of making meaning and interpretation is a logical condition of signification.

Patricia Laurence presents the view that recent reassessments of Mina Shaughnessy's Errors and Expectations and the field of composition in the 1970s overlook the historical and political forces of institutions that helped shape the rhetoric and methodology of the individual practitioners, scholars, and researchers at the time.

Reconsidering Shaughnessy's metaphor of likening the experience of basic writers to that of "uncultured natives" under European colonization, Pamela Gay advocates "a new pedagogy of voice in a dialogized classroom space that we keep constructing and reconstructing together from our different locations, a nexus of identities."

In a reply to Patricia Bizzell ( $J B W$, Fall '91) about the uses of political issues in the composition classroom, Bill Bolin warns that teachers can guide students too strongly toward certain political views at the cost of depriving these students of a more real sense of empowerment by sharing classroom authority.

Emil Roy presents research to validate and refine a computerized system for grading placement exams by comparing computerized ratings to holistic scores, grades earned in writing courses, and other measures. The study concludes that, while textual traits linked to levels of writing ability can be quantified, further research is needed with larger populations and greater numbers of textual traits to sort levels of writing ability accurately.

Jane Hindman contends that our evaluations of student writing come not from some transcendent or fixed quality of excellence, but from our own discursive practices by which we authorize ourselves within our own discourse communities. She argues that for basic writers to be agents of their own authorization, they need explicit knowledge of these practices, and proposes a languagecentered curriculum to accomplish this purpose.

In the final article, Lynee Gaillet draws between the 19th century Scottish philosopher, George Jardine, and modern basic writing theorists and practitioners, particularly Mina Shaughnessy, with respect to their creating similar plans to meet the needs of students who did not possess the prerequisites necessary to benefit from traditional modes of instruction. 


\title{
Ann E. Berthoff
}

\section{WHAT WORKS? HOW DO WE KNOW ${ }^{1}$}

\begin{abstract}
We know that what we are doing is working when the response to our assignments is lively and substantial. That happens when we "begin with where they are"-not with their weaknesses but with their strengths. We must appreciate the interdependence of personal and public, the particular and the universal, the individual and the group. The success of that mission depends on recognizing the logical role of interpretation in all meaning-making. (Paulo Freire's "pedagogy of knowing" remains useless without this principle, which he calls conscientization.) And it means that we must set about reclaiming the imagination-the powers of the active mind, the powers our students have for making meaning.
\end{abstract}

I want to warn you that since I've been retired for several years and am no longer in the front lines, I may have succumbed to utopian thinking. I used to count on my graduate studentsmostly teachers from the Boston public schools and those of the environs-to keep me honest, but I no longer benefit from their response to my claims. On the other hand, I frequently succumb to despair about what we are up against. Not seeing my old friends as frequently, not meeting new teachers as often as I once did, I do not have ready infusions of hope. Despair is easily fueled, is it not? Here are two examples which came to my attention during the time I was working on this paper.

Ann E. Berthoff, professor emeritus, University of Massachusetts at Boston, in 1989-90 was Randolph Visiting Distinguished Professor at Vassar College. She is the author of The Resolved Soul: A Study of Marvell's Major Poems (Princeton UP, 1970) and four textbooks, published by Boynton/Cook: Forming/Thinking/Writing, The Making of Meaning, The Sense of Learning, and Reclaiming the Imagination, which she edited. Her most recent publication is an edition of essays by $I$. A. Richards, Richards on Rhetoric (Oxford UP, 1991). During the 1980s she lectured widely, often making the case that the teaching of writing should be seen in philosophical perspectives. 
You've read about the young boy who was allowed to "divorce" his parents-a regrettable metaphor, but probably a good solution to a terrible problem. The account of how his foster father first met him included the following:

Russ said he first saw Gregory sitting reading a book at the ranch (the boy had been for some months at a ranch for boys) while other boys played around him. "I just had an immediate feeling he needed somebody. He needed help."

Granted that an immediate feeling might not be entirely rational, but isn't it curious that for this man, somebody reading is taken as a sign of distress? There are no qualifications, no second thoughts about what he said ... . or at least none is reported. What he said was that when he first saw this boy sitting reading a book, he immediately felt, "He needs help."

And then there is Gerald Graff who without shame tells us that he disliked books from the first and became interested in literature only when he found that critical debates among academics about texts engaged his attention. Graff tells us that learning to talk like teachers is the way to gain access to literature. But that is not so: it's the way to gain access to the favor of terrible teachers. Professor Graff exhorts us to "teach the conflicts," but I see no evidence that an interest in The Conflicts ever led him to literature; he claims that it's what led him to become a professor of English, but that, as we all know, is not the same thing.

Graff remarks that under the spell of great teachers "it often seems as if the work is itself speaking directly to the student without intervention from the teacher's interpretations and theories. But this spell is an illusion. If books really taught themselves, there would be no reason to attend classes; students could simply stay home and read them on their own." Do you agree with me that that is consonant with Mr. Russ's comment about needing help if you are reading a book rather than playing with the boys? Maybe you would also agree with me that Gerald Graff apparently suffers from a serious deficit: he has no imagination .... or he never developed his God-given power to imagine. I would guess that nobody ever read to him; he never went around chanting "Dr. FOSter went to GLOUcester . . . ." He probably never had the chance to find relevance in the story of Peter Rabbit's socially constructed experiences.

I could go on about such gangster theories as "teach the conflicts," but, as Chekhov would say, that is a tune from another opera. I'm here today to talk about composition. And I'm happy to be here. 
The reason I accepted George Otte's kind invitation was not just because I'm still a zealot longing to convert people to the doctrine of the Interpretant, longing to preach the gospel of the uses of chaos and the making of meaning, to bring the good news that we are all language animals, able to name and transform the world. I accepted because he told me you were having trouble with deans! I have a lifelong antipathy to deans, taken as a breed of those who do not understand what we are trying to do, do not value our hard work, do not hesitate to tell us what we should be doing instead. In preparing these remarks, I have tried to keep in mind the importance of justifying what we are trying to do in teaching composition-well, not justifying: that sounds too defensive. But I do think we must be ready to explain our purposes and our procedures, how each informs the other in the dialectic of our theory and practice. I am heartily tired of that term, dialectic, and have been relying instead on a term of Schleiermacher's: the word is Ineinandersein: the in-one-anotherness of purposes and procedures. Please indulge me: I will use Ineinandersein to represent the mutual dependence of the what and the how of all we are doing.

Now of course some deans are "invincibly ignorant," as the medieval church said of those men of classical antiquity born before Christ and therefore logically incapable of being saved. I'm thinking of one dean who recently told a young friend of mine that she must stop what she's been doing (and it happens that she's been doing the right things) and instead must teach to a multiple choice grammar test. "Students must learn to write a Five Paragraph Theme," he said, sounding as if he'd just invented the genre. This dean probably is invincibly ignorant, but you never know until you find out. Could my friend Amy make the case that in the business world-her dean comes from the B. School-what is needed is skill in assessment and decision-making; that both these skills depend on interpretation, and that interpretation is what we are teaching when we teach composition-reading and writing. She couldn't make the case to the dean in those terms, simply; she would have to show him an example of what we are likely to get from many students, including a majority of those we most want to reach, if they are taught The Five Paragraph Theme. I do not believe in the precept "Show, don't tell." We can't do one without the other: Show-and-tell constitutes an Ineinandersein. So the point would be to show how the dean's alleged purposes require a pedagogy which cannot lead students to write anything that is worth reading. It may well be that an invincibly ignorant 
dean could not recognize terrible prose when he sees it, but I have an example which is really rather unsettling. It's your first handout, entitled "Violence."

Violence in the cities today is very commen. Some is due to crime both organized and unorganized other violence occur naturally in the streets. Frequently, such violence result sever injury or even death, In order to control this growing problem it is necessary to reinstute capital punishment.

Frequently, violence gets out of hand. For instance, I was on my way to work one morning on the train, right besides me there was a vacant seat, so this elderly person got on the train and made an attemp to occupy the seat, but before doing so someone else got there before he did and took the seat. Instead of getting out of the seat and let the elder person have it, when he was asked to do so by another man who saw the incident. The man who was holding the seat refused. This then started the issue of who should have the seat. The argument then lead to a fight, and the use of knives in the crowded train.

Innocent people got hurt, and one person was killed. I feel that if these young men knew that they would be punished for this crime they would have controled their temper.

Statistics shows that states that have reinstitute capitol punishment have a thirty-percent lower crime rate. On account of this there are less crime in the streets.

People are more willing to conduct themselves in an orderly manner when they are faced with a difficult situation. These things are hurting organized crime because people are aware of this law.

Now you and I know-do we not? - that this terrible piece of writing is an artifact of a terrible assignment, which was ... .? The pitiful five nonparagraphs give it away. I would guess that the teacher thought she was offering useful guides by "limiting" the topic: "Violence-and Crime" . . . "Violence and Capital Punishment." But the idea of "limiting" the topic before it's been developed destroys any chance of teaching the invaluable conception of limits as heuristic. (My favorite text on that point is Allen Tate's observation: "A poet is a man [sic] willing to come under the bondage of limits-if he can find them.") My thought was that Amy could say to her dean: "You wouldn't want somebody in 
your office who wrote like this, would you?" An invincibly ignorant dean would answer that you have to be a good teacher and that whoever taught the writer of this paper was clearly incompetent, etc. To this kind of response, I do not have an answer. As an old Quaker I knew used to put it, "You can't argue somebody out of something they haven't argued themselves into."

But there is an equally disheartening response: When I have given this paper to teachers and tutors, asking how they would proceed in conference, the response has almost always been something.like this:

Well, I think I would ask the writer to tell me more about the incident. You can see he really relates to that incident, but he didn't give us enough detail. Why did it seem so important to him?

That response seems to me entirely inappropriate. Unless the incident is interpreted in the light of a carefully explored topic, a concept which is being formed; unless it can be given one or more contexts so that we can judge its significance; unless we have other incidents so that we could begin differentiating; all the detail in the world will not yield a concept. Concepts do not just appear: they must be formed and forming entails the Ineinandersein of particularizing and generalizing. Here is Vygotsky on this score:

When the process of concept formation is seen in all its complexity, it appears as a movement of thought within the pyramid of concepts, constantly alternating between the two directions, from the particular to the general, and from the general to the particular.

This profession is still chained to the idea of a ladder of abstraction; to the positivist doctrine that "the particular" comes first. We are continually told that narrative is more natural and hence easier; that detail is easier and hence more natural; that the personal is more important than the public, or vice versa; that orality is prior to and therefore superior to literacy. In Reclaiming the Imagination, I have gathered texts which I believe can help us liberate ourselves from this positivism. And I think that is what we must do, if we are to have any chance of reaching the almost invincibly ignorant deans.

What could we do to explain to them that this is terrible prose? I mean beyond the "bad grammar" and execrable style. Because of course it's not just a matter of faulty parallel construction, incomplete sentences, agreement errors, etc. Nor is it a matter of "insufficient detail"! 
What else could Amy do? Could she present an alternative, showing and telling how and why a good assignment must provide a useful point of departure? Could she not prepare a portfolio which would demonstrate the nature of the composing process, conceived of as a process of interpretation? As the making of meaning? Such a portfolio would include the chaos generated by students working in small groups; followed by conceptual maps, what I call "oppositions," glosses, whatever you think of as ways to get started in the matter of forming concepts. There would be sample paragraphs from phases of the composing process, annotated to suggest what is happening at one point or another. And there would be a few authentic paragraphs about a topic which has been developed, carefully analyzed, reviewed, and responded to in language in which words have work to do . . real work.

As an example of a point of departure for such work in composition, I am suggesting Rodney King's press conference. A friend of mine said after reading this transcript in The Boston Globe, (see below) "You can see he's brain-damaged." Well, maybe he is, but this bit of discourse would not surprise most Freshman English teachers in the real world, insofar as it exemplifies incoherence.

\section{'People ... can we all get along?'}

$\mathrm{P}$ eople, I just want to say, you know, can we, can we all get along? Can we get along?

Can we stop making it, making it hard for the older people and the kids and, I mean, we've got enough smog here in Los Angeles, let alone to get killed with setting these fires and things.

It's just not right. It's not right. It's not going to change anything. We'll get our justice. They've won the battle, but they haven't won the war. We'll have our day in court, and that's all we want

I love - I'm neutral, I love every - I love people of color. I'm not like they're ... making me out to be. We've got to quit. We've got to quit. You know, after all, I mean, I could understand the first two hours after the verdict, but to go on, to keep going on like this, and to see that security guard shot on the ground.

It's just not right. It's just not right, because those people will never go home to their families again, and I mean, please, we can get along here.

We all can get along. We've just got to stop. You know, I mean, we're all stuck here for a while. Let's, you know, let's try to work it out. Let's try to work it out.

But I'm confident you would agree that the difference between The Five Paragraph Theme on "Violence" and "People, can we all get along?" is very great, very important. The sudden bursts of eloquence, the haunting repetition of the rhetorical question, the balance of image and "topic," of particular and universal-the 
transcript gives us language in action: a mind is engaged and a full heart is expressed. Clarence Page on The MacNeil/Lehrer Newshour did a superb editorial in which the resonance of "We're all stuck here for awhile" became very moving indeed. And Charlene HunterGault conducted a series of interviews in which the many dimensions of Rodney King's question were explored. I see no reason why we couldn't do the same: the semester's work could proceed under that rubric, "People, can we all get along?" The writing produced would be worth revising and the final products would be worth presenting to a dean (or to the local newspaper editor). The contrast with "Violence" would be palpable.

How do I know? Because Rodney King's press conference engages our minds-not because of detail, not because he told us why it is important to him! It engages us because it is dialogic . . . not just because it is based on a question, though that is important, but because we are provoked to ask, "What? How come?" We want to say, "Yes, but ...." As we read this transcript, a real and authentic dialogue gets a start. "We're all stuck here": we know that here isn't just L.A.; We is not just African Americans. We see the violence Rodney King is talking about as representative of something larger; HE sees it that way too. That's why it's powerful: the power of the discourse, the interest of these statements, lies in the Ineinandersein of the particular and the more general and, indeed, of the universal facts of human life. Don't let anybody fool you into thinking that everything is "socially constructed," in some narrow, ideologically determined sense: some things go back to Cain and Abel.

This discourse draws on experience-whether for reader or writer, whether actual, personal involvement, or by way of the accounts and records and representations of violence which have become part of our lives. Everybody knows that it's important to begin with experience, but it's not because the personal is more important (or because it's a source of "more detail"); not because it's more real or more natural, but because its representative character can be identified. These resonant sentences mean something; they make meanings to which we must attend: that is what it means to say that this discourse is "compelling." Rodney King's press conference provides the kind of point of departure we should look for, because it is at once personal and public. You can see the Ineinandersein if you follow the sequence, "I'm not neutral. I love people of color. I'm not like they're ... making me out to be. We've got to quit." We have to fill in the contexts, read between the lines, hypothesize what he meant. We have to do here, I think, what we 
have to do in reading any piece of difficult discourse. Here, the difficulty arises because Rodney King is not in control of his language; he can hardly make it do what he needs it to do, but he's working it hard and it has work to do. I think students would be very interested in helping him make his language work, and in the process they would learn, for instance, how he gets from $I$ to we. Again, the reason that the transcript is a better point of departure than any inert topic-no matter how up-to-date or how carefully limited by the teacher-the reason that the transcript will lead to learning something about life and language is that it engages our minds. We must work our imagination to read it, but as we interpret, we discover the meanings Rodney King was trying to make and they are worth reading about, thinking about, writing about.

A third thing Amy might try is to say that in teaching her students to read and write, she must begin with where they are: that is a trap because the almost invincibly ignorant dean will leap to agree because he thinks that means "begin with where they are in their abysmal ignorance of the English language; begin with their errors." I don't have to tell the colleagues of Mina Shaughnessy that that is a foolish precept, a spirit-killing injunction-at least in the sense in which it is usually taken.

Perhaps you will remember this passage from Errors and Expectations:

Without strategies for generating real thought, without an audience he cares to write for, the writer must eke out his first sentence by means of redundancy and digression, strategies that inevitably disengage him from his grammatical intuitions as well as his thought. (82)

"Begin with where they are" must always include the idea of beginning with their strengths, with their capacity to teach one another. I'm not telling you anything you don't know, but I'm saying that you have to learn how to tell the dean what he doesn't know.

Let me return to the trap I think Amy should set for the dean: "begin with where they are" should mean, as well, "begin with where they are as citizens, as members of the public." I believe that every composition course should include examples of contemporary public discourse. We should offer our students assisted invitations to participate in this discourse as attentive listeners/ readers and as attentive participants. We will need to provide opportunities for our students to see themselves as dialogue partners. For such purposes, a transcript of the Clarence Thomas 
Hearings would serve. I am thinking, for instance, of the day a panel of women opposing the nomination offered testimony. Molly Yard was there; she was recovering from a stroke. Now, it's very easy to be nice to someone recovering from a stroke, and the Senators fell over themselves saluting her, but it seemed clear at the time that the main purpose being served was to cut down on the time the panelists had. There was a young African American woman from a self-help cooperative-and she was furious: "Clarence Thomas has misrepresented our history!" And she rolled out a list of hospitals, schools, associations which Negroes, Colored People, Afro-Americans, Blacks, people of color have invented in the past three hundred years. If we began a course with a transcript of these Hearings, think of the "topics" which could be generated collaboratively, beginning with definition, exemplification, analogy, and any other rhetorical concept you might want to exemplify! Students working together could easily identify their own topics, which might include ones like these: the history of self-help; the concept of fact; the idea of community; what is meant by "natural law"; the use and misuse of allusion; the fictionalized autobiography of Clarence Thomas' sister. And teachers of such courses could work together to develop a pedagogical guide for Joe Biden, who seemed to think that the way to explain something is to slow down and raise your voice.

When we "begin with where our students are" as members of the public, that should not be seen as the antithesis of where they are as individuals. The most pernicious consequence of poststructuralist theory is the spurious validity given to a dichotomy of the personal and the public. When we begin with students as citizens, we are not "privileging" the public over the private or setting aside personal concerns or individual experience. The essential principle to hold on to is that there is an Ineinandersein of public and private. That principle allows us to understand the individual as representative of humanity, not just of one ethnic group or another. I urge you to read David Bromwich's Politics by Other Means, in which you will find this idea explored very carefully.

"Begin with where they are" should also mean begin with students as symbol-using animals, as language animals-Language with a capital L. We do not have to teach our students how to symbolize; what we teach is THAT they symbolize. And this is what Paulo Freire means by conscientization: as learners come to an awareness of what they are doing, they will discover how to do it. One of the things they discover is how they might transform the 
world on the model of how they use language to represent their experience.

I have represented the Ineinandersein of the what and the how by means of the metaphor of the double helix (see below). You are meant to read from the bottom up, noting that naming/opposing/ defining are continuous and that in each lozenge, you can read up or down. Naming/opposing/defining are the ways by means of which we make sense of the world. Any and all acts of mind can

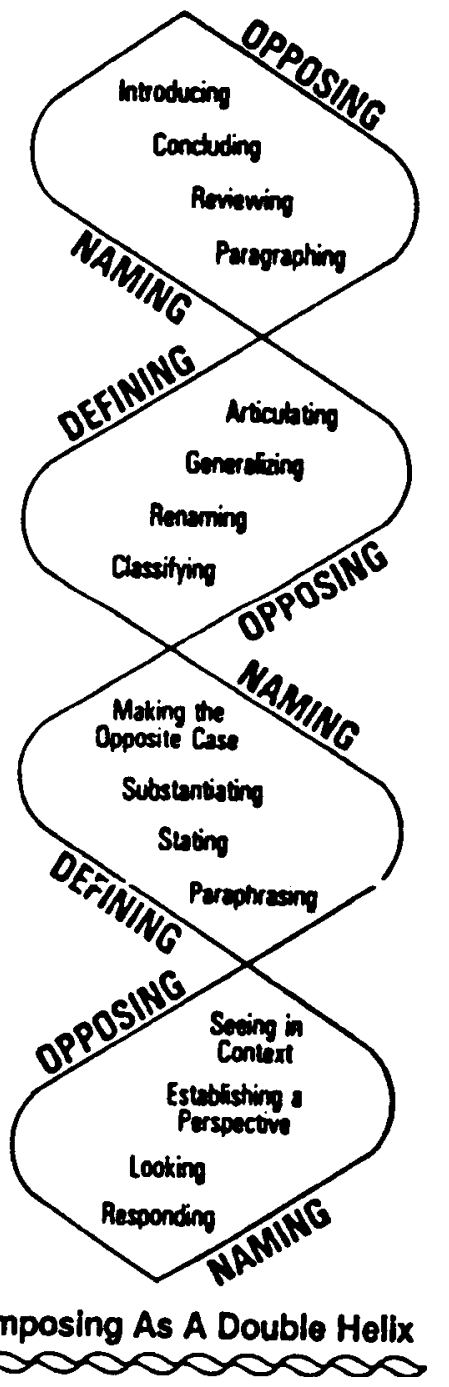

From The Making of Meaning: Metaphors, Models, and Maxims for Writing Teachers (Boynton/Cook, 1981), Ann E. Berthoff. 
be defined in these terms; any and all language acts can be identified in terms of naming/opposing/defining. These acts go on simultaneously, continuously, and correlatively throughout the composing process.

Another important Ineinandersein about language I take from Edward Sapir, the linguist we should be reading instead of Jakobson, Chomsky, Fodor, inter alios. Sapir spoke of "the linguistic process." Any process wheels on a polarity-think of polar opposites as an axle on which the wheel of process turns. The polarity of the linguistic process Sapir called "projection" and "the resistance of linguistic structure." The mind projects-seeing as, apprehending analogies; such projections are checked by the structures which language provides, those heuristic limits which morphology and syntax provide. For example, the artist Saul Steinberg frequently draws in the mode of physiognomic perception, as when he represents Summer as the open sea, Spring as an island, Autumn as a bay, and Winter as the blank mainland. In Forming/Thinking/Writing (Boynton/Cook, 1988), I have used Gombrich's "parlor game" of ping/pong: if you had only two categories, ping and pong, how would you classify elephant? And what about a mouse? It gets problematic, of course: is Marilyn Monroe ping or pong? Games with "Physogs," as I. A. Richards called them, illustrate how we project bodily impressions, how we map reality on our bodies. They demonstrate certain powers we all have to make meaning, certain unconscious instruments of thought.

The other pole of the linguistic process which is constituted by formal structures, is illustrated by what I call a Machine for Making a Toy Poem. (See next page).

This machine was originally devised to explain the Ineinandersein of the syntagmatic and paradigmatic axes: you remember that Jakobson defined poetic discourse in terms of the dialectic of these axes. But what it also demonstrates is the heuristic power of syntax. The power of syntax is that it runs along: that is what dis-course means. And as it runs along, it brings thought with it. Those of you who have read James Britton's work will be familiar with "shaping at the point of utterance," which is in fact the translation of a famous essay by Kleist ". . . the gradual readying of thought while speaking." Shaping at the point of utterance is a slogan which can remind us of the fraudulence of modeling language on the garment: we have ideas which we SOMEHOW "clothe" in words. We all know how important fluency is, but in my opinion it has been oversold as a means of helping students 
It is comprised by a syntactical frame, a semantic schema, and an ordering guide, which indicates which slots should be filled first. Experimenters have a lexicon of twelve or so words for each slot. Here is the frame:

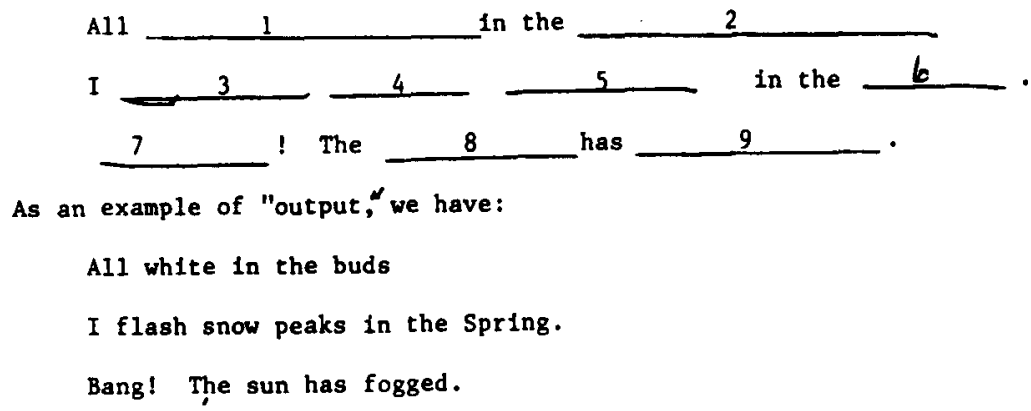

Poem example reprinted from The Times (London) Literary Supplement 18 June 1970: 667.

find a voice. Yes, it does that, but its most valuable use to us pedagogically is that fluency allows a student to take advantage of the power of syntax to help him think. As Sapir said, "Language is itself heuristic."

The machine is also fun: I'm tired of all the talk about the AGONY of writing; I think we should let our students in on the fact that it can be fun, at times. Bright students will chafe under the restrictions provided by this machine; they will have fun devising their own syntactical generators. And everybody finds that they are composing a poem almost in spite of themselves. I have never found anything so useful for showing students how the linguistic process can engage them.

Now if we interpret "Begin with where they are" to mean begin with our students both as members of the public and as members of the species, that is to say as the animal symbolicum, the language animal-the result is revolutionary. The conjunction of the political and the essentially human-or, we might say, the spiritual-this conjunction is at the heart of Paulo Freire's pedagogy of the oppressed, which is a pedagogy of knowing. If you take only the political, only the public, you get the nonpedagogy of those who think that teaching is itself an act of oppression. If you forget the personal, the individual-conceived as representative of the universals of human life-you will have cut yourself off from the greatest resource any teacher has, namely, the knowledge that language belongs to us all, as persons and as members of society; 
that the capacity to make meaning is not itself socially constructed but biologically determined; that the human mind provides the wherewithal for teaching interpretation, which I believe is what we teach when we teach reading and writing.

Interpretation, like composition, is of course a symbolic act. Not far from where we are today, at the Cooper Union, Susanne K. Langer gave a lecture in 1958 called "Man and Animal: The City and the Hive." (Collected in Philosophical Sketches, 1962.) Mrs. Langer held that all knowledge is interpretation and in this witty and provocative lecture she rejects the image of the hive as a model of human society. We are not, like the bees, semi-individuated but fully individuated. That does not mean that we are not involved with our fellow and sister human beings: Langer argues for the Ineinandersein of individuation and involvement which is motivated by our foreknowledge of death. Man is the only creature who knows that he will die and is therefore able to imagine representation, to carry out symbolic acts. It is a very carefully argued theory which she went on to develop in Mind: An Essay on Human Feeling. Susanne Langer is the philosopher we most need if we want to know what it means to say, "Begin with where they are." A socially constructed student who has been deprived of individuality and persona is no more an emblem of Man the meaning-maker than the purposeful voles, concerned tadpoles, communicating amoebas and all the other anthropomorphized denizens of the Public Television forest. Mrs. Langer concluded her lecture with these words:

Our world is a human world, organized to implement our highest individuation. There may be ten thousand of us working in one factory. There are several millions of us living in a city like New York. But we are not the masses; we are the public.

There are, I'm sure, many other ways to begin by beginning with "where they are." I will conclude by noting one which some would want you to forget. I believe that we should begin with our students as inheritors of literary traditions. I do not in any way mean what E. D. Hirsch means by "cultural literacy." That is a program without a pedagogy which is intended to get students ready to read the Great Books, if they ever get to college. It is a superb example of what Sartre ridiculed as education alimentaire . . . and what Freire calls "the banking model" of education. I mean, rather, what Louise Rosenblatt means . . . what Dan Fader meant in Hooked on Books ... what Jane Addams meant when she 
read George Eliot aloud to the women at Hull House. I could tell you dozens of stories from my forty-five years of teaching, stories of how students came to life in reading literature which the Posties would have you believe is an oppression. But I don't want to play Ms. Chips. I will tell you, though, what L. C. Knights, the literary scholar, told me. I heard this distinguished critic give a lecture in the late sixties about how he forced himself to answer the insolent and ignorant questions of his radical students who wanted to know why they should read "that rubbish." His lecture was on teaching Wordsworth's "Westminster Bridge" and it was superb. Afterwards I thanked him and told him that I was trying to assure that my UMass students had the chance to read something "great" every semester-like "Coriolanus," in a course my colleagues and I had dreamed up, "The Intellectual Confronts the Social Political Order." He agreed about the importance of this enterprise and quoted his wife who taught in a workingmen's institute. What she said was this: only the best is good enough.

I used to think that it was a matter of books, numbers of texts. I soon learned that that was not realistic; but superb paragraphs and beautiful sentences can be made accessible. I have always wanted my students to think of themselves as wealthy in the matter of literature. (That is why I've never agreed with those who want student texts to be the only ones in the composition classroom.) We work to assure that by reclaiming the imagination.

I don't know how to make that enterprise palatable for an invincibly ignorant dean, but that's not the point really: the aim of reclaiming the imagination is a covenant between you and your students. That's the most vital Ineinandersein of all, because of course they teach us how to read when we are all reading the best. Perhaps that is the most utopian thing I've said, but I have tried throughout these comments to be practical: practical criticism is what we teach in teaching reading and writing and I've been claiming that if we are to be good pragmatists we must be able to show and tell why what we are doing works and how we know. We know that what we are doing is working when the response in lively and substantial. We know that this happens only if minds are engaged and that that happens only when what our students read is seen as dialogic-when the Ineinandersein of the personal and the public is apprehended-the Ineinandersein of now and then, here and there, particular and universal, the individual and the group. And we can assure that our teaching is informed by such representations of Ineinandersein if we proceed with an understanding of language as a process of making meaning, and of 
interpretation as the logical condition of signification: there are no clean machines. Ask the dean if he holds with Charles S. Peirce that the meaning relationship is triadic. Offer to provide him with a bibliography so that he can follow your argument. Better yet: invite him to your class and suggest that he should have three writing assignments completed before you next meet. That last is not utopian, but it probably would be counterproductive; I don't want you to get fired! But I passionately believe that ours is a philosophical enterprise and that our pragmatism should include ways to clarify our expectations, to explain them to those who think that our mission should be to teach the correction of error.

\section{Note}

${ }^{1}$ This paper was originally the keynote address at the CUNY Association of Writing Supervisors (CAWS) Conference in October 1992, held in New York City. 


\section{Patricia Laurence}

\section{THE VANISHING SITE OF MINA SHAUGHNESSY'S ERRORS AND EXPECTATIONS ${ }^{1}$}

ABSTRACT: This article "historicizes" recent reassessments by Min-zhan Lu and Stephen North of Mina Shaughnessy's Errors and Expectations and the field of composition in the 1970s. It argues that these retrospective accounts neglect the historical and political forces of institutions that shape the rhetoric and methodology of particular practitioners, scholars, and researchers.

Educational writing allows for many gradations in the degree of political awareness it manifests. Besides overt argument, there are indirect ways of writing that emerge from certain educational and historical moments. When Mina Shaughnessy's Errors and Expectations was published in 1977, it adopted a degree of distance toward certain kinds of political questions that may strike today's clearly more politically self-conscious composition specialists as evasive or naive. Yet history teaches us to acknowledge that to learn to read or write at a given time in a particular place is to engage with current conventions of writing, and the social and institutional expectations of what form it can take.

Recent retrospective accounts of the teaching of writing by Min-zhan Lu and Stephen North illustrate the current neglect of

Patricia Laurence, a past director of the Composition Program at The City College, CUNY presently directs the collegewide Writing in the Disciplines Committee. She has published The Reading of Silence: Virginia Woolf in the English Tradition (Stanford UP, 1991) as well as articles on modernism, narrative theory, feminism, and most recently the pedagogy of reading in the HarperCollins World Reader (forthcoming in December 1993). 
this historical dimension of composition studies: both authors focus to varying degrees on the period of Open Admissions when Mina Shaughnessy's Errors and Expectations was part of the canon for teachers of basic writing in urban universities. Ignoring the fact that educators and linguists-no matter how hard they try-are not always in control of the definition of terms like "competency" and "error," both Min-zhan Lu in "Redefining the Legacy of Mina Shaughnessy: A Critique of the Politics of Linguistic Innocence" (JBW 1991) and Stephen North in The Making of Composition (1987) fail to represent and analyze the complexities of this educational moment. The work of composition is reduced in these accounts to one text, one voice, belying the "dialogical" nature of educational movements and the "rich" description of people, programs, institutions, and politics that the anthropologist Clifford Geertz advocates.

Min-zhan Lu, in her reassessment of Errors and Expectations, does away with the site of City College, the mute historical ground upon which this educational movement stands. An educational movement cannot be analyzed in one text for it cannot possibly represent the institutional dialogue, the "polyphony," to use Mikhail Bakhtin's term, from which it grew: its multiple expressions and silences; its multiple experiences of students and faculty; its multiple ethnicities and races; its multiple perspectives of students, faculty, administration, public figures, public relations offices; its multiple discourses. Similarly, Stephen North in his useful study of the "methodological communities" in composition-the practitioners, the researchers, the scholars-ignores in his own methodology the history, traditions, and politics of particular institutions at particular historical moments from which certain composition leaders emerge, including Mina Shaughnessy. Reading Michel Foucault's Discipline and Punish, a study of the transformation of the eighteenth-century French prison system, reveals the importance of analyzing the hidden parts of an institution to unravel its politics and philosophy, including the way its physical spaces are designed.

Recent accounts of Open Admissions in the 1970s are more preoccupied with advancing an explicit ideology of conflict in Gerald Graff's sense, than in historically reassessing Shaughnessy and the movement in which she became pivotal. Graff argues that "the most educationally effective way to deal with present conflicts over education and culture is to teach the conflicts themselves" (51). Similarly Min-zhan Lu urges the foregrounding of "politics," criticizing writing and "pedagogies [like Shaughnessy's] 
which promote ... a politics of linguistic innocence: that is a politics which preempts teachers' attention from the political dimensions of linguistic choices students make in their writing" (27). Such analysis ignores the historical currents in which writing is taught, not acknowledging that institutions shape what form the teaching of writing can take. In addition, it ignores the fact that certain educational moments are more likely to produce more overtly political discourse in the classroom (and outside of it) than others.

Rather than pluralizing students' linguistic differences, their dialects and their languages (Min-zhan Lu's "discourses") to the point where no discourse is shared in common-Mina Shaughnessy and others developed a pedagogy in 1970 in response to a given time in a given society. What students wanted to learn was standard English. Far from being a group of Mr. Gradgrinds or Ms. Choakum-childs with "essentialist views of language" repressing the voice and cultural discourses of students, a core of teachers at City College were eager to learn about linguistic difference. Enlightened by Joe Dillard and his research on Gullah, we learned of the similarities between this dialect and the underlying structure of African languages; taught by William Stewart, we studied the features of what was then called Black English Vernacular to enhance our understanding of patterns of interference and dialect variation in our students' writing; led by native speakers of foreign languages, we prepared charts of the contrastive grammars of Spanish, Chinese, and Creole (French); led by Ken Bruffee, we experimented with small-group learning; informed by Mary Epes, Carolyn Kirkpatrick and Michael Southwell, we created "hierarchies" of coding problems; visited by Don McQuade, we became more thoughtful about rewriting and the use of folders long before "portfolios" emerged; led into discussion by Bob Lyons, we learned to balance the values of meaning and correctness in writing; urged by Harvey Wiener, we considered the use of audiovisual approaches to the teaching of writing; informed by Marie Lederman, we learned of new research methodologies in composition. Joining with Paulo Freire, we taught the students the "majority" language, effectively intertwined with activities that related to their lives so that they could enter the mainstream of American academic, social, and economic life.

The first description of English 1, the first basic course in the composition sequence, included this reading list: Chapman and Abraham's Black Voices, Herman Hesse's Siddhartha, Rene Marques' The Oxcart, George Orwell's Essays, Richard Wright's 
Black Boy, Carolina Maria de Jesus' Diary. Students were required to keep an outside journal relating to their daily lives, their reading, or their trips to museums or galleries. Concurrently, students worked on high-frequency grammatical problems in the context of their writing, but the syllabus stated that "From the beginning, the student should be encouraged to take the responsibility for his development as a writer-to analyze his difficulties and to make use of the services that are available to him in the way that works best for him."

It was a delicate balancing, honing meaning and correctness in writing, but linguistic codes were not taught in isolation from meaning. To deny the common goal-to engage students in reading and to nurture students' writing in standard English-to trifle with our students' lives, sacrificing their desire to enter the educational, economic, and cultural mainstream to notions of "multiple discourses" would have been pernicious. Knowledge of student dialects and languages was always part of our linguistic and cultural discussion in class, and, sometimes, dialect was part of the writing assignment.

No rereading of Mina Shaughnessy's Errors and Expectations can occur in a neutral field without this landscape of place. The history, meaning, and understanding of ethnic succession at City College-both its faculty and students-each group with differing educational, social, and cultural needs, is missing from Lu's analysis. What T. S. Eliot called "a dissociation of sensibility" develops, an increasing refinement of language and theory with a loss that results in the separation of thought and feeling. Yet it is amidst these cultural and educational tensions, in this place, where the guiding metaphor of error was transformed by Mina Shaughnessy, and where one of the most optimistic, and perhaps naive ideas about American education began: naive because in subsequent years the necessary funding and support for this program disappeared.

\section{Reading Institutions}

To understand this transformation, we must learn to read institutions with new schemas; must gather the complex forces of an institution in our analysis. For Errors and Expectations is as much a "reading" of an institution as it is the reading of student errors and changing teacher expectations.

Let me describe some aspects of City College in 1970 with its simultaneous conversations or discourses-only a few of which, I 
might add, entered into the text of Errors and Expectations and other public statements at that time (by Irving Howe, Leonard Kriegel, Geoffrey Wagner). Other conversations are there to be read in the margins of many articles, or other yet unrepresented faculty perspectives. No one who was there could fail to hear the plurality of voices, the multiplicity of points of view-the conflicting discourses that inextricably mixed linguistics and politics in a way that could never be separated again. If it is a truism in feminism that the personal is the political, then in the field of composition, the linguistic is the political.

Guiding institutional change, as Mina Shaughnessy did, required a nuanced appreciation of cultural dynamics. There was a political and cultural subtext to all of our educational and linguistic discussions for we were dealing not simply with punctuation, perception, writing, and literature, but also with the social consequences of linguistic choice. What can now be said overtly, was submerged then: it was the 1970s, an early phase in a controversial educational movement. Sometimes it was a strategy to employ understatement and unspecified agency in public statements, not openly acknowledging the linguistic or cultural conflict inherent in certain situations. Not because of rhetorical or intellectual innocence or cowardice, as suggested by Lu, or an agenda of repression of difference or multiple discourses, as some would have it, but because of a necessary period of negotiation of values and accommodation within the institution. Note, for example, the rhetorical stance in Shaughnessy's distanced statement of "background" in the introduction to Errors and Expectations:

Toward the end of the sixties and largely in response to the protests of that decade, many four-year colleges began admitting students who were not by traditional standards ready for college. The numbers of such students varied from college to college as did the commitment to the task of teaching them .... For such colleges, this venture into mass education usually began abruptly, amidst the misgiving of administrators, who had to guess in the dark about the sorts of programs they ought to plan for the students they had never met, and the reluctancies of teachers, some of whom had already decided that the new students were uneducable. It was in such an atmosphere that the boldest and earliest of these attempts to build a comprehensive system of higher education began: in the spring of 1970, the City University of New York adopted an admissions policy that guaranteed 
to every city resident with a high school diploma a place in one of its eighteen tuition-free colleges. (1)

Anyone who knows the history of Open Admissions recognizes the exquisite control, the understatement, and the unarticulated conflict in this early description. Who can measure the force of stress in an institution like City College, of an educational movement introduced five years earlier than planned, and modeled on the state-mandated SEEK program. Initiated in 1970 because of student takeovers and the shutting down of the campus, Open Admissions was propelled by the virtual shutdown of the college campus, including the barring of gates and the burning of rooms (the beautiful music room in Finley Student Center) and buildings. Open Admissions began on the campus of City College with a virtual revolution. Note then the irony of Shaughnessy's understatement that "this venture into mass education usually began abruptly" (1).

"Error," however, though we would have wished it otherwise, became the institutional ground for discussion of Open Admissions. The institution was reformulating competency. "Error"and this may be difficult for a generation now intent on ignoring it to understand-was the public space where the latent theoretical and educational commitments of faculty members, departments, and divisions met and interacted. Do we believe in these students? Can they learn? Can we teach them? These were the questions that beleaguered faculty asked in the 1970s, placing the mission of the university in question.

Mina Shaughnessy, in transforming the guiding metaphor of error, changed the instructors' and the institution's attitude from one of negativity-the malfunctioning of students' linguistic systems-to one of possibility - that of a predictable pattern of interference from other languages and dialects. "Error" was the first word on the lips of the faculty after they read their first batch of papers. Not surprisingly, the essays these students wrote during their first weeks of class stunned the teachers who read them. In her book, Mina Shaughnessy describes this reaction:

Nothing, it seemed, short of a miracle was going to turn such students into writers. Not uncommonly, teachers announced to their supervisors (or even their students) after only a week of class that everyone was probably going to fail. These were students, they insisted, whose problems at this stage were irremediable. To make matters worse, there were no studies nor guides, nor even suitable textbooks to 
turn to. Here were teachers trained to analyze the belletristic achievements of the centuries marooned in basic writing classrooms with adult student writers who appeared by college standards to be illiterate. Seldom had an educational venture begun so inauspiciously, the teachers unready in mind and heart to face their students, the students weighted by the disadvantages of poor training yet expected to "catch up" with the front-runners in a semester or two of low-intensity instruction. (3)

Profound changes occurred in conceptions of teaching and learning. There were some in the English Department and other departments who were overwhelmed by the students' lack of preparation. The first issue then was the credibility of students as students; the second was the faculty's image of itself and its credibility as teachers. The focus in the early days of Open Admissions, indeed the focus of the first issue of the Journal of Basic Writing, founded at City College by Mina Shaughnessy, with Sarah D'Eloia Fortune, Barbara Quint Gray, Valerie Krishna, Blanche Skurnick, Nancy Lay, Betty Rizzo, Isabella Halsted, Santiago Villafane, Nate Norment, and myself in 1974, was "Error." The conversation that you read in Errors and Expectations was the response of an educational movement that still had the burden of proof to a traditional faculty in the institution and to the public. We who were involved in Open Admissions understood too well T. S. Eliot's refrain, "The eyes that fix you in a formulated phrase .... Then how should I begin. ..."

\section{The Faculty}

Though we speak a lot of the culture and diversity of our students these days, we neglect the "polyphony" (to use Bakhtin's terminology of voice) of the faculty. As Dennis McGrath and Martin Spear suggest, in models for institutional change, teachers and administrators are presented as "fully rational actors, carefully planning and choosing, in control of their institutions, shaping them to their will" (62). But no policy or practice is culturally neutral and no institutional response to educational change is "fully rational." During the early years of Open Admissions, the faculty, under stress, knew that the Open Admissions policy was not simply a few new practices added on to the old; it created a new academic culture. 
In that first core of instructors who worked with Shaughnessy were literary critics, creative writers, and linguists, all of whom were interested in teaching-a creative mix of people who believed that the borders between these fields, all focusing on language, after all, were permeable. It was this mix of specialties and people that was the second transforming factor in our traditional department. People spoke of writing with special emphases, yet with the sense of overlapping concerns, not believing or articulating (as some in our field do today) a polarization among those in literature, creative writing, and composition. A repertoire of techniques and assignments was developed and discussed with no formulaic or "essentialist" positions on the relationship between thought and language that remains as mysterious today (just read William James and Virginia Woolf), as it did then, in spite of our cognitive labeling. This core group created direction for the rest of the faculty.

It was, admittedly, a faculty torn by uncertainties, ambiguities, frustration, and isolation in those early days of Open Admissions when each faculty member was required to teach at least one basic writing course, and often two, and many went through a period of transformation. Traditionally trained literature professors came to understand their professional roles in new ways and were influenced by the institutional structures they shared but somehow felt that they had not shaped. There was resistance, there was good will; there was an air of skepticism mixed with hope about the intellectual and social environment of the institution as it was being shaped anew by Open Admissions. Very different, and even opposed educational and cultural traditions coexisted peacefullyor seemed to.

The faculty was in crisis about the meaning of the books it had grown up on, and long before it became fashionable to talk about the "canon" our Open Admissions students reinvented it. On a daily basis, we read these books through the students' ethnic, racial, and political perspectives. There was, for example, the student who, during a discussion of The Great Gatsby, wanted to discuss not Nick and the "American Dream" but the "Dream" in relation to the few shadowy Black servants represented in the novel, refocusing decades of literary preoccupation. Our own relationship to language and literature became deeper because of our teaching, seeing literature read with different cultural assumptions, recognizing what Derrida labels "the violence of the letter" to our students' sense of self and their cultures, in certain books. In the institution, the very presence of African American, His- 
panic, Asian, Haitian, and Greek students meant that there was a politically submerged and powerful subtext in every classroom that questioned the institution-the teaching of the majority language, standard English; the way we taught; what books we taught. There was no need, as Gerald Graff and Min-zhan Lu urge, to "structure" conflicts into the curriculum (Graff, 52). Perhaps such strategies are necessary at the University of Chicago and Drake University (we should begin to differentiate pedagogies that fit the cultural needs of different classes and institutions), but the presence of large numbers of minority students in the institution brought the linguistic and cultural questions and problems of our city and society into the classroom every day in our discussions of reading and writing. We struggled, at times, with this powerful subtext, trying to balance sometimes global discussions of conflict and oppression with what Stephen North calls the "practitioner's arts"-teaching ways of reading and the majority language to our students-or in discussions of techniques sorely needed by a faculty that was routinely experiencing difficulty in teaching its students.

Anyone who was there in those early days knew that we were not just dealing with language, we were dealing with our students' vulnerable lives. How can I forget my Jamaican students sitting in class with their coats on unable to warm themselves to the degree of the Caribbean sun during our New York winters; the Asian American student who when asked to write about an object in his house, wrote an essay about the one table in the middle of his kitchen and the large board that was added to it to make it into a homework table, then a table for making wontons, then a dinner table, then a resting place for the baby's bathtub, ending its day by becoming the ironing board for the laundering and ironing of other people's shirts, the family business; the Iranian students who when they were forced to return to Iran during the hostage crisis told me (suitcase in hand) that their not having passed the Proficiency Exam would mean that they could not have a career in Persia: an "international" crisis. Or the African American student who rhetorically organized his essays as if he were a preacher beginning each one with "hallelujah."

Had she lived, Mina Shaughnessy might well have written another book entitled, Confessions of a Director of Writing, or The Political Underside of Errors and Expectations: some things remain unsaid. But make no mistake, Errors and Expectations is the public face prepared to meet the faces in a public space preoccupied by "error," and the question of the teachability of these 
students. Mina Shaughnessy took the advice that she gave to her composition students, "Know your audience," and guided institutional change with a nuanced and sophisticated appreciation of the diversity of the faculty, awareness of the public, and a rhetorical strategy of indirection and understatement. What is now fashionably explicit had to be implicit at that historical and educational moment at City College.

In reading Errors and Expectations, we are reading only part of a conversation in an urban educational institution at a certain historical moment. A quality of the writing-its style of indirection, and, sometimes, elegance-creates order out of the clamor of a desperate educational moment. To cast such a moment into a timeless landscape, as Stephen North does in portraying the writing of Errors and Expectations as a heroine's archetypal quest, an "epic" told by a "special storyteller ... to promote one version or another of a community's mythic self-image" (32) is to romanticize a troubled educational moment and to deny its historical specificity. This book emerged from more than the "society" of composition or a "methodological community"; rather from the turmoil of an institution, a city, a society. Different methodologies and stances spring from different student populations at public and private colleges; urban, suburban, and rural; commuter and residential. For example, the educational stories of historically Black colleges and midwest land grant colleges, also pioneers in the field of composition, may develop differently because of different traditions or expectations. In the next decade, educational stories and accounts will emerge in all their specificity and plurality to defend against ahistorical retrospective accounts of the beginnings of the field. Each conversation will be historically informed by different personalities; different regions of the country; different classes, ethnicities, or races of students; different educational missions and traditions. And when we have this kind of knowledge to be gathered by more inclusive methodologies than those represented here, we will begin to read the texts, the institutions, and the field with more sophistication. We will learn to read the mute historical background and "political unconscious" in public texts like Errors and Expectations.

\section{Note}

'This article was a talk presented at the 4th National Basic Writing Conference held at College Park, MD in October 1992. 


\section{Works Cited}

Barber, Benjamin. "The Civic Mission of the University." Higher Education and the Practice of Democratic Politics. Dayton, $\mathrm{OH}$ : Kettering, 1991.

Derrida, Jacques. "The Violence of the Letter: From Levi-Strauss to Rousseau." Grammatology. Trans. Gayatri Chakravorty Spivak. Baltimore: Johns Hopkins UP, 1976. 101-41.

"Error." First issue of Journal of Basic Writing, Spring 1975.

Foucault, Michel. Discipline and Punish: The Birth of a Prison. Trans. Alan Sheridan. New York: Pantheon, 1977.

Geertz, Clifford. Works and Lives: The Anthropologist as Author. Stanford, CA: Stanford UP, 1988.

Graff, Gerald. "Teach the Conflicts." South Atlantic Quarterly 89 (1990): 51-67.

Lu, Min-Zhan. "Redefining the Legacy of Mina Shaughnessy: A Critique of the Politics of Linguistic Innocence." Journal of Basic Writing 10.1 (Spring 1991): 26-40.

McGrath, Dennis and Martin B. Spear. The Academic Crisis of the Community College. New York: SUNY P, 1991.

North, Stephen. The Making of Composition: Portrait of an Emerging Field. Upper Montclair, NJ: Boynton, 1987.

Shaughnessy, Mina. Errors and Expectations: A Guide for Teachers of Basic Writing. New York: Oxford UP, 1977. 


\title{
Pamela Gay
}

\section{REREADING SHAUGHNESSY FROM A POSTCOLONIAL PERSPECTIVE ${ }^{1}$}

\begin{abstract}
In "Diving In: An Introduction to Basic Writing," Mina P. Shaughnessy (1976) metaphorically likened the experience of basic writers to that of "uncultured natives" under European colonization. Gay takes the metaphor seriously. She questions colonizing basic writers to the extent that: (1) they risk losing their difference; (2) they do not develop their differences through the language they speak, the culture they know, the lives they've lived; and (3) those of us in the first world, not hearing difference, will fail to see outside our privileged lives. Gay advocates decolonizing our pedagogical practices and encourages a new pedagogy of voice in a dialogized classroom space where teacher and students keep constructing and reconstructing from their different locations, a nexus of identities.
\end{abstract}

\section{"Plus de frontieres!"/"No more boundaries!" cried the poet Jean Tardieu}

In a graduate course (Fall 1991) that I subtitled "What Are We Talking About When We Talk About Teaching Writing?" we were reading about the need to teach academic discourse to nontraditional students, especially basic writers for whom academic culture is particularly foreign. How do we help bridge the gap between the home culture of these students and the academic world where we teach? How do we help move them from the

Pamela Gay, associate professor of English at Binghamton University, State University of New York, directs the basic writing program and teaches writing and a graduate course in the teaching of writing. Her work has appeared in Issues in Writing, Computers and Composition, and in Portfolio Grading: Process and Product (P. Belanoff \& M. Dickson, eds.). She has also published a textbook Developing Writers: A Dialogic Approach (Wadsworth 1992) and is currently working on teaching writing in a postcolonial world. 
borderlands to the academic mainland? How do we get them to speak and write so that they can succeed in this new world? Philosopher Susanne Langer (1942) says that if we want to know about a particular historical period, we should look at the questions being asked. In 1977 Shaughnessy wrote Errors and Expectations in part to address these questions, but not without some concern, which I'll talk about later.

While I believe, as I believe Shaughnessy believed over 15 years ago, that it would be irresponsible not to help basic writers learn to Write for Success, I was becoming concerned about the underlying imperialistic assumptions of classroom practice designed to help these students into the academic colony. I began to question the colonizing of developing writers-I'm going to interrupt myself: I use the term "developing writers" to refer to students who are working on the development of their writing abilities, and I include so-called basic writers in this category. Perhaps Shaughnessy would approve, if not of the name, at least of my attempt to rename. She came up with "basic writers" to displace the pejorative "remedial." I began to question the colonizing of developing writers to the extent that: (1) they risk losing their difference; (2) they do not develop their differences through the language they speak, the culture they know, the lives they've lived; and (3) those of us in the first world, not hearing difference, would fail to see outside our privileged lives.

With these concerns in mind, I wandered into a talk about an African perspective on colonialism by Femi Taiwo (1991) at a conference sponsored by the philosophy department at my university. I felt like I had walked into Kenneth Burke's portrait of "an unending conversation." All the seats were taken; the talk had already begun. No one could stop and tell me what "had gone before" (1973, 110-11). I stood in the doorway and listened:

During a prayer in an ancient town in Africa on a day of renewal, a chief was heard saying "In Christ's Name We Pray" and seen wearing a crucifix, shocking the townspeople.

The colonizing process had begun. The African chief was converting to the ways (and world) of the missionary-colonizers who had come to help civilize his people. I began to think about how the experience of basic writers is like the experience of Africans under European colonization. There are different forms of colonization. Colonization may involve one country. Internal colonization occurs when a dominant group treats another group as for- 
eign. ${ }^{2}$ If we think of basic writers as colonized in some sense, how might we change our pedagogy?

While I was pondering this question, in the graduate course we read Shaughnessy's essay "Diving In: An Introduction to Basic Writing" (1976) in which she describes, in a tongue-in-cheek tone, a four-stage developmental scale for teachers, which can be used as a framework for talking about how we have tried to address "the writing problem" since the early days of Open Admissions. Not surprisingly, the first reaction of many teachers to this group of nontraditional students we call "basic writers" was to GUARD THE TOWER (Shaughnessy's STAGE ONE) - to keep out, or down, those who "do not seem to belong to the community of learners," as Shaughnessy (234) puts it, or "the unbelonging," as Joan Riley (1985) calls Black British immigrants. Natives from various colonies come to the academic colony and, in Shaughnessy's words, strain "to approximate the academic style" (235). And teachers? Teachers "hold out for the same product" they "held out for in the past but teach unflinchingly in the same way as before, as if any pedagogical adjustment to the needs of the students were a kind of cheating" (235).

Shaughnessy's STAGE TWO: CONVERTING THE NATIVES: At this stage, says Shaughnessy, "the teacher has now admitted at least some of the community are educable. These learners are perceived, however, as empty vessels, ready to be filled with new knowledge" (235). ${ }^{3}$ The teacher's purpose, continues Shaughnessy, is "to carry the technology of advanced literacy to the inhabitants of an underdeveloped country" (235). Basic writers, in David Bartholomae's words, are seen within this imperial frame as "uncultured natives" (1987, 69). In this stage, the missionary, colonizing, civilizing metaphor takes hold, if we're talking about developmental stages of teachers of basic writers, or "took hold" if we're talking about a stage in the short history of composition studies. Let's civilize the natives! Let's help them into the culture. ("Culture," perhaps you didn't know, is a cognate of "colonize.")4 But how can we educate them? "And so confident [are teachers] of the allure of what they are presenting," explains Shaughnessy, "it does not occur to [them] to consider the competing logics and values and habits that may be influencing [their] students" (64). We still had a writing problem. Well, let's study the natives we're trying to colonize. If we closely observe them writing, maybe we can figure out what's wrong with them and convert them to our ways. 
Shaughnessy's STAGE THREE: SOUNDING THE DEPTHS: "...careful observation not only of. . students and their writing but of. . . [self] as writer and teacher" (236). In composition studies, this is the period of the late 1970 s and 1980 s when we conducted case study research of skilled and unskilled writers and studied the content of their essays, including Shaughnessy's own classic study (1977) in order to find out what was wrong with them-What's their problem? ${ }^{5}$ Maybe if unskilled writers adopted the composing habits of skilled writers, that would solve the writing problem. Maybe if their erroneous beliefs about the nature of writing and how writers work were cleared up. Maybe if we studied the content of their essays. Maybe their cognitive development was arrested. They were stalled at the egocentric stage. Maybe that's the problem.

Like the composing process, however, the colonizing process is not linear; it's recursive. So after SOUNDING THE DEPTHS, we went back to the new frontier to what Shaughnessy called in Errors and Expectations (1977) the "pedagogical West" (very much into the colonial motif here) and tried to conquer this new "territory," as Shaughnessy characterized "basic writing." (4). Bizzell and Bartholomae and Rose emerged with a different view of the problem, a view which sent us back to "converting the natives": 6

Bizzell (1982): Students are unfamiliar with the conventions of academic discourse. That's the problem. Bartholomae (1987): We need to help students learn to approximate academic discourse. Rose (1989): Students do not know critical strategies. That's the problem.

In the 1980s, we were all working on this problem. I was looking at the relationship of attitude toward writing and the development of writing abilities. Maybe attitude was one of the problems (Gay, 1983).

Talk about changes in pedagogy focused on ways to ease the transition of students into the academic colony in the land of educational opportunity. To use Shaughnessy's words, these students were "on the wrong side of the academic gap" $(1977,275)$. How can we "bridge the gap" between these two worlds? Teachers became linguistic parents whose role was to move students closer and closer (ever closer) to the academic center where the cultural capital was located. I'm going to insert the cautionary voice of postcolonial critic Trinh Minh-ha from Woman, Native, Other (1989): Students who move "closer to the civilized language" come "nearer to equality" (56). (Her tongue's in her cheek, too.) When "colonizer and colonized have come to speak the same 
language," when "the Powerless have learned to parrot the language of the Powerful," that's equality (58). So much for the road to equality and the land of educational opportunity. Read "equality" here to mean "equal/like us." "They are entrapped in a circular dance," continues Minh-ha, "where they always find themselves a pace behind" (59).

Now I'm going to return to the voice of Shaughnessy (1975):

The phrase "catching up" so often used to describe the progress of BW students, is illuminating here, suggesting as it does that the only person who must move in the teaching situation is the student. As a result of this view, we are much more likely in talking about teaching to talk about students, to theorize about their needs and attitudes or to chart their development and ignore the possibility that teachers also change in response to students, that there may in fact be-important connections between the changes teachers undergo and the progress of their students. (62)

So what're we gonna do? Teachers, suggested Bartholomae (1986a) can teach students "what's at stake" (105). Shaughnessy (1977) talked about what she thought was at stake:

College both beckons and threatens basic writers, promising even to improve the quality of their lives, but threatening at the same time to take from them their distinctive ways of interpreting the world ... to assimilate them into the culture of academia without acknowledging their experience [I'm going to add here, their difference] as outsiders (292).

Fifteen years ago Shaughnessy asked members of the academy to look more critically at ourselves and the academic culture we are trying to help students join: What kind of a club is this?

Bartholomae (1986b): The academic culture is a "closed culture" (85).

Rose (1989): "Nothing is more exclusive than the academic club" (58).

Bartholomae again (1986b): Entry into this culture club requires students to "enter another's thoughts by using another's language" (85).

Bizzell (1986) lingers and asks (I'm paraphrasing here): Do they have to move out to move in?'

I interject here also from the year 1986, the voice of decolonizing critic Ngugi who warns: "Language has a dual character: it is both a means of communication and a carrier of culture" (13). 
Shaughnessy asked us to DIVE IN (STAGE FOUR) and shift our "What's wrong with them?" accusative stance to "What's wrong with us?" The gulf between the colonizer and the colonized, between them and us, this inequality, this "killer dichotomy," as Berthoff (1990) would say, is one component of what theorist Albert Memmi (1992) calls "colonial racism." "The colonialist," Memmi points out, "stresses those things which keep him separate rather than emphasizing that which might contribute to the foundation of a joint community" (71). ${ }^{9}$ Instead of trying to separate teachers from students ("us" from "them") like colonialists, what if we ask what students can contribute to the foundation of a joint community? What if, as Bizzell (1988) recommends, we revise the prevailing notion of academic literacy and come to see the production of literacy as a collaborative effort, as a process of construction based on classroom interactions?

Shaughnessy speaks about the need to acknowledge the experience, the difference of basic writers. Henry Giroux agrees that it is important to find ways to give all students opportunities to speak and to voice difference, and as bell hooks (1990) tells us, "it is no easy task to find ways to include our multiple voices" (147). Giroux (1991) goes further. He argues, as have Audre Lorde (1984) and Chandra Mohanty (1989-90), and other feminists that we need to do more than acknowledge (tolerate) difference and more than celebrate difference as "interesting material." Inclusion and celebration are not enough.

Giroux (1991) believes that we need to redefine voice "not merely as an opportunity to speak" but to engage critically in "rigorous discussions of various cultural texts" (249). Moreover, teachers, according to Giroux, must "cross over borders that are culturally strange and alien to them" in order "to analyze their own values and voices as viewed from different ideological and cultural spaces" (254-55). ${ }^{10}$ Sharon Welch (1992) argues that listening to and engaging the stories of the Other can educate members of the dominant culture to a redefinition of responsibility through what she calls an "ethic of risk." Are we willing to give up our text-centered selves, our teacherly authority, our authorship, and surrender to what Neuleib (1992) calls the "basic otherness" of many student writers? Are we teachers willing to educate ourselves?

If we are going to confront colonial inequality and work toward a pedagogy appropriate for a postcolonial world, then we must learn to use difference as a source of strength. In the words of Audre Lorde, who spoke at the Second Sex Conference in New 
York two years after the publication of Errors and Expectations, difference must be "seen as a fund of necessary polarities between which our creativity can speak like a dialectic" $(1984,111)$. A colonial model, a reductive us-them discourse, won't get us through the 21st century, not without war or more riots anyway. Postcolonial theory encourages a new pedagogy of voice in a dialogic classroom.

"Precisely because writing is a social act, a kind of synthesis that is reached through the dialectic of discussion, the teaching of writing must often begin with the experience of dialogue." (Shaughnessy, Errors and Expectations, 83). "Yet classrooms in their usual asymmetrical arrangements with the teacher on one side, talking, and the students on the other, listening-or looking at the backs of other students' heads-do not breed discussion." Whose classroom is this? What kind of a place is this?

I imagine this place where we're going "where there are no charters" (Lorde, 1984, 111) as a space, not a frontier, for frontier brings up conquest and the colonial metaphor, but a "space of dialogue" (as Maxine Greene, 1988, 13, says) or a "dialogized space" (as Bakhtin would say), a dynamic space (I'm saying) that we keep constructing and reconstructing together from our different locations (a nexus of identities: gender, race, class, enthnicity, sexual orientation, and so on). This space "is not a 'safe' place," to quote bell hooks again, (149)-both teachers and students are at risk.

In an "open forum of voices," Don Bialostosky (1991) warns, "there is no guarantee [students] will not interrupt one another" (20). Contradictory and competing voices may erupt, disrupt, or rupture the seams of the text we call classroom discussion. This view of difference, however, does not bypass the struggle for power; rather, it brings the struggle out in the open. And it is this "multicentric perspective," argues Giroux (1992), "that allows students to recognize and analyze how the differences within and between various groups can expand the potential of human life and democratic possibilities" (34).

Much of what Shaughnessy called "the territory of basic writing" is still unmapped. As Grewal et al. explain in Charting the Journey "It is safer to stick like nervous glue to what we know," to "defined land" (118). Teachers need to take risks, too. Basic writers, Shaughnessy (1977) told us over 15 years ago are "a unique group from whom we have already learned much and from whom we can learn much more in the years ahead .... They are urging us ... through their needs and their capabilities, to become 
better teachers" (291-92). "Teaching [students] to write well," Shaughnessy (1976) reminds us, "is challenging work for those who would be teachers and scholars in a democracy" (239). In the 1990s, our work is perhaps even more challenging than Shaughnessy anticipated. Rereading Shaughnessy from a postcolonial perspective can help us meet this new challenge and decolonize our pedagogical practices, thus creating educational opportunities for all in classrooms without borders.

\section{Notes}

'This article was a talk presented at the 4th National Basic Writing Conference held at College Park, MD in October 1992.

${ }^{2}$ Victor Villanueva pointed out this distinction to me in response to an early draft of "Teaching Writing in a Postcolonial World," a work-in-progress.

${ }^{3}$ Fill'em up. "Teach these boys and girls nothing but Facts," says the schoolmaster in the opening chapter of Dickens' Hard Times, while sweeping with his eyes "the inclined plane of little vessels then and there arranged in order, ready to have imperial gallons of facts poured into them until they were full to the brim." Paulo Freire's term for this transmission view of knowledge is the "banking concept of education." See Chapter 2 of Pedagogy of the Oppressed (NY: Continuum, 1968). And Sartre talks about the feeding metaphor.

${ }^{4}$ My colleague William Spanos pointed this derivation out to me and also that "colonize" comes from the Latin colunus ("tiller," "cultivator," "planter," "settler") and colere ("cultivate," "plant"). See William Spanos. The End of Education: Toward a Posthumanist University. Minneapolis: U of Minnesota P, 1992, 213. See also Raymond Williams. Keywords: A Vocabulary of Culture and Society. New York: Oxford UP, 1985.

${ }^{5}$ I think of Ed Koren's collection of cartoons from the New Yorker called “Well, there's your problem!" (NY: Pantheon, 1980). In one cartoon, a car owner is waiting for the mechanic's verdict. They are both looking under the hood. The mechanic says, "Well, there's your problem!" pointing to a furry creature who has made its home in the engine.

${ }^{6} \mathrm{I} ' \mathrm{~m}$ categorizing somewhat unfairly here and being, as academics say, overly reductive. These three scholar-teachers have written extensively about the academic discourse controversy and have made significant contributions to the field of composition 
studies and to basic writing in particular. I've reduced their positions to a couple of lines in order to argue my position in this conference presentation. For example, Bartholomae (1986b) tags his belief (academic culture is a "closed culture") with an embedded question: "The question is whether they can do this and still remain themselves" (85). He also raises this question elsewhere in his work. I've expressed Bizzell's early (1982) position; she repositioned herself in the late 1980s: "I changed my mind," she explained to me at another conference. But even in this 1982 article, she calls into question "the project of initiating students into ... the school's preferred world view" (237). In 1988, Bizzell argues that "the prevailing notion of academic literacy needs revision," though she concedes that it's difficult "to make education truly reciprocal, and not something done to one person by another" (151-52).

'Bizzell (1986) phrases her question this way: "Do basic writers have to give up the world views they bring to college in order to learn the new world view" (298)? Bartholomae (1986b) believes that basic writers (and all students) must be given access to the New World (capitalization mine) of academe. He adds, "It is a question of whether they can, as Shaughnessy says, use someone else's language and yet create out of this language their own statements" (85).

${ }^{8}$ Min-zhan Lu, who also read a paper at the 4th National Conference on Basic Writing (October 1992), said in conversation that "diving in" did not fit in with talk about borderlands. Lakoff and Johnson (Metaphors, 1980) would call "diving in" a container metaphor. The movement is from "out" to "in." But the word "border" is also problematic. "Border" can suggest a line of separation, as the editors, Grewal, et al. of Charting the Journey (1988) point out: "Whenever someone crosses a border there will be someone else on the other side, sceptical-either on the side she's crossing to or the one she's coming from" (118). "Borders," writes Gloria Anzaldúa (Borderland/La Frontera, 1987), "are set up to define the places that are safe and unsafe, to distinguish us from them" (3). Borders can be edges ("This is my home/this thin edge of barbwire") and can make "border residents" edgy. At the edge, earth and ocean overlap, sometimes bringing "a gentle coming together/at other times and places a violent clash" (Anzaldúa). Borders can be blurred boundaries, amorphous space-shapes for ever-shifting, residents who, like the nomads of Somalia, pack up their temporary housing in search of greener pastures. Borders can be what Mary Louise Pratt (Imperial Eyes: Travel Writing and 
Transculturation, 1992) calls "contact zones," which she defines as "social spaces where disparate cultures meet, clash, and grapple with each other, often in highly asymmetrical relations of domination and subordination-like colonialism" (4). Yes, like colonialism. Classroom scenes will still be asymmetrical; only the teacher won't necessarily dominate the power structure.

'Unfortunately, Memmi wrote his other-Wise \& Wonderful treatise without using the NCTE Guidelines for Non-Sexist Language. While we may perhaps excuse him for this discrimination in 1957, when the first edition was published in French, it is difficult to make excuses for him in this 1992 edition. However, according to Susan Gilson Miller ("Afterward"), Memmi "has come to regret" this omission and his male-center stance.

${ }^{10}$ However, as Neuleib (1992) observes, when text-centered teachers begin to analyze the texts of nonacademic readers and writers, they frequently feel confused and alienated:

We who have never been outside the academic community are positioned inside our own familiar ways of knowing about reading, writing, thinking, doing, and deciding. We should not be surprised when we are unable to see the potential for knowledge in many of the students we teach or study. Our problem is how best to listen to students and in turn best to learn from them. (235)

\section{Works Cited}

Bakhtin, Mikhail. The Dialogic Imagination. Ed. Michael Holquist. Austin: U of Texas P, 1981.

Bartholomae, David. "Wandering: Misreadings, Miswritings, Misunderstandings." Only Connect: Uniting Reading and Writing. Ed. T. Newkirk. Upper Montclair, NJ: Boynton, 1986a. 89-118. ---. "Released into Language: Errors, Expectations, and the Legacy of Mina Shaughnessy." The Territory of Language. Ed. D.A. McQuade. Carbondale: Southern Illinois UP, 1986b. 65-88.

---. "Writing on the Margins: The Concept of Literacy in Higher Education." Sourcebook for Basic Writing Teachers. Ed. T. Enos. NY: Random, 1987. 63-83.

Berthoff, Ann. "Killer Dichotomies: Reading In/Reading Out." Farther Along: Transforming Dichotomies in Rhetoric and Composition. Ed. K. Ronald and H. Roskelly. Portsmouth, NH: Boynton, 1990. 12-24.

Bialostosky, Don H. "Liberal Education, Writing, and the Dialogic 
Self." Contending with Words. Ed. P. Harkin and J. Schilb, 1991. 11-22.

Bizzell, Patricia. "Cognition, Convention and Certainty." PRE/ TEXT 3 (1982): 213-43.

---. "What Happens When Basic Writers Come to College?" College Composition and Communication 37 (Oct. 1986): 294-301.

---. "Arguing About Literacy." College English 50 (Feb. 1988): 141-53.

Burke, Kenneth. The Philosophy of Literary Form: Studies in Symbolic Action, 3rd ed. Berkeley: U of California P, 1973.

Gay, Pamela. How Attitude Interferes with the Performance of Unskilled College Freshman Writers. (Contract No. NIE-G0102) Washington, DC: National Institute of Education, 1983. (ERIC Document Reproduction Service No. ED234417).

Giroux, Henry. "Postmodernism as Border Pedagogy: Redefining the Boundaries of Race and Ethnicity." Postmodernism, Feminism, and Cultural Politics: Redrawing Educational Boundaries. Ed. Henry A. Giroux. Albany: State U of New York P, 1991. 217-56.

---. Border Crossings: Cultural Workers and the Politics of Education. NY and London: Routledge, 1992.

Greene, Maxine. The Dialectic of Freedom. NY: Teachers College $P, 1988$.

Grewal, Shabnam; Jackie Kay; Liliane Landor; Gail Lewis; and Parmar Pratibha. Charting the Journey: Writings By Black and Third World Women. London: Sheba Feminist, 1988.

hooks, bell. Yearning: Race, Gender, and Cultural Politics. Boston: South End, 1990.

Lakoff, George, and Mark Johnson. Metaphors We Live By. Chicago: U Chicago P, 1980.

Langer, Susanne. Philosophy in a New Key. NY: The New American Library, 1942.

Lorde, Audre. "The Master's Tools Will Never Dismantle the Master's House." Sister Outsider. Trumansburg, NY: The Crossing $P, 1984$. 110-13.

Memmi, Albert. The Colonizer and The Colonized. Boston: Beacon, 1992.

Minh-ha, Trinh. "The Language of Nativism." Woman, Native, Other: Writing Postcoloniality and Feminism. Bloomington: Indiana UP, 1989.

Mohanty, Chandra Talpade. "On Race and Voice: Challenges for Liberal Education in the 1990s." Cultural Critique 16 (Winter 1989-90): 179-208. 
Neuleib, Janice. "The Friendly Stranger: Twenty-Five Years as 'Other.'" College Composition and Communication 43 (May 1992): 231-43.

Ngugi, wa Thiong'O. Decolonising the Mind. Portsmouth, NH: Heinemann, 1986.

Riley, Joan. The Unbelonging. London: Women's Press, 1985.

Rose, Mike. Lives on the Boundary. NY: Viking Penguin, 1989.

Shaughnessy, Mina. "Diving In: An Introduction to Basic Writing." College Composition and Communication 27 (Oct. 1976): 234-39.

---. Errors and Expectations: A Guide for the Teacher of Basic Writing. NY: Oxford UP, 1977.

Taiwo, Femi. An African Perspective. Paper presented at the Philosophy, Interpretation, \& Culture Conference, Binghamton, NY, Mar. 1991).

Welch, Sharon. A Feminist Ethic of Risk. Minneapolis: Fortress P, 1990. 


\section{Emil L. Roy \\ COMPUTERIZED SCORING OF PLACEMENT EXAMS: A VALIDATION}

ABSTRACT: This article validates and refines a computerized system for grading placement exams. To test the reliability of a Structured Decision System (SDS), the author compared computerized ratings with holistic scores, grades earned in writing courses, and ACT-English and ACT Social Studies scores for forty-six placement exams. The study concludes that textual traits linked to levels of writing ability can be quantified, supporting the continued use of well-designed exams to place students in writing courses. Although scores on multiple choice tests generally validate this SDS, they cannot sort levels of writing ability accurately. Further research is needed with a larger population of test-takers, a wider range of test topics, and a greater number of textual traits.

Hundreds of colleges and schools use timed, written exams to measure the writing ability of incoming students. At their best, these schools limit student misreadings with pretested topics. To achieve uniform responses, many have designed scoring criteria illustrated by carefully selected anchor exams. To achieve consistent holistic rankings by trained readers, they also guard against fatigue, bias, and disagreement. Yet, even at their best, these exams reveal shortcomings. They are expensive to administer and grade, produce an interreader reliability of .90 (Cooper), and provide no feedback to students or instructors beyond unadorned

Emil L. Roy, professor of English at the University of South Carolina-Aiken, has also taught at the University of Southern California, Purdue University, and Northern Illinois University. He is coauthor, along with Sandra Roy, of the Prentice Hall Guide to Basic Writing, 2nd ed. (Prentice Hall, 1993). His most recent articles were "Direct-Mail Letters: A Computerized Linkage between Style and Success," in Journal of Business and Technical Communication (April 1992) and "Evaluating Placement Exams with a Structured Decision System," in Computers and Composition (April 1992).

(C) Journal of Basic Writing, Vol. 12, No. 2, 1993 
numerical ratings. These issues impinge on paper assessment generally, as Pat Belanoff has noted. She cites Ed White's point in Teaching and Assessing Writing that "our profession has no agreed upon definition of proficiency and, certainly as a consequence, no agreed upon definitions for proficiencies at various levels of schooling" (58). At the crucial juncture between high school and college writing courses, neither verbal criteria nor the performance of trained readers have approached White's "definition of proficiency." Thus, I have turned to computerized analysis to limit the ambiguities of holistic grading, as applied to impromptu placement exams.

My study used a style checker, RightWriter 4.0 (RW), to analyze forty-six placement exams. A Utah faculty member randomly selected them from more than 2,000 taken. They had been written by students entering the University of Utah in the Fall of 1990. I also used RW to analyze four anchor exams used to illustrate Utah's rhetorical "Criteria," which guide placements by readers. RW measures eight textual traits: readability levels, total number of words, the average numbers of syllables per word and words per sentence, and the percentages of prepositions and unique words. It also creates indexes of "strength" and "descriptiveness."

The Utah Writing Program (Utah) conducts placement testing within a fairly typical set of guidelines. Test-takers have forty-five minutes to write an essay supported by reasons and examples. A prompt asks them to describe a disturbing situation, explain wanted changes, and draw conclusions about people's responses to these situations. Students may consult a dictionary or handbook.

I then designed a Structured Decision System (SDS) with Quattro 2.0's data base capabilities. When based on valid ranking and sorting criteria, my computerized SDS would place papers automatically. Existing research had already established paper length as the most reliable measure of the quality of impromptu writing exams (Brossell, Ruth and Murphy). In a rare computerized study, Reid and Findlay analyzed holistically scored essays with Writer's Workbench. They concluded that longer essays "demonstrate development within paragraphs, structural completeness, and scribal fluency" (12).

My analysis of the four UWP anchor exams singled out two other crucial measurements for identifying especially weak and strong student writing: high syllable averages and low percentages of unique words. The first correlated positively, the second negatively, with fluency. In addition, Reid and Findlay correlated increased word length with essay quality, indicating command of 
"a significant vocabulary" and "a mature lexicon" (14). Furthermore, a low percentage of unique words was linked to high writing quality. This confirms injunctions by many writing handbooks to improve organizational completeness and cohesion with repeated words.

Finally, UWP had learned from experience that ratings would apportion themselves predictably. They tend to fall within the four course levels as follows: basic remedial (1-3\%), remedial (15$18 \%$ ), regular composition (60\%), and advanced composition (12$16 \%)$. My SDS used these parameters to assign placement exams to four acceptance regions; they were divided from one another by precise critical values:

\begin{tabular}{|c|c|c|c|}
\hline & $\begin{array}{l}\text { Total \# } \\
\text { of Words } \\
=<160\end{array}$ & $\begin{array}{l}\text { Average \# } \\
\text { of Syllables } \\
\# O R \#=<1.2\end{array}$ & $\begin{array}{l}\% \text { of Unique } \\
\text { Words } \\
\text { \#OR\#=>66\% }\end{array}$ \\
\hline & \multirow{2}{*}{\multicolumn{3}{|c|}{$\begin{array}{l}=>161 \# A N D \#=<284 \\
\Rightarrow 285 \# \text { AND\# }=<495\end{array}$}} \\
\hline . $\mathrm{R}$ & & & \\
\hline Advanced & $\Rightarrow>496$ & $\# A N D \#=>1.45$ & $\# A N D \#=<50 \%$ \\
\hline
\end{tabular}

At this point, the SDS prototype incorporated theoretical underpinnings from reading and rhetorical theory, patterns which emerged from my analysis of four UWP anchor exams, and predictable UWP apportionments of paper ratings. ${ }^{1}$

\section{Method}

Several questions about my SDS's validity remained unanswered:

1. Does the performance of test-takers in writing courses confirm the SDS ratings, establishing their predictive validity?

2. Do SDS ratings correlate positively with other tests (such as the ACT-English or Social Studies tests) that measure the same skills, establishing their concurrent validity?

3. Does the SDS measure the skills that writing teachers consider important, establishing its face validity?

4. Does the SDS measure the essential skills and abilities that comprise the writing competence of professional writers, establishing its construct validity?

I based validation of my SDS on several assumptions. First, I predicted that most of the SDS and holistic ratings would match. Further, the remaining divergent rankings of many of the SDSranked papers would be borderline; the SDS would rank them no 
more than one level higher or lower than their holistic grades.

Thus, the computerized data would verify the face validity of the SDS by passing the "black box" test (Ahituv and Neumann, 506). Apart from links between the SDS criteria and rhetorical theory, the SDS ratings (outputs) would regularly and predictably track the holistic ratings (inputs). I would then need reliable tests to improve the SDS's sorting accuracy of the SDS by adjusting its various critical values up or down.

Second, I also expected to find contradictory SDS and holistic ratings scattered randomly through the fluency rankings. Most, if not all, would involve SDS placements in regular composition where the UWP assigns $60 \%$ of the test-takers. To resolve these inconsistencies, I factored in subsequent course grades. For most writing teachers, course grades are more authoritative than holistic ratings. Unlike a timed writing sample, an extended classroom experience provides students with opportunities "to rethink the topic and rewrite their papers, to transform an underdeveloped or incoherent response into a competent essay that will meet the requirements of university discourse outlined in class discussion" (Millward, 109).

Twenty-two of the forty-six takers of placement tests later registered for a writing course in Fall 1990. To resolve rating discrepancies, I assigned significance to course grades. I assumed that a $B$ or $C$ would justify placement in a writing course, whatever its level of difficulty. A grade of $D$ or $F$ indicates that holistic grading placed a student too high; the test-taker needed a more elementary writing course. On the other hand, a grade of B+ or A signals that a student's holistic rating was too low: the test-taker could have handled a more demanding writing course.

In my experience, nearly all of my $B+$ or A students have already mastered most of a course's writing skills. They quickly adjust to demands of the course; then they coast, needing a more advanced course to challenge their abilities more fully. Thus, course grades would either confirm the SDS placements, or they would force revisions of critical dividing lines between placement values.

Third, adjustments of the SDS ratings or criteria might still leave unresolved placement discrepancies. To reconcile remaining ambiguities, I would search for anomalies in the RW measurements-extremely high or low counts or indexes. Quite possibly, previously overlooked textual features could override otherwise favorable or unfavorable impressions of an exam. 
Fourth, forty-one scores on the ACT-English and Social Studies tests were available for the forty-six samples. I expected these scores, especially on the ACT-English test, to generally validate the revised SDS ratings concurrently. An ACT critical value might even resolve a discrepancy in the ratings. Correlations of these test scores with the SDS ratings might also cast light on the value of multiple choice tests to measure writing ability.

Finally, research which quantifies the textual features of professional writing is still in its infancy, though Garvey and Lindstrom have published a trailblazing study. Thus, construct validity of my SDS cannot yet be verified.

\section{Results}

Thirty of the forty-six initial SDS and holistic ratings match, for an initial SDS accuracy rate of $65 \%$. Of the sixteen ambiguous ratings, ten are placed within three positions adjacent to the nextrated group. These findings confirm the strong influence of paper length on placement exam ratings. Of the ten borderline SDS rankings, grades in writing courses were available for six. They can correct or refine the critical values dividing one group from another.

My SDS had initially assigned two of the ten exams to basic remedial. Holistic grading placed one of them, Utah18, two levels higher in regular composition. Since the test-taker failed to register for a writing course, no grade exists. However, the exam produced little more than a paragraph (112 words). It also achieved the lowest syllable average (1.2) and highest percentage of unique words $(66.96 \%)$ in the entire sample. These data confirm the original SDS placement in basic remedial.

The other low-ranked test-taker, Utah44, earned a C in remedial English. This grade validated its holistic placement in this course. It also justified a drop in the SDS fluency floor for remedial placement from $=>160$ to $=>140$ words.

In the sample group initially rated remedial (2) by the SDS, three samples were high borderline: Utah5, Utah3, and Utah3 Holistic grading ranked all of them one level higher-in regular freshman composition (3). Two of the three-Utah5 and Utah3earned high grades in regular freshman composition, an " $A$ " and a "B+," respectively. These grades validated their holistic placements in regular composition. They also warranted a drop in the minimum paper length requirement for this placement from $=>284$ words to $=>243$ words. 
However, these adjustments raise doubts about the holistic assignment of Utah5's neighbor, Utah9 to remedial writing. The two essays are near-twins, with an identical 243 word count and other similar SDS measurements. Yet, the writer of Utah9 earned a D in remedial writing, confirming its holistic placement. Quite possibly, the test-taker's ACT-English score of 13 signals his or her weaknesses; this was the lowest score for the sample population. In lieu of further research regarding ACT critical values, this score should be added to the SDS remedial algorithm.

The SDS also placed three borderline exams, Utah19, Utah33, and Utah13, in advanced composition, even though holistic grading assigned them to regular composition. Three key measures justify their advanced SDS placement: a high total word count of $=>496$ added to a high syllable average of $=>1.45$ and a low percentage of unique words: $=<50 \%$. In addition, all three testtakers earned A's in their writing courses, validating these SDS critical values for advanced placement.

One remaining borderline exam, Utah40, sends mixed signals. Placed holistically in advanced composition, it falls only one word short of the SDS minimum for this ranking. Its percentage of unique words is commendably low: $43.23 \%$. Yet its use of very short words-averaging 1.3 syllables-would have triggered an SDS placement in remedial writing. However, no grade exists to resolve these discrepancies.

To sum up, of the ten borderline placement exams with divergent SDS and holistic placements, four rankings can be aligned by adjusting the fluency floors for remedial and regular composition downward. One other should be judged a holistic misreading, and course grades confirm three SDS placements in advanced composition. These confirmations and revisions for a total of thirty-eight exams improve the SDS accuracy level to $82.6 \%$. To resolve discrepancies in the ratings for Utah29 and Utah40, some other means is needed.

The SDS initially placed the remaining six exams with divergent rankings in regular composition: Utah20, Utah15, Utah17, Utah37, Utah16, and Utah6. All of them fall well within the SDS acceptance region for regular composition. Yet, holistic grading ranked two of them higher and four of them lower. The low syllable count for three of the six-Utah20, Utah16, and Utah6justifies their holistic placement in remedial writing. Accordingly, the SDS for this criterion should rise from $=<1.2$ to $=<1.3$. In the minds of holistic readers, short, simple words probably overrode the favorable impression created by paper lengths. 
At the same time, Utah6 exhibits an interesting anomaly: the lowest percentage of unique words in the sample group: $36.38 \%$. A certain amount of word repetition improves a paper's cohesion. However, trained readers usually prefer mature transitional connections to an overuse of unimaginative repetition. This anomaly suggests that trained readers discriminate against proportions of unique words which are either too high or too low. Perhaps these percentages should not exceed $=>66 \%$ or drop below $=<38 \%$. Adjusting the critical values for the three major SDS criteria resolves no other discrepancies in the ratings.

It seems quite likely, then, that the holistic ratings of a few divergent papers may have been decisively influenced by notable strengths or weaknesses not identified by the dominant SDS measurements. The existence of such anomalies would imply the power of some stylistic traits to sway uncertain holistic graders, toward either the next higher or lower ratings.

Anomalies in their RW measurements may also help resolve discrepancies in the ratings of Utah15, Utah17, and Utah37. Holistic grading placed the first two of them in advanced composition. Yet, on the basis of their modest lengths-327 and 329 words, respectively - the SDS rated them one category lower. While both used commendably long words, their high percentages of unique words suggest writing weaknesses.

However, Utah15 uses the second-longest sentences in the sample population, 23.29 words. No grade is available. Yet the essay's lengthy sentences reinforce its other writing strengths. Reid and Findlay note that "quality impromptu prose . . . does indeed have longer sentences" (13). Tentatively then, sentence lengths averaging $=>23.25$ words apparently override modest word production, confirming Utah15's holistic assignment to advanced composition.

Utah17 reveals another anomaly, the second highest FleschKincaid readability level in the sample population: 11.44 . These readability grades are calculated from a formula combining and weighing average sentence length and average syllables per word. Reid and Findlay note the high correlation of readability scores with essay quality. Like long sentences, a F-K readability level of perhaps $=>11.4$ should be included in the SDS algorithm for advanced composition. When their numbers are high enough, both sentence length and readability seem capable of overriding mixed ratings in other key stylistic areas.

A third exam with divergent ratings, Utah37, uses the highest percentage of prepositions in the sample population: $15.26 \%$. The 
essay's other textual measurements are respectable, even quite good. It uses 367 total words, a 1.52 average syllable count, and a relatively low percentage of unique words: $47.96 \%$. However, the RightWriter User's Manual warns that "too many prepositional phrases make the writing wordy and hard to follow" (7-17). Thus, overuse of prepositions confirms the essay's holistic placement in remedial writing. This justifies the addition of $a=15.25 \%$ critical value for prepositions to the algorithm for remedial placement.

To sum up, these anomalies apparently exert great influence on the placement of exams which otherwise send mixed stylistic signals. They point to the inclusion of two additional options in the SDS sorting algorithm for advanced composition: $=>23.25$ average words per sentence or readability levels of $=>11.4$. On the other hand, the SDS sorting algorithm for remedial writing should include critical values of $=>15.26 \%$ prepositions or $=<38 \%$ unique words. Like criteria for percentages of unique words, percentages of prepositions probably signify weaknesses in writing if they are either too high or too low. The RightWriter User's Manual warns that using too few prepositional phrases "indicates a simple and rigidly structured writing style" (7-16). However, evidence supporting the influence of these critical values is fragmentary. Confirming their effects must await research on a larger population.

None of the data provides any basis for correctly placing the remaining two exams with divergent SDS and holistic ratings, Utah29 and Utah40. Therefore, holistic grading correctly placed thirty-nine of the forty-six samples, for an accuracy rate of $85 \%$. On the other hand, as validated and revised, the SDS places fortyfour of the forty-six samples, for an accuracy rate of $95.66 \%$.

The relative influence of RW measurements on SDS ratings can be measured statistically. As indicated by R Squared values, fluency accounts for $42 \%$ of the SDS ratings, strength for $21 \%$ (a negative correlation), readability for $18 \%$, the average number of syllables for $12 \%$, and words per sentence for nearly $10 \%$. All the other RW variables were less influential.

The ACT-English and Social Studies scores generally validate the SDS rankings concurrently, with one exception. The average ACT-English scores rise from 18.13 for remedial writing to 23.6 for regular composition to 26.4 for advanced composition. The average ACT-Social Studies scores rise from 20.75 for remedial writing to 25.5 for regular composition; however, they drop a point and a half to 24 for advanced composition. This data indicates that a writing sample provides a more reliable basis for distinguishing between levels of writing ability than a highly reputable standardized test. 
Finally, the influence of course grades on the computerized rankings of placement exams needs more study. For example, both the SDS and holistic grading place Utah31 in regular composition, where the test-taker earned an A. Does this high grade reflect strong motivation which can't be measured by a placement test? Or does it confirm the predictive powers of a high readability score (11.25)? Two other similarly placed exams, Utah5 and Utah8, also earned A's. Do their grades reflect improvement? Or do their high descriptive indexes, 1.13 and .92, respectively, indicate the predictive force of a neglected RW measurement (involving a writer's use of modifiers)? These questions and others regarding grades cannot yet be answered.

\section{Conclusions}

My SDS for placement tests partly accomplishes Garvey and Lindstrom's goal: "What was once presented as an intuitive benchmark may now be explicable in quantitative terms" (93). This study validates several textual features for rating placement exams:

- Fluency to rank and sort the four rating levels from one another

- Average syllable length and percentages of unique words to sort out basic remedial, remedial, and advanced exam

- Readability level and average sentence length to further distinguish advanced exams

- Percentage of prepositions to sort out remedial exams

- An ACT-English score to identify particularly weak basic remedial exams

Moreover, ACT-English and ACT-Social Studies scores generally correlate with SDS groupings, though (with one exception) they cannot sort placement tests.

A strong case can be made for replacing holistic exam-reading with a still-hypothetical, fully validated SDS. At their best, both systems share a common base: timed impromptu writing samples based on well-designed test prompts, along with an explicit set of grading criteria backed by anchor tests. However, a computerized SDS is superior, in many ways, to holistic grading. It sidesteps interreader disagreements; since it ignores content, exams never trigger reader bias; and no slippage of rating accuracy results from prolonged reader fatigue or boredom.

Basic writing programs, in particular, would benefit from an improved, sharable SDS. No teacher can (or should) say, "For 
advanced placement in a writing course, spend no more than forty-five minutes turning out over 500 words averaging at least 1.55 syllables a word and 20 words a sentence. Your writing should also have a readability level of tenth grade or higher, with about $11.5 \%$ prepositions and somewhere between $45 \%$ and $60 \%$ unique words." However, an SDS evaluation system would give in-depth, initial analyses of basic writing students' placement tests to them and their instructors. Equipped with this data, basic writing teachers could more easily arrange teaching priorities. They could also target help with special problems for particular students. Repeated SDS evaluations would also help instructors better measure student progress in crucial areas like scribal fluency, sensitivity to audience, sophisticated use of vocabulary, coherence, and other writing qualities.

Moreover, an SDS evaluation system could help put more electronic classrooms and labs in colleges and more basic writing students in them. This adds up to empowerment for basic writing students and instructors alike. Computer-assisted instruction in and outside the classroom provides more accessible answers to the crucial questions: "What's wrong with this writing sample?" and, with the instructor's input, "Why is it flawed?" and "How do I improve it?"

Further study is needed to confirm or correct some SDS critical values, especially those based on isolated anomalies or on course grades. Researchers need to consider the effects on an SDS of differing types of placement topics and prompts (such as description or persuasion). They should also study the influence of other textual features on quality.

A large-scale test of this SDS on a larger population is justified and feasible. However, it is not likely soon. Schools with rigorously designed testing systems are rare; many place daunting barriers between their data and researchers; local and federal funding for such research is virtually nil; the knowledge base is scattered and primitive; and the supply of researchers with the right mix of skills and interests is extremely limited, even nonexistent. When one adds the staunch resistance of what one reader terms "sec-hume Luddites" in the profession, movement toward a sharable, validated SDS for placement exams is bound to be slow. Yet, as many writing teachers already know, the computer is a new and authoritative tool, with many underutilized and undiscovered applications to the writing situation. 
University of Utah Placement Exams

Code Reada- Total Ave\# \#Wrds \%Wrds St'gth Desc't \%Uniq Name bility \#Words Sylbls Sent Preps

Words

Sort Basis:

Basic Remedial [1]

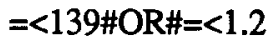

\#OR\#=>66\%

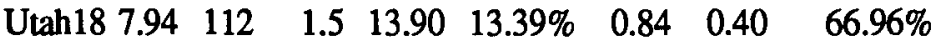

Sort Basis: $\quad$ Regular Remedial [2]

\#OR\#=>140 \#OR\#=<1.21\#OR\#=>15.25\% \#OR\#=<38\%

\#AND\#=<242\#AND\#=<1.3

Code Reada- Total Ave\# \#Wrds \%Wrds St'gth Desc't \%Uniq Name bility \#Words Sylbls Sent Preps

Words

$\begin{array}{lllllllll}\text { Utah44 } & 8.73 & 150 & 1.6 & 13.55 & 8.00 \% & 0.57 & 0.86 & 50.67 \%\end{array}$

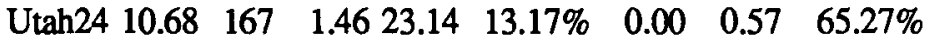

$\begin{array}{lllllllll}\text { Utah45 } & 5.37 & 173 & 1.37 & 12.28 & 12.72 \% & 0.62 & 0.86 & 59.54 \%\end{array}$

$\begin{array}{lllllllll}\text { Utah11 } & 9.87 & 176 & 1.58 & 17.50 & 11.90 \% & 0.33 & 0.64 & 61.93 \%\end{array}$

$\begin{array}{lllllllll}\text { Utah14 } & 7.40 & 178 & 1.46 & 14.75 & 8.99 \% & 0.62 & 0.71 & 63.48 \%\end{array}$

$\begin{array}{llllllllll}\text { Utah9 } & 7.99 & 243 & 1.39 & 18.39 & 12.76 \% & 0.36 & 0.65 & 49.79 \%\end{array}$

$\begin{array}{lllllllll}\text { Utah20 } & 4.58 & 302 & 1.3 & 12.50 & 10.93 \% & 0.69 & 0.73 & 47.68 \%\end{array}$

$\begin{array}{lllllllll}\text { Utah16 } & 8.18 & 368 & 1.27 & 22.63 & 8.40 \% & 0.06 & 0.73 & 45.38 \%\end{array}$

$\begin{array}{lllllllll}\text { Utah6 } & 8.70 & 437 & 1.3 & 22.95 & 8.90 \% & 0.00 & 0.73 & 36.38 \%\end{array}$

COUNT 9

\% OF TOTAL $19.57 \%$

$\begin{array}{lllllllll}\text { MIN } & 4.58 & 150 & 1.27 & 12.28 & 8.00 \% & 0 & 0.57 & 36.38 \%\end{array}$

$\begin{array}{lllllllll}\text { MAX } & 10.68 & 437 & 1.6 & 23.14 & 13.17 \% & 0.69 & 0.86 & 65.27 \%\end{array}$

$\begin{array}{llllllllll}\text { AVG } & 7.94 & 243.8 & 1.41 & 17.52 & 10.64 \% & 0.36 & 0.72 & 53.35 \%\end{array}$

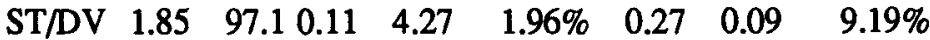


Sort Basis:

Regular Composition [3]

\#AND\#=<494

Code Reada- Total Ave \# \# Wrds \%Wrds St'gth Desc't \%Uniq Name bility \# Words Sylbls Sent Preps

Words

\begin{tabular}{lcccccccc}
\hline Utah5 & 8.18 & 243 & 1.5 & 15.13 & $10.29 \%$ & 0.30 & 1.13 & $61.32 \%$ \\
Utah3 & 8.16 & 259 & 1.5 & 14.88 & $11.58 \%$ & 0.71 & 0.57 & $52.12 \%$ \\
Utah41 & 5.45 & 277 & 1.35 & 13.09 & $10.83 \%$ & 0.70 & 0.61 & $56.32 \%$ \\
Utah23 & 8.46 & 290 & 1.44 & 18.06 & $8.28 \%$ & 0.30 & 0.77 & $49.31 \%$ \\
Utah1 & 9.59 & 297 & 1.44 & 21.07 & $12.12 \%$ & 0.14 & 0.62 & $53.54 \%$ \\
Utah39 & 8.74 & 297 & 1.52 & 16.44 & $13.47 \%$ & 0.43 & 0.70 & $52.86 \%$ \\
Utah21 & 9.12 & 309 & 1.5 & 18.10 & $10.36 \%$ & 0.32 & 0.78 & $52.43 \%$ \\
Utah35 & 9.71 & 337 & 1.57 & 17.47 & $13.95 \%$ & 0.35 & 0.63 & $49.85 \%$ \\
Utah2 & 10.14 & 343 & 1.59 & 18.00 & $12.83 \%$ & 0.37 & 0.70 & $51.90 \%$ \\
Utah42 & 3.97 & 347 & 1.35 & 9.35 & $9.79 \%$ & 0.69 & 0.71 & $49.86 \%$ \\
Utah46 & 6.16 & 350 & 1.34 & 15.13 & $11.43 \%$ & 0.47 & 0.65 & $56.57 \%$ \\
Utah30 & 10.92 & 364 & 1.58 & 20.17 & $13.18 \%$ & 0.38 & 0.71 & $54.95 \%$ \\
Utah31 & 11.25 & 365 & 1.64 & 19.16 & $11.00 \%$ & 0.17 & 0.95 & $47.95 \%$ \\
Utah37 & 11.13 & 367 & 1.52 & 22.50 & $15.26 \%$ & 0.00 & 0.73 & $47.96 \%$ \\
Utah22 & 5.55 & 379 & 1.4 & 13.50 & $11.87 \%$ & 0.69 & 0.68 & $51.72 \%$ \\
Utah27 & 7.18 & 385 & 1.49 & 13.21 & $11.43 \%$ & 0.54 & 0.52 & $55.58 \%$ \\
Utah7 & 8.60 & 423 & 1.35 & 21.10 & $11.35 \%$ & 0.00 & 0.76 & $47.52 \%$ \\
Utah4 & 7.53 & 432 & 1.28 & 20.48 & $9.49 \%$ & 0.21 & 0.75 & $44.91 \%$ \\
Utah32 & 7.15 & 451 & 1.42 & 15.52 & $9.50 \%$ & 0.42 & 0.62 & $49.22 \%$ \\
Utah38 & 7.66 & 452 & 1.48 & 15.03 & $11.28 \%$ & 0.34 & 0.71 & $40.93 \%$ \\
Utah433 & 8.32 & 460 & 1.49 & 16.39 & $10.22 \%$ & 0.47 & 0.80 & $46.96 \%$ \\
Utah12 & 9.85 & 462 & 1.4 & 21.95 & $10.17 \%$ & 0.13 & 0.92 & $39.83 \%$ \\
Utah25 & 9.37 & 468 & 1.48 & 17.21 & $10.47 \%$ & 0.32 & 0.66 & $50.43 \%$ \\
Utah8 & 8.54 & 481 & 1.33 & 21.73 & $13.93 \%$ & 0.32 & 0.92 & $45.11 \%$ \\
Utah29 & $\mathbf{6 . 2 5}$ & $\mathbf{4 9 3}$ & $\mathbf{1 . 3 7}$ & $\mathbf{1 5}$ & $\mathbf{1 1 . 7 7 \%}$ & $\mathbf{0 . 5 1}$ & $\mathbf{0 . 7 2}$ & $\mathbf{4 0 . 1 6 \%}$ \\
Utah40 & $\mathbf{7 . 3 8}$ & $\mathbf{4 9 5}$ & $\mathbf{1 . 3}$ & $\mathbf{1 9 . 6 0}$ & $\mathbf{1 1 . 5 2 \%}$ & $\mathbf{0 . 2 0}$ & $\mathbf{0 . 6 3}$ & $\mathbf{4 3 . 2 3 \%}$ \\
Utah10 & $\mathbf{7 . 6 6}$ & $\mathbf{5 0 6}$ & 1.38 & 18.00 & $11.07 \%$ & 0.39 & $\mathbf{0 . 7 9}$ & $42.49 \%$ \\
\hline
\end{tabular}

COUNT 27

\% OF TOTAL $58.70 \%$

$\begin{array}{lllllllll}\text { MIN } & 3.97 & 243 & 1.28 & 9.35 & 8.28 \% & 0 & 0.52 & 39.83 \%\end{array}$

$\begin{array}{lllllllll}\text { MAX } & 11.25 & 506 & 1.64 & 22.5 & 15.26 \% & 0.71 & 1.13 & 61.32 \%\end{array}$

$\begin{array}{lllllllll}\text { AVG } & 8.22 & 382.7 & 1.44 & 17.31 & 11.42 \% & 0.37 & 0.73 & 49.45 \%\end{array}$

$\begin{array}{llllllll}\text { ST/DEV } 1.75 & 78.02 & 0.09 & 3.16 & 1.55 \% & 0.19 & 0.13 & 5.29 \%\end{array}$ 
Sort Basis: $\quad$ Advanced Composition [4] \#AND\#1.45

\#OR\#=>11.4\#OR\#=>495\#OR\#=>23.25 \#AND\#=>50\% $\#$ AND\#=<65\%

Code Reada- Total Ave \# \#Wrds \%Wrds St'gth Desc't \%Uniq Name bility \# Words Sylbls Sent Preps

Words

$\begin{array}{lcclccccc}\text { Utah15 } & 11.21 & 327 & 1.56 & 23.29 & 7.95 \% & 0.00 & 0.73 & 58.41 \% \\ \text { Utah17 } & 11.44 & 329 & 1.57 & 21.86 & 9.12 \% & 0.01 & 0.92 & 52.89 \% \\ \text { Utah19 } & 8.91 & 496 & 1.5 & 17.70 & 12.70 \% & 0.20 & 0.61 & 46.98 \% \\ \text { Utah33 } & 7.58 & 499 & 1.45 & 15.56 & 10.60 \% & 0.32 & 0.66 & 45.89 \% \\ \text { Utah13 } & 12.84 & 499 & 1.63 & 23.70 & 14.80 \% & 0.10 & 0.64 & 49.70 \% \\ \text { Utah26 } & 8.67 & 518 & 1.45 & 18.46 & 11.39 \% & 0.15 & 0.78 & 46.72 \% \\ \text { Utah28 } & 9.59 & 532 & 1.56 & 17.47 & 12.40 \% & 0.23 & 0.70 & 46.62 \% \\ \text { Utah36 } & 10.14 & 537 & 1.59 & 17.80 & 11.17 \% & 0.13 & 0.81 & 47.49 \% \\ \text { Utah34 } & 11.39 & 576 & 1.53 & 23.00 & 12.85 \% & 0.10 & 0.82 & 45.31 \%\end{array}$

\begin{tabular}{|c|c|c|c|c|c|c|c|c|}
\hline \multicolumn{2}{|c|}{$\begin{array}{l}\text { COUNT } \\
\% \text { OF TOTAL }\end{array}$} & \multicolumn{2}{|c|}{$\begin{array}{l}9 \\
19.57 \%\end{array}$} & \multirow[b]{2}{*}{15.56} & \multirow[b]{2}{*}{$7.95 \%$} & \multirow[b]{2}{*}{0} & \multirow[b]{2}{*}{0.61} & \multirow[b]{2}{*}{45.31} \\
\hline MIN & 7.58 & 327 & 1.45 & & & & & \\
\hline MAX & 12.84 & 576 & 1.63 & 23.7 & $14.80 \%$ & 0.32 & 0.92 & 58.4 \\
\hline AVG & 10.20 & 479.2 & 1.54 & - 19.87 & $11.44 \%$ & 0.14 & 0.74 & 48.8 \\
\hline ST/DEV & V 1.57 & 84.2 & 0.06 & 2.90 & $1.95 \%$ & 0.10 & 0.09 & \\
\hline $\begin{array}{l}\mathrm{R} \mathrm{Sq} \\
\text { Values }\end{array}$ & 0.185 & 0.41 & 0.126 & 0.095 & 0.008 & 0.217 & 0.085 & 0.06 \\
\hline
\end{tabular}




\section{Note}

${ }^{1}$ This study entitled "Evaluating Placement Exams as a Structured Decision System" was published in Computers and Composition 9.2 (Apr. 1992): 71-83.

\section{Works Cited}

Ahituv, Niv, and Seev Neumann. Principles of Information Systems for Management. 3rd ed. Dubuque, IA: Wm. C. Brown, 1990.

Belanoff, Pat. "The Myths of Assessment." Journal of Basic Writing 10.1 (1991): 54-66.

Brossell, Gordon. "Current Research and Unanswered Questions in Writing Assessment." Writing Assessment: Issues and Strategies. Ed. Karen L. Greenberg, Harvey S. Wiener, and Richard A. Donovan. New York: Longman, 1986. 168-82.

Cooper, Charles. "Holistic Evaluation of Writing." Ed. Charles R. Cooper and Lee Odell. Evaluating Writing: Describing, Measuring, Judging. Urbana, IL: NCTE, 1977.

Garvey, James J., and David H. Lindstrom. "Pros' Prose Meets Writer's Workbench: Analysis of Typical Models for First-Year Writing Courses." Computers and Composition 6.2 (1989): 81109.

Millward, Jody. "Placement and Pedagogy: UC Santa Barbara's Preparatory Program." Journal of Basic Writing 9.2 (1990): 99112.

Reid, Stephen and Gilbert Findlay. "Writer's Workbench Analysis of Holistically Scored Essays." Computers and Composition 3.2 (1986): 6-32.

RightWriter User's Manual. Sarasota, FL: Que, 1990.

Ruth, Leo, and Sandra Murphy. Designing Writing Tasks for the Assessment of Writing. Norwood, NJ: Ablex, 1988. 


\section{Jane E. Hindman REINVENTING THE UNIVERSITY: FINDING THE PLACE FOR BASIC WRITERS}

ABSTRACT: A poststructuralist critique of basic writing placement and pedagogy, this paper argues that our notions of good writing (i.e., the criteria by which we as English professors and compositionists authorize and "place" students) come not from some general or transcendent standards, but rather from the practices by which we self-authorize within our own discourse community. Using Bartholomae and Petrosky's curriculum presented in Facts, Artifacts, Counterfacts as a point of departure, I propose a language-centered curriculum which uses discourse itself as the subject of the semester-long project wherein students eventually learn to critique our practices and create their own discourse communities. This modification, the author argues, comes closer to empowering students to be the agents of their own authorization and placement at the academy.

In transition from one theory to the next, words change their meanings or conditions of applicabilities in subtle ways. . .the ways in which some of them attach to nature has somehow changed. Successive theories are thus, we say, incommensurable. (Kuhn 338)

Thomas Kuhn's reflection on the ways paradigm shifts change the meanings of terms foregrounds what I see as a shift in David Bartholomae's use of the term "marginal." This change in meaning supplies the point of departure for my argument. ${ }^{1}$ My preliminary examination of "Inventing the University" and "Writing on the

Jane E. Hindman is a doctoral student in the Rhetoric, Composition, and Teaching of English Program at the University of Arizona. In addition to her work with basic writers, she is interested in African American quiltmaking, especially as a metaphor for the aesthetic and technique in the fiction of African American women writers and as a site of verbal art as performance among quiltmakers.

(C) Journal of Basic Writing, Vol. 12, No. 2, 1993 
Margins" will contextualize Bartholomae's use of this term and my critique of his and Petrosky's Facts, Counterfacts, Artifacts will illuminate how that shift affects the usefulness of their curriculum. I argue that, because it does not provide basic writers with the means for the agency or critical consciousness necessary to situating themselves on the margins of a language practice, Facts cannot make good on its promise to teach basic writers to seek out the margins of the language and methods of the university. In Section Two of this essay, I outline an alternative to Facts that will facilitate the necessary agency and awareness essential to basic writers' situating themselves in the language and practice of the university.

However, my purpose here is not simply to critique but also to expand on Bartholomae and Petrosky's notions of what goals and needs should drive basic writing curricula, to ask some very important questions about what constitutes authority in the university. Accordingly, in Section Three of this article I consider how, as professors of English-by which I mean anyone whose work it is to profess English, to carry on the academic labor of the discipline-we practice a discourse and discipline that function to conceal the ways by which we earn authority at the university. Consideration of how a basic writer can authorize herself or himself at the university and earn a place therein provides, at best, persuasive evidence of the effectiveness of my proposed revision to Facts and, at least, suggestions for new ways in which to conceive of and practice composition and basic writing pedagogy.

\section{Ludic or Ghettoized: Which Margin Is Whose?}

In his 1985 article, "Inventing the University," Bartholomae classifies basic writers as "marginalized," students who are on the outside of the university because they do not yet know how to appropriate academic discourse. However, their "mainstream counterparts," the ones whose writing earns them unrestrained access to the academic community, are able to enter into the discourse by "placing [themselves] in the context of what has been said and what might be said" (152).

It is very hard for them to take on the role-the voice, the persona- of an authority whose authority is rooted in scholarship, analysis, or research. They slip, then, into a more immediately available and realizable voice of authority, the voice of a teacher giving a lesson or the voice of a parent lecturing. ... They offer advice or homilies rather than "academic" conclusions. $(136,137)$ 
Because "the university . . . is the place where 'common' wisdom is only of negative values-it is something to work against" (156), basic writers must learn how to set themselves against the commonplace, learn how to invent the university for themselves so that they can move from their marginalized, excluded positions on the outside of the work of the academy to the inside.

Bartholomae's 1987 article, "Writing on the Margins: The Concept of Literacy in Higher Education," also considers what it means to be writing on the "margins" and how teachers decide what kind of writing is considered "outside" of the writing accepted at a university. Here, Bartholomae pays particular attention to those borderline cases "that put pressure on what we take to be correct . . . that call into question our assumptions about orderly presentation, standards of copy editing, and the stability of conventional habits of thinking" (68). In reviewing the many sample placement exam essays that are included in his essay, Bartholomae demonstrates that the more clearly marked basic writers' essays are the ones in which we "don't see ourselves in what they [the student writers] do" (69). He explains that "the difference between the top and bottom rank is marked by the ease with which a student (in 15 minutes) could place himself within a conventional discourse" (75). As he did in "Inventing," Bartholomae again defines the problem of the basic writer as a problem of place, of "moving into and appropriating the specialized discourse of a privileged community ... a community with its peculiar gestures of authority, its key terms and figures, its interpretive schemes" (69). Securing a place for themselves in academic discourse is a strategy that basic writers must adopt if they choose and/or are chosen to remain in the university. As a result:

We [basic writing instructors] must put marginal students immediately within representative academic projects (in courses like the seminars we offer to advanced students) so that we can see (and they can see) the position of their writing within the context of those varieties of writing that enable the work of the academy. (70)

Bartholomae and Petrosky do just that in their creation and implementation of a curriculum-described in Facts, Artifacts, and Counterfacts-specifically designed to enable basic writing and reading students to authorize and locate themselves in the university. 
The purpose [of the course], then, is to engage students in a process whereby they discover academic discourse from the inside. They have to learn to define a subject ... to assume the burden of developing working concepts and a specialized vocabulary. In this sense, they are given the task of inventing an academic discipline. . . . They will begin to learn what a subject is-how it is constituted, how it is defended, how it finds its examples, ideas and champions, how it changes and preserves itself. (301)

It is in this essay describing the theory which drives the curriculum presented in Facts that we can see the shift in Bartholomae's use of the term "marginal." This shift is crucial because it unwittingly conceals the curriculum's failure to elucidate how a discipline authorizes itself and therefore to facilitate basic writers' gaining the authority their writing lacks. We can easily recognize the transformation in the notion of "marginal" in this specific essay because it occurs within a single concluding paragraph:

The course we've defined above demonstrates our belief that students can learn to transform materials, structures and situations that seem fixed or inevitable, and that in doing so they can move from the margins of the university to establish a place for themselves on the inside. At the end, however, these relationships may remain hesitant and tenuous-partly because they will continue to make more mistakes than their "mainstream" counterparts (although not so dramatically as before), but also because they have learned (and perhaps in a way their "mainstream" counterparts cannot) that successful readers and writers actively seek out the margins and aggressively poise themselves in a hesitant and tenuous relationship to the language and methods of the university. (305)

Initially, this paragraph presents the "margins" as undesirable, a "ghetto" outside of the university where basic writers have involuntarily been placed and from which they need to flee in order to become insiders. At its close, however, the paragraph presents the "margins" as a place to pursue actively because (the implication is) truly successful writers are outsiders who crave the arch self-rule of these margins. Bartholomae and Petrosky claim that their curriculum will teach a basic writer how to choose to be such an outsider because it involves such students in a project that empowers them to earn the position of insider. 
Let's scrutinize this claim. Can we accept the assertion that students in this course will come to know an academic subject and its discourse? Students of the course will study and form a theory of "adolescence" or of "work" (the topics for the academic projects that Bartholomae and Petrosky suggest). Thus, they will experience the problematization of their own existential situations that Freire sees as essential to the adult literacy process; likewise, they will learn that an essential practice of the university, of a discipline, is to make general commonplace, "fixed," knowledge look like naive assumptions. Thus, Bartholomae and Petrosky's promise that their course will empower students to locate and authorize themselves on the inside of the university is a claim more than justified.

However, I see no evidence for fulfillment of the promise that the curriculum will enable students to seek out the margins of the methods of the university. Yet, actively seeking those oppositional margins and aggressively poising themselves in a tenuous relationship to the university is what Bartholomae and Petrosky say successful writers must do. How empowering can their curriculum be if it does not enable that movement, that shift from center to margins?

I would argue that there is another kind of "enabling" going on, an enabling of the status quo within our own discipline (professing English) that disables the voluntary move to the margins that Bartholomae and Petrosky propose. We professors of English-by which I mean not simply basic writing instructors or even composition teachers but all those who practice the discipline of English-are probably not wittingly disabling anyone. On the contrary, we all-like most enablers-have only the best of intentions: we only want to empower inexperienced writers who want to learn how to write well. Nonetheless, much of our pedagogy involving these "marginalized" students fails to give real power or place or freedom to them because it does not elucidate the source of English professors' authority within the discipline; our pedagogy does not contextualize our own writing within the academy. Thus it is the politics, not the intention, of our methods, that are disabling.

Consider how Freire elaborates on his evaluations of the imitative, mechanical, decontextualized literacy pedagogies that Bartholomae and Petrosky's curriculum strives to supplant. Notice too how Freire employs the term "marginal," how he distinguishes between the "involuntarily excluded" aspect of the term and the "voluntarily refusing to be implicated" coinage: 
...the a-structural perception of illiteracy revealed in these texts exposes the other false view of illiterates as marginal men. Those who consider them marginal must, nevertheless, recognize the existence of a reality to which they are marginal. ... But being "outside of" or "marginal to" necessarily implies a movement of the one said to be marginal from the center, where he was, to the periphery. This movement, which is an action, presupposes in turn not only an agent but his reasons. ... Who is the author of this movement from the center of the structure to its margin? Do socalled marginal men, among them the illiterates, make the decision to move out to the periphery? (161, emphasis added)

Bartholomae and Petrosky claim that their curriculum will empower the student to be the author of this movement to the borderlands or "margins" of the language and methods of the university, to make a choice where before no choice was possible. I think not: while such a course may illustrate to students how to transform their own reality in the sense of the facts of the subject-be it adolescence or work-the course does not unveil for them the context within which they have been denied a place or authority in the university. In short, the course does not empower the basic writer to identify the authors who have to preventhowever unwittingly - a student's movement from the center to the margins of our own potentially disabling discipline.

If, then, [his] marginality is not by choice, marginal man has been expelled from and kept outside of the social system .... In fact, however, the social structure as a whole does not "expel," nor is marginal man a "being outside of." He is, on the contrary, a "being inside of," within the social structure, and in a dependent relationship to those whom we call falsely autonomous beings, inauthentic beings-for-themselves. These men, illiterate or not, are, in fact, not marginal. ... They are not "beings outside of"; they are "beings for another." (Freire 162)

In other words, basic writers are beings for us as professors of English; the notion of marginal students as "marginal" (involuntarily excluded) is essential to the functioning of our own system; our own autonomy and place are dependent upon someone else's dependence on our authority to assign or deny location.

Bartholomae points to this dysfunction in the educational system (and by implication within our own discipline) when he cites Foucault's "The Discourse of Language": 
In its [the educational system's] distribution, in what it permits and in what it prevents, it follows the well-trodden battle-lines of social conflict. Every educational system is a political means of maintaining or of modifying the appropriation of discourse, with the knowledge and the powers it carries with it. (227)

As Bartholomae explains how the system's function translates into the students' position:

If the university officially places some students on the margins (in remedial writing courses), that position is a representation (perhaps in its most dramatic and telling form) of the position of every writer. ("Margins" 70)

Mike Rose argues too that:

The function of labelling certain material remedial [or basic] in higher education is to keep in place the hard fought for, if historically and conceptually problematic and highly fluid, distinction between college and secondary work. "Remedial" gains its meaning, then, in a political more than a pedagogical universe. (349)

It is this political and systemic context driving the labeling and assigning of place to marginalized, basic, remedial students that undermines Facts. I find it unlikely that Bartholomae and Petrosky's model curriculum will explicitly provide the agency for basic writers (the students we call "marginalized" in the sense of "excluded" but whose entrapment is at the very center of our system) to move to the real "margins" of academic discourse and university methods, to the borderlands wherein one can resist being implicated in or even subvert the dysfunctional power structure of a system. On the contrary, the course provides students the opportunity to move from the excluded position of the "margins" to the included position at the center. And the subjects which Facts proposes as the focus for students' academic projects do not illuminate the institutional context of the language and methods against which students need to position themselves in order to be successful writers. Inventing the study of adolescence or of work will not facilitate the basic writers' critique of the writing practices which authorized their "mainstream counterparts" and denied them access to "mainstream" writing courses. Such a critique is essential to the voluntary and active search for the margins of any practice or institution. In order to be the agents of their own marginalization, basic writers need to be able to recognize their 
position at the center of the system that-in part at least-gains its authority by de-authorizing them.

\section{Altering the Facts}

In its emphasis on semester-long academic projects, Facts provides a crucial point of departure for a basic writing pedagogy because it establishes much of the context that surrounds academic writing. I want to pursue that model a step further and suggest a course whose subject matter is discourse itself, the discourse of the students and of the university. I propose a revised curriculum whose content is language-centered, rather than focused on the topics of adolescence or of work. A language-centered curriculum that, among other things, contextualizes the institutional practices of evaluating and placing writers in the university will illuminate for basic writers not only their position as writers in the university, but also the position of nonbasic writers, of honors student writers, and of the evaluators of writing in English courses.

My proposal relies heavily on Facts because-unlike other imitative, decontextualized, atomistic approaches to teaching basic writing-Bartholomae and Petrosky's curriculum acknowledges that for basic writers the problem of writing in the university is the problem of appropriating power and authority through a particular way of writing. Their curriculum also considers-though not to a sufficient extent, I believe-the problem of place, of context, "not only physical space, but historical, social, cultural, and economic realities-i.e., the structural dimensions of reality" (Freire 161). These realities are essential because:

the relationship of the writer to the institutions within which he writes [is] . . . central rather than peripheral (a social or political problem external to writing and therefore something to be politely ignored). . . . We cannot assume that we can teach the sentence or the paragraph as though they were context-free (as we do in workbook exercises or in courses that offer a version of writing that has little to do with writing in the academic disciplines). (Bartholomae "Margins" 70)

Though the proposed topic for study is revised, the methods of the course I propose are no different from those described in Facts: beginning from their own personal experiences, students in such a course examine the language used by their families, their 
peer groups, and/or other subcultures. Their semester-long, seminar project considers such questions as the following: Who is authorized to speak in the discourse of any particular group? How is such authority recognized and practiced? What privileges does the authority provide? How do the dominants of the group protect that privilege? Beginning with their families and peers, students begin by observing and recording some of the language practices of those familiar groups. Drawing from their early writing about their own experiences as "case studies," students then begin constructing theories about the language systems they have examined. Later on in the semester, students observe and record some of the language practices of academic groups and then compare the theories they construct about those practices with the theories of the professionals, that is with ours. To facilitate the comparison, students can focus on the language specific to English studies, in particular all aspects of the English placement exam settings that result in assigning students to basic writing courses.

Study of this aspect of English practice proves particularly illuminating because this context is a site wherein professors of English calibrate their notions of "good writing." At the institution where I profess English, for example, all graduate teaching assistants and associates - the imminent generation of instructors of upper division literature, creative writing, second language acquisition, rhetoric and composition classes, and the current generation of instructors of first-year composition courses-are required to participate in the training sessions for the holistic grading of Freshmen Placement Exams (FPEs). In addition, a more concise version of this training precedes every grading session of FPEs. The purpose of the session is to align the instructors' notions of "unsatisfactory," "average," and "sophisticated" college level writing-as well as the corresponding assignations to basic, mainstream, or honors composition courses-with those existent in the discipline. In this context an essential legacy of English professors is passed on: here is tangibly identified that which constitutes the boundaries of authority in our discipline; herein are we professors of English implicated by and in our own practice.

These features are precisely those that make this context one most fruitful for basic writers to examine and critique. The purpose of their study is not to "pass" placement exams: in most institutions, such as the one where I teach, students in a basic writing course will already have "flunked" the exam in the sense that they have been placed in a course that isolates them from 
"their mainstream counterparts." Rather, their concentration on this context of composition instructors' discursive practices is intended not only to make explicit to students what those instructors see as "good" writing, but also to provide the opportunity for students to analyze and critique the language system valued in composition courses and (presumably) throughout the academy. In other words, after seeking out the materials necessary to observing our placement exam expertise (e.g., audio tapes of holistic training sessions, a large sampling of student exams and the scores they earned, interviews with graders), students can compare their theories about discourse and authority in the university with those of the specialists, that is, with the professors of English, those whose self-authorization put the students in the basic writing courses in the first place.

Such a curriculum, I believe, enables students to examine the ways in which authority is meted out in any language system. This study problematizes the existential situation of language use itself, especially as that use occurs at the university. It illuminates (or at least makes possible the illumination of) what Peter Elbow describes as

the very thing that is attractive and appealing about academic discourse [but that also] is inherently problematic and perplexing. It tries to peel away from messages the evidence of how those messages are situated at the center of personal, political, or cultural interest; its conventions tend toward the sound of reasonable, disinterested, perhaps even objective (shall I say it?) men. (141)

Unlike Elbow, who wants to "argue for one kind of nonacademic discourse ... [a kind] that tries to render experience rather than explain it" (136), I want to argue not necessarily for a particular kind of discourse but for a curriculum that will reveal the evidence of how the messages of academic discourse and our practice of evaluating them are situated. Like Elbow, I'm arguing that "we need to take a larger view of human discourse" (137) into our classrooms; I disagree, however, that merely providing a place for basic writing students to find and express their authentic voices will elucidate this larger view. Such a discovery, I think, certainly would not hurt, notwithstanding Bartholomae's objections that "it is wrong to teach late-adolescents that writing is an expression of individual thoughts and feelings." ("Reply" 128). To teach students only that writing is a form of personal expression does seem wrong: I concur with Bartholomae that such myopia renders students "powerless, at least to the degree that it makes them blind to 
tradition, power and authority as they are present in language and culture" (128-29).

An empowering basic writing pedagogy, then, should provide a space where students can not only express individual thoughts and feelings but also uncover the hidden positionality of academic discourse; it should reveal what's at stake for English teachers in the practice of teaching English, how their self-authorization is essential to their definition of "good" writing in the academy. What better way to promote self-reflexivity and linguistic awareness in students, to "relate speaking the word to transforming reality" (Freire 164)? Through such a pedagogy, students may develop the critical consciousness necessary to being the authors of their own movement from a dependent, uninformed, "marginalized" position at the center of an obscure, enigmatic system to an autonomous position on the "margins," that place where successful writers "aggressively poise themselves in a hesitant and tenuous relationship to the language and methods of the university." They will certainly become situated such that they can begin to see how successful writers'-indeed, even teachers'-authority is of their own construction, a construction that has often kept basic writers at the mercy of a disabling system. In this case, then, it may be our basic writing students who develop the ability to move to the outside of, to deconstruct the notion of place and authority as it relates to professing English.

\section{III. [Mis]Recognizing Good Writing}

It remains to be seen whether a curriculum such as this one will actually work. And even though my primary purpose in this essay is not to argue for this specific curriculum, I do believe that this model, or one similar to it, needs to be realized, tested, and probably further revised. What I am primarily concerned with here is carrying on the work that Bartholomae and Petrosky began when they revolutionized the way we think about the goals and needs that should drive a basic writing curriculum.

In order to instigate this project (and by extension, to ascertain the feasibility of my own curriculum proposal), I want to consider at some length how existing practices of professors of English might delimit basic writers. Thus, in this section of the essay, I want to look more carefully at what it is that we do when we profess English in general and-more specifically-when we teach composition courses. I want to get as much distance as possible from, in order to examine the system of, the norms and beliefs that 
drive what we accept as "natural" and "true" about our composition practices and our standards for good writing. I hope to demonstrate here how academic discourse and disciplinary practice both work to conceal the ways in which authority is earned in our own and in students' writing, how this camouflage is so effective that we ourselves may not even recognize it. My examination in this section is intended to convince us that we as basic writing teachers need to make efforts to reveal (rather than conceal) the ways that student writers can earn authority in their writing. We can begin these efforts by initiating and persuading other professors of English to participate in a redirection of some of our discipline's expertise with critique, a shift from our usual focus on texts to our own disciplinary conventions. By demonstrating that English professors need to learn to read against our own practices and by explaining methods that might help us accomplish such a goal, I will also be making a case for my specific curriculum proposal as a means by which basic writing teachers can learn to "read against the grain" and basic writers can learn to authorize themselves as successful writers in the academy.

I want to begin by looking at the rudiments of professing English. One undeniable aspect of our general practice as professors of English is evaluating student writing. Reading placement exams is one task among many in our practice as professors of English who have a place in and are authorized by a discipline within an institution. What is it, then, that we are doing when we read these exams and place students in the "appropriate" composition course?

When he describes the kind of writing that we authorize in our capacity as evaluators of placement exams, Bartholomae points to a definitive aspect of our practice as professors of English. He explains that the successful student writer establishes authority (that is, earns a place in a "mainstream" writing course) by using an "enabling gesture,"

a posture, with its attending language, that stood before this paper ... [and was] brought forward to enable his narrative, "his" story of "his" experience, the sort of thing a decent, educated person ought to say. ("Margins" 76)

The language attendant to the posture involves a specialized vocabulary,

terms [which] locate the experience in the context of a recognizable interpretive scheme. ... [This kind of] argument is a more powerful one ... "powerful" in the political 
sense since it is an argument that complicates a "naive" assumption (it makes scholarly work possible, in other words). ("Inventing" 152, emphasis added)

What this means, of course, is that successful writers make an essential gesture to English professors' authority by presenting arguments that enable scholarly work. We are trained to read these gestures as masterful (I use the term intentionally) because when we as professors (scholars) of English function as readers of placement exams, what we are doing-consciously or not-is authorizing an argument that makes our own work possible. How could we do otherwise? Denying place or authority to such an argument would take an "unnatural" act of hyperconsciousness, some may even say self-destruction, for we are seeing ourselves in what these writers do: their work is our work. Likewise, how could we do other than refuse to authorize or honor a commonplace argument, one that simplifies or that accepts "naive" assumptions? If the argument based on naive assumption were one with authority, scholarly work would become impossible or at least superfluous; accepting such an argument would deny us our own hard-earned places in the institutions that authorize us.

In other words, our places and authority within the university determine our vision. Yet, we are usually unaware of how that vision is circumscribed, taking instead its definitions and standards as given or universal. Stanley Fish describes his own colleagues

as actors within an institution [who] . . . automatically fall heir to the institution's ways of making sense, its systems of intelligibility .... Such a person, when pressed, is likely to say, "but that's just the way it's done" or "but isn't it obvious" and so testify that the practice or meaning in question is community property as, in a sense, he is too. (320-21)

Always implicated in our own practice, we professors of English who grade placement exams are on the lookout for what we do, and when we find it we call our discovery "good writing." A constructed artifact "already embedded within the institutional structure that makes it possible," our notion of what constitutes good writing-that judgment which authorizes one student to move to a guaranteed place in the academy and sentences another to a restricted, temporary place pending further "development"is an entity which has "palpability and shape only because of the assumption of some other system of intelligibility, and [it is] 
therefore just as available to a deconstructive dissolution as are poems, assignments, and lists" (Fish 330-31).

Our systemic belief in the inadequacy of general or communal knowledge points to another important facet of what we as practitioners do within a discipline at a university: not only do we evaluate student writing, but also we do the research necessary to establish ourselves as authorities in our fields. That is, we push for our own specialized place which-when won-authorizes us because we and only we can claim to know it. As Edward Said describes this struggle:

the status of a discipline [is such that] its subject matter becomes a field or territory. Along with these goes a whole apparatus of techniques ... to protect the coherence, the territorial integrity ... the social identity of the field. . . You have to pass through certain rules of accreditation, you must learn the rules ... speak the language . . . master the idioms . . . accept the authorities of the field. (7-8)

To earn-or at least maintain-a specialized place, writers at the academy must learn the techniques that protect the territory of their knowledge. The university, in other words, is a place of specialists, a place where the way to earn authority is to have so much specific knowledge as to be able to complicate any issue, to make general knowledge look like naive assumptions. Further, as practitioners at the university, we English professors develop a certain specialized style of vocabulary, idioms, gestures to authority in our writing. And, like the self-conscious, self-reflexive writing practices which we English professors develop, the writing we expect from a student requires her to

enter into a discourse ... . [and] by stylistic maneuvers, to take possession of it at the same time. . . The writer must learn that his authority is not established through his presence but through his . . . ability . . . to speak as a god-like source beyond the limitations of any particular social or historical moment, to speak by means of the wisdom of convention, through the oversounds of official or authoritative utterance, as the voice of logic or the voice of the community. (Bartholomae, "Inventing" 151,155)

The student, as well as any or all of us who are engaged in the practice of English studies, does this by "placing himself in the context of what has been said and what might be said"; by authorizing himself by who he is rather than by what he can say about 
his topic in the context of what is generally said" (i.e., the commonplace); and by using a more specialized vocabulary of terms "which locate the experience in the context of a recognizable scheme," a scheme "in which the text continually refers to its own language and the language of others" (Bartholomae, "Inventing" $152,153)$. In other words, as scholars at a university, we authorize ourselves by commandeering the right to speak definitively to readers who demand highly specialized (that is, inaccessible to the uninitiated) complications of commonplace topics; we only authorize student writers who follow suit.

Overall, then, we could say that what we do when we practice English is protect our interests. When we map out a certain place as our specialty, our project, we are protecting our interests, as we are when we speak with "god-like authority" on our subject. Likewise when we evaluate student writing and grade placement exams, we are safeguarding our investments: it's in our own best interests to evaluate the argument that gestures to our own authority as "powerful" (in the political sense), or "good," or "college level material," or even "cognitively mature," and to label argument of the "naive" type as unacceptable. It's obvious, we might say, that the writer of the "sophisticated" sample has a demonstrated fluency with written language and deserves a place in the university while the writer of the "naive" essay, on the other hand, is not really "literate" and will not "feel comfortable" in the university or in the "regular" first-year composition course.

This is not to say that those of us who are seeing ourselves in the "sophisticated" writer's work and who are therefore reading that work as masterful are conspiring against people who do not do what we do. Chances are that we're not even conscious of what we are "seeing." Rather, I am arguing that we have a misrecognized penchant to honor arguments (writing) like our own. ${ }^{2}$ My point here is not to chastise those who assign a "developmental" course to a writer who doesn't say what a "decent, educated person ought to say," not to condemn our practice but rather to try to recognize (rather than misrecognize) it for what it is. Neither is my point that-because we can deconstruct our own notions of what constitutes good writing-what we think is good writing isn't "really" good, nor that we should stop placing students in composition courses or quit evaluating them.

Rather I want to establish that English professors' evaluations of student writing are determined by their own discursive practices rather than by some transcendent or fixed quality of excellence. However, rarely-if ever-do we as basic writing instruc- 
tors tell students that the skills required to be a successful writer in a composition course are, in a sense, like those required to be an English professor. In fact:

Most teachers tell students (and themselves) that these skills are the best uses of language and mind-not the skills of a particular class in a particular productive system. This is mystification, and . . . it works by suppressing the social and potentially political content of English. (Ohmann, 170)

The point I am arguing is that we will be better basic writing teachers if we demystify our own use of language, if we reveal this potentially political content of an English composition course. Such revelation is most essential to a basic writing course. Given the unlikelihood (impossibility, some say) that, in our capacity as basic writing instructors and professors of English, we will be willing or able to step outside of our own system of intelligibility, we need at least to find some means to step to the side of it, to recognize what our practice is and how our system of intelligibility works. It's the mystification of our practice, I think, that delimits basic writers and keeps them in a dependent relationship to the English professor and the institution. Thus, we basic writing instructors-indeed all writing instructors-need to become more aware of what we do in all our capacities as professors of English so that we can make explicit to basic writers (or any other writers for that matter) what it is that we are on the lookout for when we evaluate student writing.

Oddly enough, this task has yet to be accomplished. Though Richard Ohmann's analysis is fifteen years old (and-one could convincingly argue-composition studies have undergone substantial revision since his review), his appraisal of the rhetoric textbooks and pedagogies intended to define and enable "good writing" still stands: "the failure is in their inability to translate what English instructors know and practice ... into good sense about Freshman English" (139). Ohmann pinpoints the failure even more specifically: "really the textbooks are about tidying up and transcribing thought, not thinking" (136).

\section{IV: Facts Revisited: The Critical Gesture}

Ohmann's criticism and its emphasis on "thinking" brings me to the final rudiment of our practice as professors of English that I'd like to consider, namely "critique." I devote this last section to a discussion of that aspect of our practice, for it is specifically 
with respect to this crucial element of what we recognize as authoritative writing that Facts shortchanges students. I'm convinced that without the opportunity to witness, participate in, and evaluate this and other aspects of our discursive practice, basic writing students cannot realize Facts' promise that they will "actively seek out the margins and aggressively poise themselves in a hesitant and tenuous relationship to the language and methods of the university."

What is it that we do when we "critique"? Our practice as professors of English requires us to set ourselves against the bias and ideology of other critics, other disciplines, other practitioners, even our own conventions. We set out a space for ourselves by identifying the assumptions of an interpretive community and then aligning ourselves with and/or setting ourselves against these assumptions. And-as we have seen in the way that other aspects of our practice determine what we consider authoritative when we place and evaluate students-because critique is an aspect of our own work, we also expect to see it in "good" student writing.

Thus, a further demand we are making on students who want to earn a place for themselves in the university is that they know how to think, how to make the "critical gesture." This gesture to our expertise with critique, the demonstration of what we call "critical thinking skills," is perhaps the surest way for a student to earn authorization from us. Because it is also a gesture that pushes against the commonplace language use that would render a student no different from everyone else, this critical gesture necessitates an understanding of not just our specialized vocabulary and schemes, but also the practices of our discipline: one cannot critique that which she or he does not understand or of which she or he is unaware. The operative question then is how can a student writer become aware of our practice?

In his explanation of how one comes to understand the terms and practices of any interpretive community, Stanley Fish reminds us that

in order to grasp the meaning of an[y] individual term, you must already have grasped the general activity ... in relation to which it could be thought meaningful; a system of intelligibility cannot be reduced to a list of the things it renders intelligible. ... Communication occurs only within such a system (or context, or situation or interpretive community) and ... the understanding achieved by two or more persons is specific to that system and determinate only within its confines. (304) 
In other words, students cannot write (communicate) authoritatively within the university system simply by memorizing a list of things that the system considers authoritative; they must comprehend the activity, the practices, of the system.

So, even if they were equipped with explicit instructions elucidating how to reproduce the gestures that English professors recognize as "good" (that is, as imitations of their own), basic writing students would not be able to do much more than imitate our discourse without comprehending our discursive practice; they would not be able to recognize its purposes nor its potential for critique, for transforming reality, for creating place and authority. Yet, understanding academic discourse's potential for transforming reality is crucial to students becoming the agents of their own movement from the center of a disabling system to its margins, to becoming autonomous beings for themselves who can speak with authority. Freire maintains that imitative activity does minimal or no good for the student, for

linguistic contexts ... when mechanically memorized and repeated, are deprived of their authentic dimension as thought language in dynamic interplay with reality. Thus impoverished, they are not authentic expressions of the world. (161)

Imitation does not enable writers to work against convention, to situate themselves on the margins of the practice and protocol of a discipline.

The Facts curriculum does involve students in the practice of creating a discipline by engaging them in semester-long projects in which they examine the topics of "work" or "adolescence"; it does empower students by problematizing their existential situations with respect to work or growing up. However, and despite the fact that such topics are accessible to students, a curriculum that enables the creation of disciplines on those particular topics does not provide the authentic context for students to learn about power in discourse. Within the discipline wherein the students are being evaluated, the course does not reveal what their evaluators do to earn authority in the institution and therefore what they have been trained to consider authoritative when they evaluate students' discourse.

The existential situation for students in basic writing courses is that the authority respected within academic discourse is often of a type they don't recognize; in fact, academic authority requires students to set themselves against "convention," against the com- 
monplace authority that basic writers do recognize. Furthermore, the power structure within the university system often excludes basic writers, placing them on the outskirts (outside of, on the "margins") of the system in remedial, "no-credit" composition courses. At the same time, these exclusionary practices of the system conceal the fact that authorized writers are those who voluntarily travel those same outskirts, those who expropriate autonomy and authenticity by challenging the conventional language and practices of the university. Problematizing this existential situation is what will empower basic writers to make the critical gesture essential to academic discourse.

It seems clear, then, that unless students are presented with the authentic context within which the practice of composition studies is revealed and open for critique, they will not be empowered to learn "that successful readers and writers actively seek out the margins and aggressively poise themselves in a hesitant and tenuous relationship to the language and methods of the university." The Facts curriculum can reveal to students how academic disciplines are created, how to complicate the commonplace and thereby make scholarly work possible, how to create the specialized language associated with and recognized as authoritative by a discipline; in short, Facts shows students how to mark off the territory necessary to creating a discipline, to inventing the university.

However, because it does not reveal for them the authentic context of their situation at the university, those conditions under which they have been delimited by the language and methods of the university, the Facts curriculum does not empower students to critique those conditions. Yet, this critical gesture is essential to students' learning to write with authority:

The movement toward a more specialized discourse begins ... when a student can define a position of privilege, a position that sets him against a "common" discourse and when he or she can work self-consciously, critically, against not only the "common code" but his or her own. (Bartholomae, "Inventing" 156)

As a way to provide the authentic context of composition studies, I have proposed a revision of the Facts curriculum. Rather than on the subjects of "adolescence" or "work," my revision focuses on discourse and language use as its topic. Because that subject would help provide more explicit disclosure of what we do when we profess English, I believe it will facilitate students' 
recognition of how to appropriate authority in composition courses as well as in other sites of academic discourse. Furthermore, because my proposed academic project would include students in (or at least reveal to them) the process by which placement exam essays are evaluated, they will be engaging in our practice as composition instructors. Therein, I believe, lies the strength of the curriculum.

However, and as I mentioned at the outset, more work needs to be done to discover if in fact this revision makes good its claims. I have begun that project myself. ${ }^{3}$ I hope to hear about others' successes or lessons with revisions to current basic writing pedagogy theory or practice. Whatever the strengths or weaknesses of the particular revision I propose here, however, it seems essential that we all hold open to investigation our ideas of what goals and needs should drive a basic writing curriculum. Especially as we approach the 21st century and its potential (if the projections hold true) for students of even more diverse economic, cultural, and educational backgrounds than those we already know, that curriculum becomes increasingly crucial to the retention and academic success of basic writing students. We only maintain the status quo, perpetuate mysticism, when we refuse or neglect to consider the questions of how basic writers can locate and authorize themselves in the university, a status quo that denies those students entry altogether or that allows them only temporary place with little or no authority. The sort of pedagogy that I propose provides a way not only for our students to know and locate their places but also for basic writing instructors to do the same, for us to step to the side of our own practice and keep a watchful eye on our often unconscious or inadvertent choices about where to locate ourselves and, by implication, our students.

\section{Notes}

'I gratefully acknowledge David Bartholomae, Tilly Warnock, and Duane Roen for their support and assistance in reviewing and commenting on various versions of this paper.

${ }^{2}$ For this term "misrecognition," especially as it relates to "gesturing," I am indebted to Bill Epstein's definition ("gesture. . .a way of sanctioning critical activity under the cover of some other activity") and to his explanation: "because gesturing attempts to transfer authority. . .from a human body. . .to a reified sign... seemingly stabilized within an autonomous, disciplinary matrix, 
it is also a way of misrecognizing the participation of individual critics in the community of professional practice. If practice is, as Pierre Bourdieu has suggested, a contingent temporal activity poised on the margin between discursive and nondiscursive behavior that can only be 'misrecognized,' then gesturing is one of the characteristic forms of this behavior-'a truth whose sole meaning and function are to deny a truth known and recognized by all, a lie which would deceive no one, were not everyone determined to deceive himself [or herself].'" (Epstein 64-65)

${ }^{3}$ During the Spring and Fall semesters of 1992, I experimented with this curriculum, especially the unit on training the basic writers to be graders of the Freshmen Placement Exam. Based on my own initial responses, as well as those of the students in the pilot sections and other instructors who observed, my theory holds up in practice. But, of course, these initial responses constitute another paper, evidence that needs demonstration before it can be persuasive.

\section{Works Cited}

Bartholomae, David. "Inventing the University." When a Writer Can't Write: Studies in Writer's Block and Other Composing Process Problems. Ed. Mike Rose. New York: Guilford, 1985. 134-65. (Abridgement rptd. in Journal of Basic Writing 3.1 (Spring 1986): 4-23.

---. "A Reply to Stephen North." Pre/Text 11 (1990): 121-30.

---. "Writing on the Margins: The Concept of Literacy in Higher Education." A Sourcebook for Basic Writing Teachers, Ed. Theresa Enos. New York: Random, 1987. 66-83.

Bartholomae, David and Anthony R. Petrosky. "Facts, Artifacts, and Counterfacts: A Basic Reading and Writing Course for the College Curriculum." Rptd. in A Sourcebook for Basic Writing Teachers. Ed. Theresa Enos. New York: Random, 1987. 275306.

Elbow, Peter. "Reflections on Academic Discourse: How It Relates to Freshmen and Colleagues." College English 53 (1991): 13555.

Epstein, William H. "Counter-Intelligence: Cold-War Criticism and Eighteenth-Century Studies." English Literary History 57 (1990): 63-99.

Fish, Stanley. Is There a Text in This Class? The Authority of Interpretive Communities. Cambridge, MA: Harvard UP, 1980. 
Foucault, Michel. The Archaeology of Knowledge and the Discourse on Language. New York: Harper, 1972.

Freire, Paulo. "The Adult Literacy Process as Cultural Action for Freedom." Harvard Educational Review 40 (1970): 205-25. Rptd. in A Sourcebook for Basic Writing Teachers. Ed. Theresa Enos. New York: Random, 1987. 158-75.

Kuhn, Thomas. The Essential Tension: Selected Studies in Scientific Tradition and Change. Chicago: U of Chicago P, 1977.

Ohmann, Richard. English in America: A Radical View of the Profession. New York: Oxford UP, 1976.

Rose, Mike. "The Language of Exclusion: Writing Instruction at the University." College English 47 (1985): 341-59.

Said, Edward W. "Opponents, Audiences, Constituencies, and Community." Critical Inquiry 9 (1982): 1-26. 


\section{Bill Bolin}

\section{ENCOURAGING STUDENTS TO (CONTINUE TO) SHARE AUTHORITY IN THE CLASSROOM: A RESPONSE TO PATRICIA BIZZELL}

ABSTRACT: While it is both desirable and necessary to confront controversial, politically charged issues in a writing class, it is self-defeating to subject students to a pedagogical relationship in which the teacher convinces them to surrender authority. This paper questions attempts to persuade students to trust the opinions of the teacher too completely, suggesting instead that students who are presented important issues have the interest and the capability to examine those issues critically and fairly while still maintaining control.

In the Fall 1991 issue of Journal of Basic Writing Patricia Bizzell presents a notion of authority that justifies the teacher's leading the class toward his or her political views. Bizzell's argument is that we can actually teach our "left-liberal" views in our writing classes without worrying that we are imposing our authority on the students. While many in our discipline might consider these views admirable, Bizzell's notion of a three-part model of power, with the third part serving as the guiding but not authoritative scheme, actually seems to justify coercion in the classroom. I want to show that while Bizzell's approach may please most of

Bill Bolin is assistant professor of literature and language at East Texas State University (Commerce, TX). His interest in classroom authority comes from both his doctoral research at Texas Christian $U$ (Ft. Worth) and his twelve years of teaching writing at the secondary school, community college, and university levels.

() Journal of Basic Writing, Vol. 12, No. 2, 1993 
us left-liberal educators, our adoption of such an approach might well obstruct our students' progress as developing writers and thinkers. Such an approach might very well also marginalize several of these same students.

I readily concede that we teachers present our political values. whether implicitly or explicitly, in every class we teach. Bizzell, as I read her, frames this realization by saying that our perception of literacy informs the way we teach composition, and she suggests that we examine "what alternate notions we may want to convey" (55). However, Bizzell promotes exercising authority, some would say oppression, over writing students in such a way that may alienate them more than educate them. She assumes that the perception of authority held by writing teachers is dichotomous, marked by either coercion or persuasion. In the model of coercion, "A uses B to benefit A and there's nothing B can do about it" (56). One problem with coercion, from a left-liberal standpoint, is that it benefits B only by measuring how far from A's elite group B will fall, or by finally allowing $B$ to participate in that group. An example is a college entrance examination that classifies students as those who need remedial help, those who are ready for firstyear composition, or those whose test results warrant giving them credit for first-year composition. The second type of power that Bizzell presents is persuasion: A exercises power over B only with B's consent. And B would grant consent only if A can convince B that $A$ has B's best interests at heart. In a rather totalizing claim, Bizzell posits that "we" prefer this type of classroom strategy because it encourages us not to abuse our authority as teachers. She posits further that under such a strategy "we" choose not to "set standards for good writing that we can compel our students to meet. Rather, we simply try to create a climate in which the students can generate their own standards of good writing" (56). We simply offer advice to students on how their writing can best meet certain objectives. A cannot transact with $B$ in this instance without also being changed, and the absence of such a change indicates coercion rather than persuasion.

But Bizzell apparently does not consider herself part of this "we." Stating her discomfort with the inadequacy of persuasion to move students toward a desirable target, her own left-liberal goals, Bizzell then presents a third alternative. This alternative, which she calls "authority," seems at first blush to combine the first two, but in fact it is simply coercion again:

Authority is exercised by A over B instrumentally in the sense that sometimes $B$ must do what $A$ requires without 
seeing how B's best interests will be served thereby, but A can exercise such authority over B only if B initially grants it to A. (57)

In other words, the teacher must persuade the student that the teacher's unquestioned authority will ultimately benefit the student. Bizzell phrases the model in such a way that B empowers A to direct the course of action after some initial dialogue, but this approach actually just soft-pedals the coercion. After the student is persuaded to recognize such power in the position of the teacher, the student must participate in any activities the teacher deems appropriate. "The student's initial reluctance to undertake these activities is not allowed to prevent their practice, however, or delay it while a lengthy process of persuasion is undertaken" (58). This is actually an extension of Bizzell's argument in an earlier article, "Beyond Anti-Foundationalism to Rhetorical Authority," in which she describes James Berlin's experimental course at Purdue. Berlin encourages his students to deconstruct ideologies regarding gender and economics, but his "value-neutral" approach prevents him, according to Bizzell, from taking his students beyond investigation of the nature and ramifications of sexism and capitalism (672). She suggests that he "openly state that his course aims to promote values of sexual equality and left-oriented labor relations and that this course will challenge students' values insofar as they conflict with these aims" (672).

Bizzell, in her more recent piece, presents educator bell hooks [sic] as a model for the pedagogy of authority. Hooks admits that her teaching style is confrontational in order to jar students into becoming critical thinkers. And although many of her students resent her, at least during the course, hooks justifies her approach by invoking a no pain-no gain principle in encouraging her students to develop as writers and thinkers with the belief that they will benefit in the end (Bizzell, "Power" 64-65). However, this confrontational style will surely silence a number of students for a significant period of time before eventually, if ever, encouraging them to become assertive themselves. Without overemphasizing the significance of cultural traits, I do feel obligated to point out that students from some cultures may have more trouble dealing with hooks's style than other students. For instance, many East Asian students have indicated discomfort with making negative statements (Allaei, Connor 24) so these students would clearly be marginalized. They would not be encouraged, it seems evident, to voice any opinion unless it aligns with that of the teacher.

Certainly teachers present their politics in their classes. Not to 
recognize this fact is to hold "politics" to a confined definition. For example, Maxine Hairston, in defending her position against using freshman English classes as arenas for social change, sees such politically charged pedagogy as harmful to the idea of using classes as student-centered workshops designed to promote the students' self-confidence. She complains:

Nevertheless, everywhere I turn I find composition faculty, both leaders in the profession and new voices, asserting that they have not only the right, but the duty, to put ideology and radical politics at the center of their teaching. (180)

However, it is one thing to put politics at the center of teaching and quite another to convince, even require, the students to aspire to the teacher's political leanings. Writing instruction and classroom instruction focusing on political issues can lead to fruitful dialectic among students and teachers without being shut down by the students' surrendering to the teacher's point of view. For example, I assign my writing students to read the NCTE's statement concerning the use of inclusive language. Although most of my students see no problem with using androgenic terms to signify both males and females, as well as certain occupations, we discuss the possibility that language creates knowledge. Such a philosophy spawns the belief that using androgenic terms for specific occupations might actually reinforce the idea that such occupations are appropriate only for males. "Chairman," rather than "chair" or "chairperson," inculcates the perception of solely male leaders of businesses and organizations. Although the importance of inclusive language informs my own writing, I hesitate to do more than present the concept to my writing class and let them consider the issue. Most of them never have previously, and I find it fruitful to establish a discussion with them without coercing them to accept or practice inclusive language with the understanding that I have their best interests at heart.

The importance of presenting social issues, without necessarily requiring a particular stance, is made clear in the establishment of a culturally sensitive basic writing program at the University of Massachusetts at Amherst. In the wake of racial tension and subsequent demonstrations, minority student demonstrators encouraged the requirements of a writing curriculum that would help students on the margins "move confidently and thoughtfully through private meaning-making to significant communication with others" (Herrington, Curtis 490). The students provided the 
political agenda, but they were not penalized for failing to follow the presented ideology. An English-speaking Anglo student considered the importance of bilingualism indicative of the fact that she was able, during a trip to Spain, to tell impoverished beggars, "Don't bother me!" and "Why don't you get a job?" in two languages. Her exuberance over learning Spanish, she continued, would never cause her to want to lose her primary culture as did the educator Richard Rodriguez when he learned English according to Herrington and Curtis. The authors write regarding this student:

[S]he tells us pretty emphatically that there are boundaries of identity and identification that she's simply not ready to cross. We did not penalize her for her reluctance, nor did we prevent her from expressing her frustration. In fact, we believe there is/was a lesson for her and for us in her resistance and the emotions it expressed. We believe it was demonstrating precisely what many marginalized students must feel every day in traditional courses. And we hope she actually was experiencing, however unwillingly, an identification with marginalized people that she might be able to reflect upon later. (494)

Through exposure to social issues, the students in the basic writing program at UMass-Amherst reevaluate their opinions. But there is no authoritative agenda to join the thinking of the instructors. Most teachers would agree that centering marginalized students is an important consideration in any curriculum. But first attempting to persuade the students that the teacher will take care of their interests and then coercing all the students to accept the centering of marginalized students may prove antiproductive for a number of those students. The program at UMass-Amherst seeks to move students to the center by considering the personal histories, the micronarratives, of these students, thereby recognizing the authority of their thinking and writing. Herrington and Curtis report success in accomplishing academic aims for their basic writing courses when the curriculum arises from collaboration of instructor-assigned readings and student-generated text (495-96).

Bizzell worries that leaving the students responsible for handling politically charged material will give them the impression that those issues are simply a matter of personal choice and, therefore, not quite so urgent. Recognizing that many teachers believe that a pedagogy of pluralism will inherently promote a left-oriented philosophy, Bizzell repeats the urgency to guide these 
students through the material ("Power" 66). In contrast, Baumlin and Corder see the importance of allowing students to construct meaning out of the material they come across, even though the teacher sees some shortcomings. Baumlin and Corder propose a view of the world that is analogous to "jackleg" carpentry, a carpentry practiced by adequate but not expert woodworkers: "Well, there it is, by God, - it ain't much, but it'll hold us until we think of something better" (18). Based on that view, the carpentry, or perception of the world, will hold together until its makers think of something better, not necessarily when they are led to something better. In discussing how authority becomes restrictive, even destructive, when it becomes fixed as law, Baumlin and Corder point toward the importance of the student asserting his or her own authority to find his or her own truth. Each student's ethos is important to the structure of the class (19). The teachers and the students must both contribute to unveiling (I would say constructing) reality without the stipulation that one herds the other toward a certain view of reality after being granted full authority to do so (Freire 56). Although Bizzell offers first to persuade the students to relinquish any authority before imposing her political views for their benefit, are those students then not trapped for the remainder of the course?

To be sure, there is a sense of authority that pervades most, if not all, writing classes. At some point the students' writing will be evaluated, and the students may have to take some sort of test to measure a sense of writing proficiency. In a course for developmental writers at a local community college, for instance, my students participated in a largely student-centered writing environment. But at semester's end they were administered a twentyquestion, standardized, multiple-choice test to determine whether or not they might advance to standard first-year composition. Students answering correctly at least fourteen of the questions were deemed eligible for freshman composition while the others were required to repeat the developmental course. Oftentimes wondering, I'm sure, why they had not picked up the gift of writing the first (or second) time around.

G. Genevieve Patthey-Chavez and Constance Gergen present an interesting plan for working within the parameters of such authority while still allowing the students to develop as subjects with authority and an active part in their own education. They recognize the crossroads encountered when teachers privilege diversity yet must preach conformity in order to address the writing of students that does not fall within the guidelines set up by the 
academic community (76). They propose allowing the students to question the origins of such conventions; in other words, the students might be asked what they think constitutes a "good essay." Such discussion would invariably lead to criteria that the students gleaned from previous classes, or from what the authors term "folk theories," and at some point the students will realize that the standards of academic discourse are not absolute, but are, nevertheless, to be reckoned with (84). At any rate, the students are active participants, "subjects" according to Freire, in their own learning as they deal with an authoritative framework. The difference between this approach and Bizzell's model of authority, as I see it, is that the students in Patthey-Chavez and Gergen's study at no point surrender their authority to the good intentions of the teacher. Rather, they work with the teacher in recognizing academic factors outside their classroom.

Teachers need to strike a delicate balance here. They have genuine authority over the subject matter, and they do know the standards to which their students will be held. But too much emphasis on standards and authority will quickly degenerate into a unidirectional, "banking" exchange. (Patthey-Chavez, Gergen 86)

In discussing the academic standards that the university imposes, the teacher in this model creates a learning community within the classroom.

Bizzell ends her argument by offering suggestions for assignments borne out of politics and that would engender political discussion in the writing class. She recommends gathering a selection of written material that reflects a pluralism of thought and culture. Further, she suggests that this reading list include recommendations of students, faculty members, and even members of the community. This approach would certainly work well with what Bizzell dismisses as the persuasive model of teacher/student relationship, especially in light of the research done by PattheyChavez and Gergen, as well as by Baumlin and Corder. I suggest following up each of those readings that are assigned by the teacher or chosen by the students with class discussion that is student-led and, for the most part, student-directed. The teacher may voice his or her views as a participant without much fear of directly realigning the thinking of the students because the classroom power structure is, ideally, persuasive. The students may then begin writing drafts after having examined a variety of opinions, but they maintain authority, at least to a greater degree than 
they would under the "authority" model. Then, as the students revise their writing after a series of peer responses and teacher/ student conferences, they have even more opportunities to articulate or even change their positions on various issues. But they will do so, ideally, through their own reconsideration, and not merely to please a teacher who supposedly sees a larger picture and therefore watches out for them. Granting such authority to the students also grants them more responsibility.

In his response to Hairston's "Diversity, Ideology, and Teaching Writing," John Trimbur makes a sensible case against Hairston's value-neutral approach to teaching. Trimbur mentions a letter he wrote with Bizzell in support of the composition course at the University of Texas at Austin. Such a course, which utilizes timely and important topics as a means of teaching rhetorical strategies, is laudable, but to persuade the students to accept the teacher's point of view unquestioningly, as Bizzell proposes in $J B W$, is to jeopardize any empowerment the students may feel as they tackle the sensitive issues that affect them. As a teacher of writing, I present my political leanings to my students, and I want them to read about, think about, and write about various social issues as they participate in my class. But I certainly do not want them to adopt my beliefs out of duress; they would be much better off actively participating in creating their own realities. "Who shall be the 'authorities' in our writing classes? Just ask yourself: who are the 'authors'? Must it be so hard to say, 'Our students'?" (Baumlin, Corder 20). To develop as communicators, students need the empowerment that is a byproduct of cooperating-in other words, sharing authority-with the teacher.

\section{Works Cited}

Allaei, Sara Kurtz, and Ulla Maija Connor. "Exploring the Dynamics of Cross-Cultural Collaboration in Writing Classrooms." The Writing Instructor 10.1 (1990): 19-28.

Baumlin. James S., and Jim W. Corder. "Jackleg Carpentry and the Fall from Freedom to Authority in Writing." Freshman English News 18.2 (1990): 18-20.

Bizzell, Patricia. "Beyond Anti-Foundationalism to Rhetorical Authority: Problems Defining 'Cultural Literacy'." College English 52 (October 1990): 661-74.

---. "Power, Authority, and Critical Pedagogy." Journal of Basic

Writing 10.2 (Fall 1991): 54-70. 
Freire, Paulo. Pedagogy of the Oppressed. Trans. Myra Bergman Ramos. New York: Continuum, 1989.

Hairston, Maxine. "Diversity, Ideology, and Teaching Writing." College Composition and Communication 43 (May 1992): 17993.

Herrington, Anne J., and Marcia Curtis. "Basic Writing: Moving the Voices on the Margin to the Center." Harvard Educational Review 60 (November 1990): 489-96.

Patthey-Chavez, G. Genevieve, and Constance Gergen. "Culture as an Instructional Resource in the Multiethnic Composition Classroom." Journal of Basic Writing 11.1 (Spring 1992): 75-96.

Trimbur, John. "Responses to Maxine Hairston, 'Diversity, Ideology, and Teaching Writing."' College Composition and Communication 44 (May 1993): 248-49. 


\title{
Lynée Lewis Gaillet A LEGACY OF BASIC WRITING INSTRUCTION
}

\begin{abstract}
This article introduces George Jardine, an eighteenth-and nineteenthcentury Scottish professor of logic and philosophy at the University of Glasgow, and demonstrates how his practical plan for teaching beginning writers prefigures contemporary theories and practices of modern basic writing instruction. The author draws parallels between the works of Jardine and Mina Shaughnessy to illustrate how a theoretical and practical bridge based on social and economic factors does exist between early nineteenth-and late twentieth-century basic writing instruction.
\end{abstract}

I recently had the opportunity to examine the Scottish manuscript holdings concerning a little-known, nineteenth-century teacher at the University of Glasgow, George Jardine. As I attempted to align Jardine's findings with earlier theories of rhetoric, I found myself repeatedly comparing both his classroom experiences and writings to modern-day theories and practices characteristic of basic writing. Although current American theorists and practitioners are certainly well-acquainted and dedicated to the nineteenth-century rhetorician George Jardine's concept of education, very few are even familiar with this Scottish educator's name. Jardine's intense concern with communication and comprehension, student-based learning, the preparation of students to function in and contribute to society, and pedagogical practices which we currently label "peer-editing," "writing across the cur-

Lynée Lewis Gaillet, assistant professor of English at Georgia State University, teaches classes in rhetoric and writing. Her forthcoming works include contributions to Eighteenth-Century Rhetorics and Rhetoricians, edited by Michael Moran for Greenwood Press; and Three Nineteenth-Century Rhetoricians: Bain, Aytoun and Jardine, edited by Winifred Bryan Horner for Southern Illinois UP. 
riculum," "writing as process," and "writing as discovery," reveal his anticipation of much of what we consider to be twentiethcentury developments in the field of composition and rhetoric.

Although Donald Stewart identifies in The Present State of Scholarship in Historical and Contemporary Rhetoric 160 pieces of scholarship published from 1980 to the present having some bearing on nineteenth-century rhetoric, only one work by Winifred Bryan Horner mentions Jardine. Stephen North in his influential work The Making of Knowledge in Composition: The Portrait of an Emerging Field (1987) is critical of historical studies that investigate the work of one particular figure; however, the case of George Jardine proves that the need for this type of research in nineteenth-century history of composition still exists. We generally don't know who the influential figures of this period were or what contributions they made to modern writing theory. One reason for the obscurity of nineteenth-century rhetoricians' work lies in the fact that the practice of widely publishing professors' lectures decreased by the end of the eighteenth century; therefore, many nineteenth-century professors' lectures and thoughts are preserved only in student notes, letters, and other materials in manuscript form in Scottish manuscript libraries. Winifred Bryan Horner offers another explanation why the advances of many nineteenthcentury rhetoricians were subsequently obscured:

The Scottish universities initiated a series of "reforms" that abandoned the nineteenth-century philosophic and democratic system and resulted in one which conformed to the English university model and which was dedicated to the education of the select few. . . . [T] ime important records of their work were often lost or overlooked in the persistent call for educational "reform." (Nineteenth-Century Scottish Rhetoric 7)

Although enormously popular at his own institution during his own time, Jardine's work is lost to modern composition instructors. The nineteenth century provides the immediate background for current rhetorical theory. We must study the tradition we come from in order to put into perspective our own contributions.

Jardine is a forerunner of contemporary composition researchers whom North labels "practitioners," teachers who are in the best position to conduct inquiries but often the least prepared or equipped to do so (35). North explains that the most successful practitioner-researchers are those who (1) stay in the field for a long period of time, (2) work under favorable conditions, and (3) 
strive to make their practice a form of inquiry (35). George Jardine meets these qualifications. From 1774 to 1824 , Jardine taught logic and philosophy at only one institution, the University of Glasgow ("George Jardine" 387). Upon taking over the class, he realized that both the class curriculum and lecture method of teaching did not meet the needs of his students and that even when the brighter students grasped the abstract principles taught in the class, the material would not aid the student realistically in any future profession or employment. As a result of his observations, Jardine radically altered his class to include daily free writing exercises, sequenced essay assignments, and peer evaluation to facilitate the development of communication skills which would help his students function in society. He believed that students failed to learn unless they were required to write essays and compositions that were then critiqued by both the teacher and the other students (Lectures on Logic and Belle Lettres iii). From Jardine's letters preserved in the manuscript library at the University of Glasgow and from the testimony of his colleagues found in the Royal Commission Reports, it is evident that he was highly regarded by both his students and colleagues, who after his retirement carried on the method of instruction that he had initiated. Finally, he organized his research and disseminated his findings to other practitioners and researchers in his major work Outlines of Philosophical Education, first published in 1818 and reprinted in 1825. Jardine describes Outlines as "having been found by experience to answer at least some of the most important purposes of a first philosophical education . . . combining elementary instruction with active habits on the part of the student" (Outlines 42). Jardine believes that improvements in education will occur only when teachers assume the duties of practitioner-researchers: "to collect facts, - to record observations, - to watch under the influence of education;-and thus to unite their efforts for the general improvement of our academical establishments" (Outlines 524).

\section{A Profile of Jardine's Students}

The eighteenth century was a period of great change for the Scottish universities. The regenting system of instruction, whereby one professor taught a group of students all courses during their entire program, was abolished during this century at the Scottish universities-at Edinburgh in 1708, at Glasgow in 1727, at St. Andrews in 1747, and at King's College in Aberdeen in 1798. The regents, who were responsible for teaching a range of classes 
including Greek, Latin, Logic, Moral and Natural Philosophy, Mathematics, Chemistry, and Rhetoric, were gradually replaced by specialist professors. As a result, the quality of education and instruction was strengthened. The first university professor to teach English composition, literature, and rhetoric was John Stevenson, professor of logic and metaphysics at Edinburgh from 1730 to 1777 and most noted for his two famous pupils Hugh Blair and John Witherspoon-two figures who helped institutionalize the study of English in Scotland and America. Before becoming professors at the major Scottish universities, many of the most noted figures of this period, such as Adam Smith and Hugh Blair, delivered series of public lectures on English language and literature. Interest in English language studies spread because these lecturers were often hired to teach at universities other than at the ones where they delivered their public lectures. The Scottish professors were not paid set salaries. Instead their income was derived from fees paid by students in their classes, giving rise to the need to address popular interests and topical issues. These lectures appealed to the many provincial students who were trying to raise their station in life by improving their understanding and usage of English. The demographic make-up and number of students attending the universities also underwent great change during the eighteenth and nineteenth centuries due to the growth of Scotland's large industrial cities and the Scottish philosophy that education was a public responsibility and should be open to all classes of students. Glasgow University kept abreast of these changes and thrived during this period.

According to the University of Glasgow Calendar, the number of students at the institution increased from approximately 150 in the early seventeenth century to approximately 400 by $1702(x x)$. Enrollment continued to increase steadily for the next two centuries as the industrial city of Glasgow grew and expanded. As enrollment increased, the "Common Table" was abandoned, and Glasgow gradually became a nonresidential university with only forty students "living in" by 1704 (Calendar xx). The strength of the university increased in the eighteenth and nineteenth centuries for a variety of reasons: its prominent professors, among whom the most influential and well-known were Francis Hutcheson and Adam Smith in the eighteenth century; its sensitivity to topical issues and historical changes; generous support from its benefactors; and its ability to keep abreast of new academic developments. The University's adaptability and strength are evidenced in the number of professorships restored or founded during this 
period: seven new professorships were created or reinstated by 1732, and at least eighteen new professorships were founded in the nineteenth century (Calendar xx). George Jardine's conduct of the logic and philosophy class at Glasgow reflects the strength of the University of Glasgow and, in fact, goes one step further. Jardine also took a stand against the prevailing practice at the Scottish universities to teach solely by lecture:

It is with reluctance I repeat the remark, that, in several of our academical establishments, the philosophical education of youth is very imperfectly understood, and most inefficiently conducted. The exertion, whatever it may be, is almost entirely confined to the professor. The pupils are not required to do anything. It is pretty much left to themselves whether they shall be utterly idle or partially employed, whether they shall derive any advantage from their attendance on the lecture, or go away, at the end of the course, as ignorant and uninformed as when it began. Surely, the common sense of the nation will not much longer permit such an abuse of the means of improvement. (Outlines 523-24)

Jardine specifically states that his primary motivation for making theoretical and practical changes in the logic and philosophy class was the realization that the class no longer met the specific needs of his students: "[E]very day more and more convinced me that something was wrong in the system of instruction, pursued in this class; - that the subjects on which I lectured were not adapted to the age, the capacity, and the previous attainments of my pupils" (Outlines 27-28). More than any other factor, the background of his students at the University of Glasgow influenced Jardine's decision to make changes in both the subject matter and method of instruction in his class. According to Jardine, young men at this time (women were not admitted) were sent to college at a much younger age than had previously been the custom (Outlines 28). In fact, the Scottish university students were often as young as thirteen or fourteen in the late eighteenth century and were graduated at age seventeen or eighteen. In Scotland, the student population was often drawn primarily from the working classes. By the nineteenth century, the University of Glasgow attracted a diversified range of students, consisting of many different ages, classes, and occupations. Jardine explains that his students were younger than their predecessors and, therefore, educationally unprepared for the lectures in ontology, metaphysics, and 
Greek which characterized the logic and philosophy class. In addition, they were lured away from college at an earlier age than students of the past because of increased employment opportunities both in Scotland and abroad, opportunities which children of the working classes could not easily afford to ignore (Outlines 28).

Although Jardine's students were not necessarily "typical" basic writers-those who produce small numbers of words with large numbers of errors (Shaughnessy, Errors and Expectations 14)-they were beginning writers, who in many cases were illequipped and unprepared for university classes. In addition, they were receiving instruction which they had neither the prerequisites nor perhaps the maturity to understand, like many modern students. Characteristic of basic writers, Jardine's students also came from diverse educational and socioeconomic backgrounds where the students had limited writing experience due to the traditional lecture method of instruction and where people spoke in a variety of rusticisms. Jardine explains that one goal of his students was to acquire an understanding and appreciation of "correct, chaste and graceful English style" to improve their station in life; he advocates writing as a means of achieving this end but warns that "the art of composition is one of no easy attainment ... without careful study and constant habit, in endeavoring to acquire it" (Outlines 489-90). Contemporary composition theory opposes teaching methods that demand slavish devotion to "correct" English; however, for basic writing students the desire to write "correctly" is often paramount. Mina Shaughnessy explains that "so absolute is the importance of errors in the minds of many writers that 'good writing' to them means 'correct writing,' nothing more" (Errors and Expectations 8). Like many contemporary basic writers, Jardine's students were trying to improve their lot through education. A knowledge of "correct" English improved their employment opportunities. Because of the shortened time spent at college, the students' education became "less systematic and considerably more abridged. Thus, the changes which were taking place in society required a more miscellaneous and practical kind of instruction in the first philosophy class" (Outlines 2829).

The syllabus for the logic and philosophy class prior to Jardine's appointment as professor of logic was as follows:

- October 10 (commencement of the term) to November l-the students read and analyzed portions of memorabilia of Socrates.

- November 1 to February l-the instructor explained Aristotle's logic. 
- February 1 to April 15-the instructor lectured on metaphysics.

- April 15 to the end of the term-the instructor lectured specifically on ontology "or that branch of metaphysical science which comprehends the various doctrines on the general attributes of being, existence, essence, unity, bonity, truth, relations, modes of possibility, impossibility, necessity, contingency, and other similar abstract conceptions of pure intellect" (Outlines 23).

The lectures were delivered early in the morning and were followed by an oral one-hour examination in the afternoon. At intervals throughout the term, the instructor assigned two or three compositions loosely connected to the subjects discussed in class (Outlines 23-24). From his experience as both a student in and later as professor of the philosophy class at Glasgow, Jardine surmises that this method of teaching failed because the class was both boring and useless. In fact, the class was routinely known as "the drowsy shop of logic and metaphysics" among the students (Outlines 24). Jardine claimed that traditional education failed to prepare the students "to adorn conversation, or to qualify the student for the concerns of active life" (Outlines 26). Jardine knew that knowledge alone was not enough for the Scottish students to succeed in business: "A man may be capable of great reflections but if he cannot communicate it to others, it can be of but little use" (GUL ms. Gen. 737, vol. 2, 155-56). He felt that the Scottish Arts program depended upon writing and rhetoric in its fullest sense.

Citizens of Glasgow, a growing commercial city, echoed Jardine's thoughts on the unsuitableness of the class of philosophy. In an undocumented reference, Jardine quotes a published opinion of education at this time:

Some of the classes in universities bear evident marks of their original design; being either totally, or in part, intended for the disputes and wranglings of divines, and of little use to the lawyer or physician, and still less to the merchant and the gentleman. Of this sort we reckon logic and metaphysics. These arts or sciences (for it is not agreed yet which of them they are) to the greatest part of students, are quite unintelligible; and, if they could be understood, we cannot for our life discover their use. (qtd. in Outlines 26-27)

The successful merchants, who financially supported the University, called for a liberal arts education tempered with classes 
suitable for students going into business. Jardine agreed and called for an alteration and expansion of the class in logic and philosophy:

It ought therefore to be the great object of a first philosophy class to supply the means of cultivation, . . . to present appropriate subjects for their exercise; to watch over their movements, and to direct their expanding energies. . . . To secure a suitable education for young men destined to fill various and very different situations in life, the course of instruction ought not certainly to be limited to the narrow range of logic and metaphysics; but, on the contrary, should be made to comprehend the elements of those other branches of knowledge, upon which the investigation of science, and the successful despatch [sic] of business, are found chiefly to depend. (Outlines 31)

Jardine believed that any change in the class depended on a change in the role of the teacher. It was no longer adequate for the instructor to simply convey information in a teacher-centered lecture. Instead the teacher must take on the role of "companion or friend," stimulating and cultivating the student's natural abilities "when his difficulties are most formidable" (Outlines 315). Jardine encouraged teachers to closely analyze the needs of their students and to abandon prescriptive textbooks in favor of picking and choosing appropriate subject matter for the students from all the arts and sciences (Outlines 51).

Jardine also supported discussion and writing as a way of learning in conjunction with lectures. He knew that adopting his plan would mean more work for the teacher than simply composing lectures, but he felt his system was necessary in the Scottish universities where there were many students who were "not qualified, either in respect of age or of previous acquirements" (Outlines 427). Jardine used writing as a means of encouraging students to be their own best teachers and as a way of tracking their development. For example, he discouraged the traditional practice of taking down verbatim the teacher's lectures and instead advised students to "commit to writing, in their own composition, whatever they judge[d] to be of leading importance" (Outlines 279). He encouraged his students to write down the most interesting or important thoughts they encountered as they read for pleasure (Selections 282). And he promoted a method of revision by suggesting that students keep a journal of all the letters they both received and wrote, encouraging them to write several drafts in 
order to teach themselves "accuracy and exactness" (Selections 284). His more formal assignments included daily writing exercises, which he wrote along with and shared with his students; a lecture review through discussion and writing; and a hierarchy of four levels of sequenced writing assignments spaced throughout the course. Jardine stressed the concept of writing as process, and recognized the value of prewriting and revision: "In all cases, perfect specimens must be preceded by many unsuccessful efforts." Imperfect early drafts are the "natural and indispensable steps which lead to higher degrees of perfection" (Outlines 313). Both Jardine's problems and solutions sound familiar and are instructive for modern teachers at the college level who face large classes and inadequately prepared students.

\section{George Jardine and Mina Shaughnessy}

A comparison of the works of Jardine and Mina Shaughnessy supports the claim that Jardine prefigured many modern theories and practices of basic writing. Both educators were instructing a population of students who varied from the traditional student; both were dedicated to searching for alternatives to the pedagogical methods of instructing these new students; and both wrote easily accessible treatises that outlined their own teaching problems and solutions. These educators wrote from their personal experiences as classroom teachers and directed their works to teachers who are only beginning to work with disadvantaged students. Just as the demographic makeup of Jardine's students reflected Scotland's democratic philosophy toward education and the growth and change taking place in the industrial city of Glasgow, so did Shaughnessy's students reflect America's shifting society and policy toward education in the 1960s and 1970s The Open Admissions policy of the 1970s, which was enacted at many American universities, including The City University of New York where Shaughnessy taught, was part of a vast shift within American society "from a rural to an urban population, from an industrial to a service-oriented labor force, from a culture of conformity to one of diversity" (Shaughnessy, "Open Admissions" 401). This new policy guaranteed to every New York City resident who held a high school diploma admission into one of eighteen tuition-free colleges. The emphasis of public education in America during this period was to prepare a wide range of students for increased business opportunities within a growing urban area, an educational scenario similar to the one of Jardine's time. This policy 
lowered or in many cases eradicated college entrance requirements so that higher education was made accessible to everyone. In most cases, these students simply did not possess the prerequisites necessary to benefit from traditional pedagogical methods and curriculum-much like Jardine's students of more than 150 years earlier.

Shaughnessy's works, on which all subsequent scholarship in the field of basic writing relies to some degree, echo Jardine's twofold teaching objective: to encourage students to cultivate their individual reasoning abilities and to perfect their communication skills. She stresses that by and large basic writers are not students who have failed but rather beginning students whose needs have not been met by traditional instruction. Like Jardine's major treatise Outlines of Philosophical Education, Shaughnessy's Errors and Expectations outlines what has been traditionally taught in her classes and why this curriculum and methodology now fail. Both teachers call for renewed respect for students' needs and abilities, and offer concrete pedagogical advice for meeting these needs based on their classroom experiences.

Specifically, Shaughnessy embeds within Errors and Expectations three primary goals for teachers of basic writers: (1) to encourage students to recognize their own thought processes, examining their responses to outside information; (2) to stress learning by writing; and (3) to instill in students the ability to connect all parts of grammar and logic. Likewise, in Outlines, Jardine includes a chapter entitled "Science of the Human Mind," four chapters on theme writing, and a chapter concerning logic and grammar entitled "On The Origin and Progress of Language, and the Principles of General Grammar." The strong correlation between Jardine and Shaughnessy's teaching objectives is evidenced in her echo of Jardine's emphasis on training students for business and civic responsibility: "The goals of a basic writing course are generally practical, namely, the development of a readable expository style that will serve for courses and, later, for professional or civic writing assignments" (Errors and Expectations 280). Shaughnessy and Jardine agree that students must learn to master formal written English because it is the "language of public transactions-educational, civic, and professional" (Shaughnessy, Errors and Expectations 125).

Shaughnessy and Jardine suggest similar practical methods for carrying out these goals. First, in the matter of errors they agree that teachers should initially be "satisfied with overlooking some of these faults" (Jardine, Outlines 366), so that students are not 
totally alienated from the process of writing. Shaughnessy explains that "there is no reason why the BW student must wait until all his sentence problems have been dealt with before he can begin to work on the organization and development of academic papers" (Errors and Expectations 274). They both stress that for the beginning writer the lack of "confidence in himself and in academic situations. .. magnifies his inadequacies" (Shaughnessy, Errors and Expectations 85). To remedy this self-doubt, they advocate trying to remove the stipulative academic conditions under which the student is expected to write. Jardine says that the "rules to juvenile composers should be addressed not only to their understanding but to their feelings, and should carry with them the authority both of reason and of sentiment" (Outlines 314). He explains that beginning writers can't be expected to compose the simplest of themes unless the teacher modifies assignments and encourages students to find their individual expression for thoughts on the topic (Outlines 315-16). Shaughnessy also says that "without reforming the conditions under which students are expected to write, particularly during the early stages of their apprenticeship, it is difficult to see how they will ever learn-or want to learn-to write well (Errors and Expectations 87). To successfully communicate, she explains that the beginning students must be made to believe that they have something of interest to say. They also agree that the teacher of beginning writers should avoid the temptation to mark all errors and instead "mingle some approbation with his censure, and lay hold of every thing that can afford encouragement" (Jardine, Outlines 366). Both teachers sequence assignments so that students can achieve early success and thereby build confidence in their writing abilities. The early assignments are less "academic" and attempt to alleviate the writer's selfdoubts. Shaughnessy and Jardine both think that narrative papers focusing on historical events or ideas are good early assignments for beginning students (Errors and Expectations 288; Outlines 300).

Both teachers help beginning students get initiated into the writing process by focusing on the social act of writing. As a means of avoiding redundancy and regression, students are encouraged to write for a "real" audience-their peers. Jardine developed a detailed method of peer review whereby the students didn't merely point out defects but noted effective parts of the essays as well. His method of collaborative learning, similar to the one championed by Kenneth Bruffee in this century and advocated by Shaughnessy (Errors and Expectations 83), was designed 
to improve the writing of both the writer and reviewer. Shaughnessy and Jardine agree that student writing should be reviewed by both peer tutors and teachers (Errors and Expectations 288; Outlines 367-68). They also agree that the classroom should be structured so that students can "talk openly about what they don't understand" (Shaughnessy, Errors and Expectations 40).

Shaughnessy and Jardine believe that teachers should write the assignments they give and revise student papers in demonstration lessons so the students better understand what is expected of them (Errors and Expectations 271; Outlines 306). They also suggest holding essay contests to generate models for the students to emulate (Shaughnessy, Errors and Expectations 271; Jardine, Outlines 376). And they believe that for beginning writers the biggest problem is getting started because these students perceive writing as a single act (Shaughnessy, Errors and Expectations 81; Jardine, Outlines 313). Jardine offers this insightful advice to beginning writers: "[I]t is abundantly obvious, that if a young man did not begin to compose on any subject till he has obtained a complete knowledge of it, he would never begin at all" (Outlines 313). Shaughnessy agrees that apprentice writers are "ignorant" of the process of writing and should not blame themselves "for having to revise or correct sentences or for taking a long time to get started or even for not being able to start at all" (Errors and Expectations 81).

A final arresting similarity between the theories of Jardine and Shaughnessy is found in their characterizations of the ideal teacher. In "Diving In: An Introduction to Basic Writing," Shaughnessy describes successful teachers as those who are willing to remediate their own teaching deficiencies and to seek a deeper understanding of their students' learning needs (302). She points out that the best teachers are the ones who instill in their students the ability to identify and remediate their own learning difficulties so that they are capable of teaching themselves (299). This characterization directly parallels Jardine's summation of a successful teacher:

A teacher must not expect to carry his pupils, in the course of a few months, to the higher parts of those sciences, which it may, notwithstanding, be proper to put them in the way of studying for themselves. . . By inducing them to employ their intellectual faculties, according to the plan of diligence proposed, he will enable them to know their own strength; and, at the same time, to acquire the command of a powerful instrument which nature has put into their hands, for the most valuable purposes. For when the habit of investigation is once formed, and the energies of the mind are 
placed under the control of well-regulated attention, the student becomes his own best teacher, and the important work of education goes on of its own accord, without either pain or effort. (Outlines 421-22)

Certainly, there are many differences between George Jardine's educational plan and modern basic writing instruction. He was not dealing with the wide ethnic and linguistic diversity that characterizes many modern basic writers. Also, 150 years of social, political, and economic development separates his work from ours. However, he did develop a plan for instructing beginning writers that is characteristic of basic writing instruction. The parallels between the work of Shaughnessy and Jardine illustrates the writing connection between modern practices and Jardine's educational plan. His adaptation of teaching methods and curriculum to meet the needs of poorly prepared students at the University of Glasgow provides an historical link in the developing discipline of composition.

\section{Work Consulted}

Evidence, Oral and Documentary, Taken and Received by The Commissioners Appointed by His Majesty George IV. July 23d, 1826; and Re-Appointed by His Majesty William IV., October 12th, 1830; for Visiting the Universities of Scotland: Volume II. University of Glasgow. London: W. Clowes and Sons, 1837. Horner, Winifred Bryan. "Nineteenth-Century Rhetoric at the University of Glasgow with an Annotated Bibliography of Archival Materials." Rhetoric Society Quarterly 19 (1989): 173-85.

---. Nineteenth-Century Scottish Rhetoric. Carbondale: Southern Illinois UP, forthcoming.

---. "Rhetoric in the Liberal Arts: Nineteenth-Century Scottish Universities." The Rhetorical Tradition and Modern Writing. Ed. James J. Murphy, 85-95. New York: MLA, 1982.

---, ed. The Present State of Scholarship in Historical and Contemporary Rhetoric. 2nd ed. Columbia: U of Missouri P, 1991. “Jardine, George." Chamber's Dictionary of Eminent Scotsmen. 1868-70 ed.

Jardine, George. "Correspondence of Professor Jardine with Baron Mure." Selections from the Family Papers Preserved at Caldwell. Ed. William Mure. Paisley: A. Gardner, 1883.

---. Lectures to the Logic Class at Glasgow University. MS Gen 737. University of Glasgow Manuscript Library, Scotland, 179394. 
---. Lectures to the Logic Class at Glasgow University. MS Gen 166. University of Glasgow Manuscript Library, Scotland, 1783.

---. Letters to Robert Hunter. 12 September 1765 to 30 October 1810. MS Gen 507. University of Glasgow Manuscript Library, Scotland.

---. Outlines of Philosophical Education, Illustrated by the Method of Teaching the Logic, or, First Class of Philosophy in the University of Glasgow. Glasgow: A \& J Duncan, 1818. 2nd ed. Edinburgh: Oliver \& Boyd, 1825.

---. Quaedam Ex Logicae Compendius Selecta. Glasgow: J. Mundell, 1797. Reptd. in 1820. Bound with Jardine's Synopsis of Lectures on Logic and Belles Lettres.

---. Synopsis of Lectures on Logic and Belles Lettres; Read in the University of Glasgow. Glasgow: J. Mundell, 1797. 2nd ed. Glasgow: University Press, 1804.

North, Stephen. The Making of Knowledge in Composition: Portrait of an Emerging Field. Portsmouth, NH: Boynton/Cook, 1987.

Report Made to His Majesty by a Royal Commission of Inquiry Into the State of the Universities of Scotland. London: W. Clowes and Sons, 1831.

Shaughnessy, Mina. "Diving In: An Introduction to Basic Writing." College Composition and Communication 27 (Oct. 1976): 234-39.

---. Errors and Expectations: A Guide for the Teacher of Basic Writing. New York: Oxford UP, 1977.

--- "Open Admissions and the Disadvantaged Teacher." College Composition and Communication 24 (1973): 401-04.

University of Glasgow Calendar 1975-76. Glasgow: Glasgow UP, 1975. 


\section{NEWS AND ANNOUNCEMENTS}

November 5-6-7,1993: Adelphi University and The City University of New York will hold "Autumn in New York," the first annual Conference on Redefining Basic Skills in Higher Education in Garden City, NY. The theme is "Exploring New Approaches and Transforming Our Pedagogies." Topics to be explored in panels and workshops include models of literacy education and assessment; new approaches toward basic skills education in reading, writing, mathematics, visual literacy, and ESL; basic skills assessment; and computer applications in basic skills instruction. Keynote speakers include Peter Elbow and Joseph Harris (new editor of College Composition and Communication). For information: Write Dr. Max Kirsch, CUNY, 555 West 57th Street, 14th Floor, New York, NY, or call (212) 541-0324.

March 4,1994: The Sixth Annual Conference of the CUNY Writing Centers Association will have as its theme, "Critical Times-Critical Teaching." Hosted by Kingsborough Community College, CUNY, in its recently completed Conference Center overlooking the Atlantic Ocean, the featured speaker will be Dr. Ira Shor, College of Staten Island, CUNY, author of Empowering Education, and well-known for his writing and lecturing on Paulo Freire's philosophy and practice. For information: Lucille Nieporent (718) 368-5405 or Steven Serafin (212) 772-4212.

March 4-5, 1994: The MacBeth National Conference on Computing in the Liberal Arts, a national forum on the use of the Macintosh computer in college classrooms, will be held at Bethany College, Bethany, WV 26032. Directed to higher education classroom practitioners, and to professionals who support faculty in the use of technology, the conference will also present the MacBeth Awards, given for excellence in the use of Macintosh computers in college liberal arts classrooms. For information: Dr. Leslie Lucas, Conference Coordinator. Voice: (304) 829-7749; Fax: (304) 8297333; Internet: LeslieL@delphi.com. Deadline: was October 1, 1993 but please inquire.

April 18-20, 1994: The Regional Language Centre (RELC), educational project of the Southeast Asian Ministers of Education Orga- 
nization (SEAMEO), will hold its Regional Seminar on Reading and Writing Research: Implications for Language Education in Singapore. Papers and workshops are invited on Reading and Writing Research in the First/Second/Foreign Language and on Issues and Concerns in First/Second/Foreign Language Reading and Writing Acquisition/Learning/Instruction. To submit proposals: A 200-word abstract and a 50-word bio should be sent postmarked no later than November 15, 1993. Proposers will be notified of results no later than December 31, 1993. If accepted, a floppy diskette and a hard copy of the complete text of the paper/ workshop will be required by March 10,1994. Contact: The Director, Att. Seminar Secretariat, SEAMEO, 30 Orange Grove Rd., Singapore 1025, Republic of Singapore. Tel.: (65) 7379044; Fax: (65) 7342753; Telex: RS 55598 RELC; E-mail: GBORELC @NUSVM

July 13-16, 1994: The 13th Annual Penn State Conference on Rhetoric and Composition will be held in State College, PA. Plenary speakers Shirley Brice Heath, Susan Miller, and John Swales, and other featured speakers including Thomas B. Farrell, Cheryl Geisler, Patricia Harkin, Joseph Harris, and George Myerson will be among the participants. Scholars, researchers, and teachers of rhetoric and writing are invited to propose papers, demonstrations, panels, or workshops on any current topic in rhetoric and composition. One-page proposals (including a 150-word abstract) will be accepted through April 4, 1994. For conference information, to submit a proposal, or to volunteer to chair a session, contact: Don H. Bialostosky, Department of English, Penn State University, University Park, PA, 16802 (e-mail, rae2@psuvm.psu.edu).

Members wanted: The National Council of Writing Program Administrators, a nonprofit, professional organization that focuses on administration of college and university writing programs, invites those involved in helping administer writing programs, as well as graduate students who will be so involved, to join this proactive group. Regular membership fee of $\$ 15.00$-full-time graduate students $\$ 10.00$-includes subscription to WPA's journal and an invitation to WPA's annual workshop and conferences. Address: National Council of Writing Program Administrators, Dept. of English, Miami University, Oxford, OH 45056. 
Information needed: Jane Maher, assistant professor who teaches writing in Nassau Community College's Basic Education Program, has begun research for a biography of Mina Shaughnessy. She would appreciate hearing from anyone who knew Mina Shaughnessy, who has letters, photographs, or other relevant material. Please contact her at 299 Overlook Drive, Greenwich, CT 06830 , (203) 869-8468. 


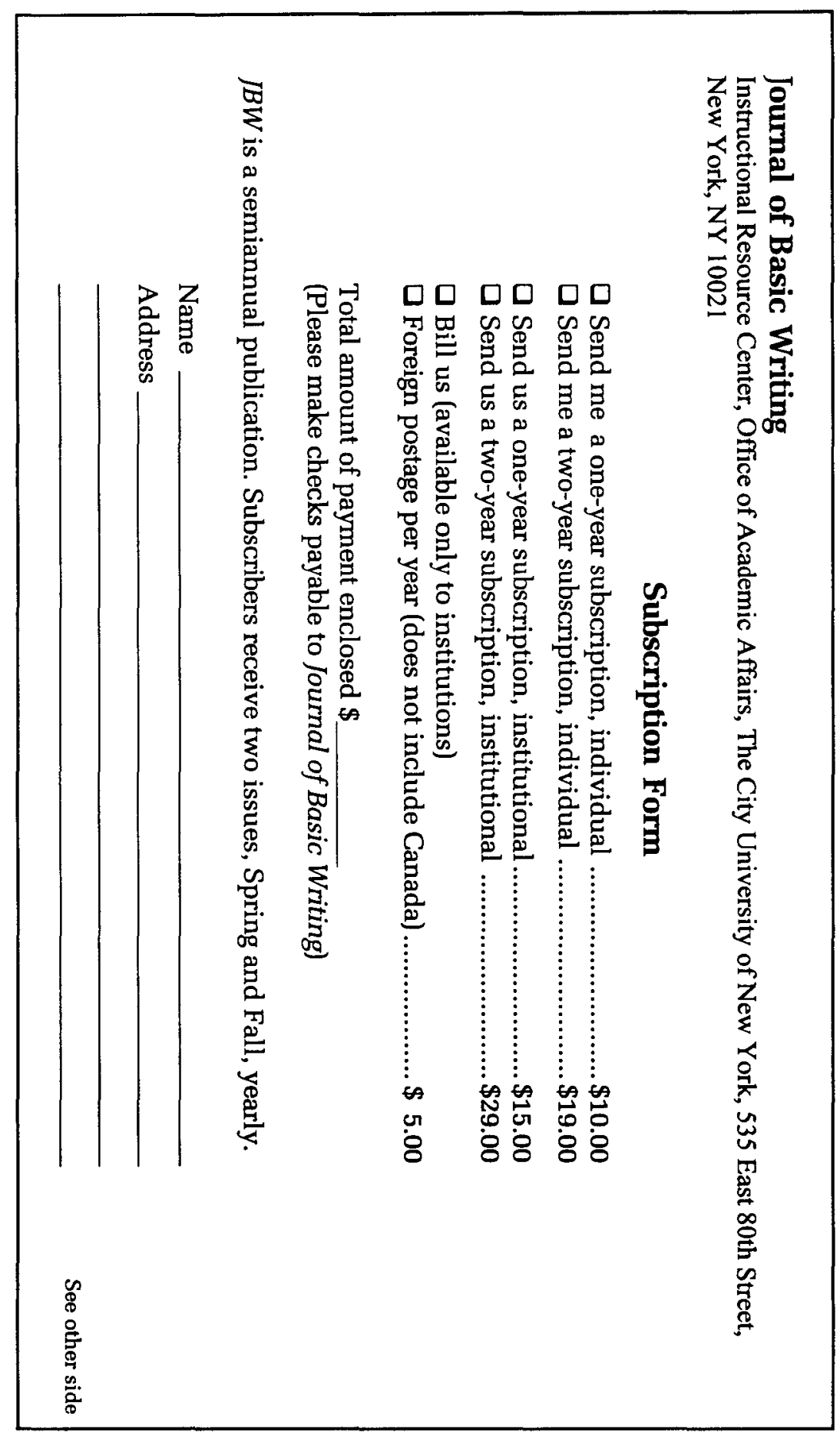




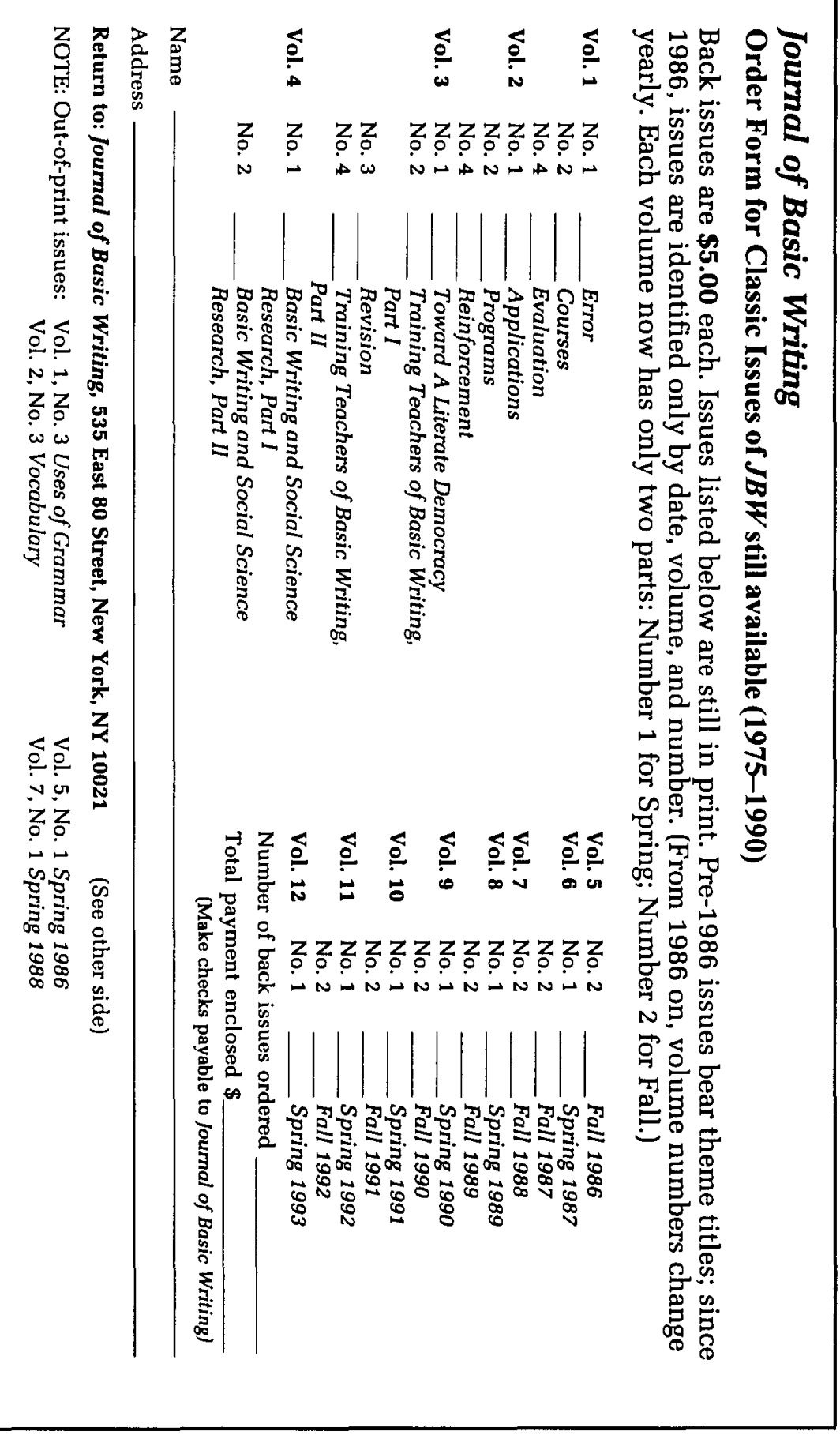


